\title{
Proximal Nephron
}

\author{
Jia L. Zhuo and Xiao C. Li \\ Laboratory of Receptor and Signal Transduction, Department of Pharmacology and Toxicology; \\ Center of Excellence for Cardiovascular-Renal Research; Division of Nephrology, Department of \\ Internal Medicine; University of Mississippi Medical Center, Jackson, Mississippi 39216-4505, \\ USA
}

\begin{abstract}
The kidney plays a fundamental role in maintaining body salt and fluid balance and blood pressure homeostasis through the actions of its proximal and distal tubular segments of nephrons. However, proximal tubules are well recognized to exert a more prominent role than distal counterparts. Proximal tubules are responsible for reabsorbing approximately $65 \%$ of filtered load and most, if not all, of filtered amino acids, glucose, solutes, and low molecular weight proteins. Proximal tubules also play a key role in regulating acid-base balance by reabsorbing approximately $80 \%$ of filtered bicarbonate. The purpose of this review article is to provide a comprehensive overview of new insights and perspectives into current understanding of proximal tubules of nephrons, with an emphasis on the ultrastructure, molecular biology, cellular and integrative physiology, and the underlying signaling transduction mechanisms. The review is divided into three closely related sections. The first section focuses on the classification of nephrons and recent perspectives on the potential role of nephron numbers in human health and diseases. The second section reviews recent research on the structural and biochemical basis of proximal tubular function. The final section provides a comprehensive overview of new insights and perspectives in the physiological regulation of proximal tubular transport by vasoactive hormones. In the latter section, attention is particularly paid to new insights and perspectives learnt from recent cloning of transporters, development of transgenic animals with knockout or knockin of a particular gene of interest, and mapping of signaling pathways using microarrays and/or physiological proteomic approaches.
\end{abstract}

\section{INTRODUCTION}

A homeostasis of body extracellular electrolyte composition and fluid volume is essential for all animals and humans to survive. Either excess or deficit of key extracellular electrolytes or overall fluid volume may lead to disturbance of the circulation, including cardiac output and blood pressure, and the abnormalities of cellular functions, including cell volume and intracellular $\mathrm{pH}(46 ; 178 ; 187 ; 295 ; 358 ; 396)$. Although the digestive system (small and large intestines), the skin, and the lungs may also be involved in body electrolyte and fluid excretion, there is no doubt that the kidneys play the most important role in the regulation of body electrolyte and fluid balance $(79 ; 81 ; 101 ; 178 ; 179 ; 187 ; 291 ; 336 ; 375)$. Indeed, the importance of the kidney is best supported by the simple statistics that the kidneys of a normal adult human filter approximately 180 liters of blood daily, and $99 \%$ of filtered electrolytes, solutes and fluid are reabsorbed and returned to the circulation. Only $1 \%$ of the filtered load is eventually excreted in urine. With a healthy kidney, animals and humans may survive in extreme conditions such as being trapped in a collapsed mine or the

\footnotetext{
Address for correspondence: Jia L. Zhuo, M.D., Ph.D., Professor, Department of Pharmacology and Toxicology, University of Mississippi Medical Center, 2500 North State Street, Jackson, MS 39216-4505, USA, Phone: (601) 984-1707 or Fax: (601) 984-1637, jzhuo@umc.edu.
} 
rubbles of earthquakes for days without ingestion of any water and food. Conversely, rapid ingestion of large quantity of fluid and electrolytes in a short period of time leads to marked diuresis and natriuresis, with little retention of excessive salt and fluid at least in the short term. Thus, the kidney has the unique capacity to precisely adjust the urinary excretion of electrolytes and fluid in order to match spontaneous variations in their intake to maintain body electrolyte and fluid homeostasis, acid-base balance, and normal blood pressure (79; $81 ; 101 ; 178 ; 179 ; 187 ; 291 ; 336 ; 375)$.

The kidney plays a fundamental role in maintaining precise body and/or extracellular electrolyte and fluid balance and blood pressure homeostasis primarily through its proximal and distal tubular segments of nephrons. However, it is well recognized that proximal tubular segments exert a more prominent role. Proximal tubules are responsible for reabsorbing approximately $65 \%$ of filtered load and most, if not all, of filtered amino acids, solutes, and low molecular weight proteins $(358 ; 413 ; 422 ; 537 ; 547)$. Proximal tubules also play an important role in the maintenance of body acid-base balance by reabsorbing $80 \%$ of the filtered bicarbonates $(1 ; 5 ; 6 ; 46 ; 59 ; 60 ; 154 ; 401)$, and glucose metabolism by reabsorbing all filtered glucose and regulating gluconeogenesis $(24 ; 301 ; 339 ; 468 ; 516$; $552 ; 553)$. The purpose of this review is to provide a comprehensive overview of new insights and perspectives in our understanding of proximal tubules, with an emphasis on the ultrastructure, molecular biology, cellular and integrative physiology, and the underlying signaling mechanisms. Since the historical perspectives and the classic physiology of proximal tubules are described in other legacy articles, this review will focus more on the new insights and perspectives learnt from recent studies on newly cloned transporters, transgenic or mutant animals with knockout or knockin of a particular gene, and newly identified signaling transduction pathways using microarrays and physiological proteomic approaches.

\section{CLASSIFICATION OF NEPHRONS}

\section{Definition of nephrons}

Historically, the term of nephron was derived primarily from a Greek term, nephros, which generally means the kidney (Wikipedia, the free encyclopedia). The definition of the nephron has not changed during the last several decades. Nephron is defined as the essential structural and functional unit of the kidney. In the structural context, each nephron consists of a renal corpuscle including the glomeular tuft, which contains a network of capillaries and Bowman's capsule $(291 ; 336)$, and a tubule unit including proximal tubule, loop of Henle, distal tubule, connecting tubule, and perhaps the collecting duct (see reviews on Nephron heterogeneity; Proximal tubule, loop of Henle, distal tubule and connecting tubule, collecting duct for details). All major structural components of the nephron are believed to embryologically originate from the metanephric blastema $(291 ; 336)$. However, some renal anatomists have argued that the entire cortical and medullary collecting ducts should not be considered to be parts of the nephron, because they are embryologically derived from the ureteric bud rather than the metanephric blastema $(291 ; 336)$. In the physiological context, a nephron represents a functional unit that filters blood, reabsorbs the filtered electrolytes, solutes and fluid, and excretes wastes and excessive electrolytes and water $(184 ; 291 ; 336$; $343 ; 401 ; 497 ; 537 ; 546)$. The glomerulus is exclusively responsible for filtering blood up to $25 \%$ of a normal cardiac output (see reviews on GFR and Glomerular filtration for details). The tubules of the nephron are responsible for reabsorbing $99 \%$ of glomerularly filtered electrolytes and water and returning them to the circulation $(184 ; 291 ; 336 ; 343 ; 401 ; 497$; $537 ; 546)$. 


\section{Classification of nephrons and their intrarenal distribution}

Nephrons are broadly classified depending on the location and the structural characteristics of the nephrons. For instance, nephrons are often classified into superficial cortical and juxtamedullary nephrons, based on the localization of its associated glomerular tuft (291; 294; 336). Superficial cortical nephrons have their glomerular tufts located in the superficial cortex, whereas juxtamedullary nephrons have their glomerular tufts situated in the juxtamedullary region, also called deep nephrons (Fig. 1) (291; 336). The localization and structural heterogeneity of superficial and juxtamedullary nephrons have been extensively investigated since the $1960 \mathrm{~s}(68 ; 68 ; 84 ; 115 ; 182 ; 221 ; 248 ; 249 ; 335 ; 350 ; 411 ; 431 ; 439)$. Studies using light and high resolution electron microscopes have demonstrated that nephrons in rodents and humans differ not only in their glomerular localization, but also in their structural characteristics. The glomeruli are usually larger in juxtamedullary nephrons than in superficial nephrons in rats (22), dogs (83), and rabbits (26). The genetic and molecular mechanisms underlying the nephron structural heterogeneity in animals and humans are not well understood. One theory is that the glomeruli develop from the tips of the branching ureteric buds in a centrifugal manner, and thus those glomeruli located in the juxtamedullary region are expected to develop first and become larger at birth and postnatally $(439 ; 481)$. This explanation remains unsatisfactorily at least in humans. For instance, human studies using the maceration or the dissector/Cavalieri technique showed no differences in mean glomerular diameters between the superficial and juxtamedullary nephrons across different ages $(135 ; 385 ; 439)$. However, there is evidence that genetics may play a role, for example American Blacks do have larger glomerular volume or size than American Whites in juxtamedullary nephrons independent of age, body surface area and glomerular number (439). The differences in gestational lengths between animals and humans may partly explain the presence of nephron structural heterogeneity in animals but not in humans.

For several decades, nephrons are also classified into short-loop and long-loop nephrons, based on the length of their respective loop of Henle (291; 336). Most superficial and midcortical nephrons are referred to as short-loop nephrons, because these nephrons have short loops of Henle in the inner stripe of the outer medulla $(291 ; 336)$. By contrast, most juxtamedullary nephrons have long loops of Henle with long thin descending and ascending limbs entering the inner medulla $(291 ; 336)$. Rodent and human kidneys appear to have more short-loop than long-loop nephrons. Alternatively, many renal physiologists often simply divide nephrons into proximal and distal nephrons, and the practice still continues today. Proximal nephrons are generally referred to proximal convoluted tubules and proximal straight tubules from S1 to S3 segments (Fig. 2) (291; 336). Distal nephrons generally include the loop of Henle, distal convoluted and connecting tubules, and perhaps collecting ducts (see the overviews on Nephron heterogeneity; Proximal tubule, loop of Henle, distal tubule and connecting tubule, collecting duct for details). Some renal physiologists may simply define the proximal nephron as the segment between the glomerulus and the macula densa, since the latter provides a clear feedback point to define proximal versus distal nephron function. However, the classification of proximal and distal nephrons remains an issue of continuous debates, because the definition of proximal or distal nephron has not been established (see the definition of nephron in Wikipedia and medical dictionaries). In this article, the scope of the overview will accordingly focus on the structural and functional characteristics of proximal tubular segments of the nephron, proximal convoluted tubule (pars convoluta) and proximal straight tubule (pars recta).

\section{Nephron numbers in health and diseases}

The exact number of the nephrons in animal and human kidney remains an issue of continuous debates. For more than a century, renal histologists, pathologists and 
nephrologists have attempted to estimate the number of nephrons in animal and human kidneys using different techniques $(38 ; 45 ; 212 ; 224 ; 230 ; 415 ; 593)$. Although the technique used may vary from laboratory to laboratory, the number of nephrons in a given kidney is often determined by estimating the number of its glomeruli $(38 ; 45 ; 212 ; 224 ; 230$; $415 ; 593)$. Since it is laborious and time-consuming to accurately count every glomerulus in a kidney, the current understanding of the nephron numbers in animal and human kidneys is primarily derived from indirect estimations $(38 ; 44 ; 45 ; 212 ; 224 ; 230 ; 415 ; 593)$.

The number of nephrons in the human kidney was first estimated by Eysenhardt as early as in $1818(131 ; 212)$. The nephron number was later reported in the rat kidney by Kittelson almost one century later (273). The number of nephrons and their intracortical distribution in the dog kidney were not reported until early 1970s $(136 ; 219)$. A number of quantitative techniques have been developed to estimate the number of nephrons in the kidneys of different species. The so-called "dissector" unbiased stereological method as described by Sterio in 1984 (485) and magnetic resonance imaging (MRI) of the kidney by Basgen in 1994 (34) are widely used today. Although there is still disagreement on which technique is more accurate for estimating the nephron numbers in animals and humans, the unbiased stereological technique is generally considered to be the gold-standard approach to estimate the number of nephron or glomeruli in the kidney $(226 ; 231 ; 415 ; 450 ; 593)$.

As estimated by the non-biased stereological technique or the noninvasive MRI technique, the number of nephrons varies widely from animals to humans (Table 1). Mice and rats have the lowest number of nephrons, ranging from approximately 20,000 per kidney in the former (360) to 35,000 per kidney in the latter species $(38 ; 45 ; 212 ; 348 ; 452 ; 488)$. However, there are no marked differences in the number of nephrons among different strains of rats from Lewis, Sprague-Dawley, to Spontaneously Hypertensive rats (Table 1$)(38 ; 45 ; 212 ; 452$; 488). Rabbits have about 170,000 nephrons (337; 493), while dogs have 350,000 to 550,000 nephrons per kidney $(34 ; 219)$. In humans, each kidney consists of between 800,000 and 1 million nephrons (178). In a recent report on the nephron numbers of 5 ethnic groups from 3 continents (225), the number of nephron can vary widely from $\sim 460,000$ to 1.3 million among healthy American Caucasians and African subjects (224; 230-232; 593). In the European Spanish population, the number of nephrons may reach 730,000 per kidney (144). Finally, the numbers of nephrons ranges from 364,262 to 1.1 million in Australian aborigines and from 380,517 to 1.5 million in Australian non-aborigines (226). Thus even in healthy human subjects, there can be nearly 5 -fold differences in the number of nephrons per kidney.

The nephron number may be physiologically relevant and important. There is evidence that low nephron numbers may be associated with the development of hypertension and kidney diseases. Brenner et al. first hypothesized an association between low nephron numbers in the kidney and the risk in the development and progression of hypertension, glomerular injury and chronic renal diseases, and renal allograft survival (63). According to the hypothesis, any reduction in the filtration surface area, whether acquired in renal disease or after surgical renal ablation, can lead to systemic hypertension and progressive renal insufficiency. For example, hypertension and progressive renal diseases are commonly found in individuals born with a solitary kidney, oligomeganephronia, or in certain inbred rat strains in which the filtration surface area is congenitally decreased (63). Brenner further postulated that a reduced number of nephrons may also contribute to the increased susceptibility of certain Type I and Type II diabetes to develop overt glomerulopathy (63). Brenner's hypothesis has led to intensive investigations on the associations between the deficit of nephron number and the risk of hypertension and chronic renal diseases in animal models and different ethnic human populations $(34 ; 45 ; 144 ; 226 ; 231 ; 328 ; 337 ; 348 ; 415$; $450 ; 452 ; 488 ; 493 ; 593)$. However, the conclusive evidence supporting this association 
remains to be established $(360 ; 450 ; 452)$. While a low nephron number in the kidney has been linked to a high risk for the development and progression of hypertensive and chronic kidney diseases in African Americans and Australian aborigines (226; 231; 415; 450; 593), the reduction of the nephron number by $50 \%$ by surgically removing one kidney from healthy rodents or by donating one kidney for transplantation in humans may not lead to the development of glomerulosclerosis and renal failure. This suggests that the nephron number may not necessarily be the most important factor in maintaining a normal kidney function and blood pressure (407).

\section{ULTRASTRUCRAL HETEROGENEITY OF PROXIMAL TUBULE}

\section{Superficial vs. juxtamedullary nephrons}

The ultrastructure of proximal tubular segments in rodents and humans has been extensively studied and characterized $(291 ; 336)$. Proximal tubules of the nephron in animals and humans include proximal convoluted tubules, which are situated in the cortical labyrinth and connected directly to the glomerulus, via the Bowman's space, and proximal straight tubules in the inner cortex and outer stripe of the outer medulla (Figs. 1-3) $(291$; 336). Only those proximal convoluted tubules of superficial nephrons usually traverse the cortical surface of the kidney, which are accessible to in vivo micropuncture or microperfusion investigations. By contrast, proximal convoluted tubules in juxtamedullary nephrons run deep into the medullary rays and are not accessible to micropuncture and microperfusion in vivo. Proximal convoluted tubules are approximately $25 \%$ longer in juxtamedullar nephrons than superficial nephrons (551). In vitro juxtamedullary preparation has been extensively used to study hemodynamic and vascular responses in juxtamedullar nephrons $(84 ; 203 ; 204 ; 237$; $238 ; 240 ; 241 ; 370)$, but whether the preparation can be adapted for micropuncture or microperfusion of proximal tubules of juxtamedullary nephrons still remains uncertain. Accordingly, the current understanding of proximal tubular function, which is largely based on in vivo micropuncture studies, may only apply to the proximal convoluted tubules of superficial nephrons.

\section{Ultrastructures of segmental proximal tubules of the nephron}

At the high resolution light microscopic level, each proximal tubule consists of three interconnecting segments, namely: a) the $S_{1}$ segment which comprises the beginning and middle portion of the proximal convoluted tubule, b) the $S_{2}$ segment which includes the late portion of the proximal convoluted tubule and the beginning portion of the proximal straight tubule, and c) the $S_{3}$ segment which is the remaining portion of the proximal straight tubule (Figs. 2 \& 3) $(291$; 336). Thus, the proximal convoluted tubule of both superficial and juxtamedullary nephrons contain $S_{1}$ and $S_{2}$ segments, the proximal straight tubule of superficial nephrons consists of $S_{2}$ and $S_{3}$ segments, whereas only $S_{3}$ segment can be found in the proximal straight tubule of juxtamedullary nephrons $(246 ; 291 ; 551)$. However, the subdivision of three proximal tubular segments is generally not clear-cut. At the high resolution electron microscopic level, basic ultrastructural characteristics can be further differentiated between three segments of proximal tubules. As summarized in Table 2 and Figs $2 \& 3$, the $S_{1}$ segment has much wider brush border membranes with greater number of microvilli, endocytic compartments, and a well-developed vacuolar-lysosomal system per unit length and therefore greater luminal surface area for transport and endocytic function. Furthermore, the $S_{1}$ segment also has more extensive lateral interdigitations or invaginations on the basolateral membranes, a larger network of mitochondria and well-developed Golgi apparatuses in the cytoplasm, compared with the $S_{2}$ and $S_{3}$ segments of proximal straight tubules $(291 ; 336)$. Thus, it is not surprising that the $S_{1}$ segment possesses the highest capacity for sodium, solute, amino acid, and fluid transport among all renal tubular segments. By comparison, the brush border appears to be shorter, invaginations on the 
basolateral membranes are fewer, mitochondria are smaller, and endocytic compartments are less prominent in the $\mathrm{S}_{3}$ segment. Nevertheless, most of tubular transport functional studies often use the classification of proximal convoluted and straight tubules instead of the $S_{1}$ to $\mathrm{S}_{3}$ segment description.

\section{FUNCTIONAL HETEROGENEITY OF PROXIMAL TUBULE}

Functional heterogeneity of proximal tubules of the nephron has been widely investigated and documented since 1960 s (Table 3$)(246 ; 248 ; 249 ; 291 ; 551)$. It was reported that glomerular filtration rate is relatively higher in juxtamedullary nephrons compared with that of superficial nephrons $(221 ; 246 ; 248)$. As expected, absolute proximal tubular reabsorption of sodium, bicarbonate, and fluid in juxtamedullary nephrons exceeds that of superficial nephrons, so that fractional proximal tubular reabsorption would be similar between superficial and juxtamedullary nephrons $(244 ; 245)$. The heterogeneity in transport activity between superficial and juxtamedullary nephrons have been described and compared previously by Lameire et al. (294). Early biochemical studies showed that the sodium to chloride permeability ratio also differs along the length of superficial pars convoluta, with sodium more permselective in early and chloride more permselective in late proximal convoluted tubules, suggesting that the rate of sodium transport is higher in the early than the late segment of superficial proximal tubules (333). By contrast, proximal convoluted tubules do not exhibit this heterogeneity in relative sodium and chloride permeability in juxtamedullary nephrons (246). With respect to the bicarbonate to chloride permselectivity ratio, it is greater in juxtamedullary proximal tubules than in superficial proximal tubules (10). Finally, a lumen-negative electrical potential difference persists in juxtamedullary but not in superficial proximal convoluted tubules. Thus depletion of organic solute and bicarbonate, or abolition of a transepithelial chloride concentration gradient alters the rate of fluid reabsorption in superficial but not in juxtamedullary proximal convoluted tubules (244). The mechanisms underlying this functional heterogeneity of proximal tubular segments are not fully understood. However, the heterogeneity in the expression and distribution of biological enzymes, aminopeptidases, sodium and hydrogen exchangers or antiporters, such as the sodium and hydrogen exchanger 3 (NHE3), $\mathrm{Na}^{+}-\mathrm{K}^{+}$-ATPase, $\mathrm{Na}^{+} /$ $\mathrm{HCO}_{3}{ }^{-}$, organic solutes and glucose, different $\mathrm{G}$ protein-coupled receptors (GPCRs) and signaling mechanisms is clearly implicated $(291 ; 401 ; 433 ; 435 ; 460 ; 468 ; 469 ; 521 ; 537)$.

\section{PHYSIOLOGICAL REGULATION OF PROXIMAL TUBULE FUNCTIONS}

\section{Role of basolateral membrane $\mathrm{Na}^{+}-\mathrm{K}^{+}$-ATPase in active sodium transport}

It was well established in the 1960s to 1970 s that in proximal tubules, sodium is primarily reabsorbed via an active transport process mediated by an energy-dependent mechanism (14; $42 ; 43 ; 159 ; 160 ; 283 ; 284 ; 422 ; 537 ; 537 ; 540 ; 542$ ) (also see reviews on $\mathrm{Na}^{+}$transport mechanisms, principles of electrolyte transport across plasma membranes of renal tubular cells for details). Wesson and Anslow appeared to first suggest that sodium might be actively transported across the proximal tubular epithelium against a sodium concentration gradient, but had no direct evidence to support the hypothesis at the time $(540 ; 542)$. Kokko et al. subsequently showed that the sodium concentration gradient was developed apparently due to fluid retention within the tubular lumen by the nonelectrolytes, while sodium transport continuously proceeded $(283 ; 284)$. In addition to the sodium concentration gradient, sodium transport appears to occur against a transtubular electrical potential gradient as well, with the proximal tubular lumen being about $20 \mathrm{mv}$ negative vs. the interstitial and peritubular fluid $(73 ; 158 ; 296 ; 544)$. However, later studies found that the transtubular electrical gradient across proximal convoluted tubules was probably smaller than previously reported, which only ranged from -6 to $+2 \mathrm{mv}(143 ; 510)$. Nevertheless, it is 
still possible that even such smaller transepithelial electrical gradient may play an important role in the regulation of proximal tubular sodium transport.

Molecular characteristics of $\mathrm{Na}^{+}-\mathrm{K}^{+}-$ATPase-The molecular nature of $\mathrm{Na}^{+}$and $\mathrm{K}^{+}$ concentration gradient across the plasma membranes was not known until Skou isolated an enzyme from the cell membranes of nerves that may be activated by $\mathrm{Mg}^{2+}, \mathrm{Na}^{+}$and $\mathrm{K}^{+}$, and involved in the active transport of $\mathrm{Na}^{+}$and $\mathrm{K}^{+}$across the cell membrane (470). Skou was awarded the Nobel Prize in Physiology and Medicine in 1997 for discovering of $\mathrm{Na}^{+}-\mathrm{K}^{+}-$ ATPase (97). It is now well recognized that $\mathrm{Na}^{+}-\mathrm{K}^{+}$-ATPase plays an indispensable role in driving active sodium transport across proximal tubules (132). $\mathrm{Na}^{+}-\mathrm{K}^{+}$-ATPase was isolated and purified in the early 1970s $(251 ; 252)$, and molecularly cloned in the 1980 s $(266 ; 267$; 459 ; 464-467). Molecular characterization of $\mathrm{Na}^{+}-\mathrm{K}^{+}$-ATPase confirmed that $\mathrm{Na}^{+}-\mathrm{K}^{+}-$ ATPase belongs to the P-type family of ATPase and has two major subunits namely the catalytic $\alpha$ and glycosylated $\beta$ subunits $(119 ; 132 ; 260 ; 334 ; 444)$. The a subunit consists of four isoforms, $a_{1}$ to $a_{4}$, and its protein contains about 1000 amino acids with a molecular wt. of $110 \mathrm{kDa}(119 ; 132)$. It has a total of 10 transmembrane domains $\left(\mathrm{M}_{1}\right.$ to $\left.\mathrm{M}_{10}\right)$ with both binding sites for $\mathrm{Na}^{+}$and ATP and phosphorylation site at the cytoplasmic domain and binding sites for ouabain and $\mathrm{K}^{+}$at the extracellular domain $(119 ; 132)$. The $\beta$ subunit, which is smaller with about 300 amino acids, has three isoforms, $\beta_{1}$ to $\beta_{3}$, a single transmembrane domain, and a large extracellular domain with glycosylation sites $(119 ; 132$; 260). The a subunit is responsible for the enzymatic or transport activity of $\mathrm{Na}^{+}-\mathrm{K}^{+}-$ ATPase, whereas the $\beta$ subunit may provide a supporting role. In addition to $a$ and $\beta$ subunits, a $\gamma$ subunit with 53 amino acids has been cloned, but its role in the regulation of $\mathrm{Na}^{+}-\mathrm{K}^{+}$-ATPase activity is not well understood $(39 ; 132 ; 349)$. Beguin et al. reported that the $\gamma$ subunit does not influence the formation and cell surface expression of functional $\mathrm{Na}^{+}$$\mathrm{K}^{+}$-ATPase $\alpha-\beta$ subunit complexes, but it may interact with assembled, transport-competent $a-\beta$ subunit complexes and modulate the $\mathrm{K}^{+}$activation of $\mathrm{Na}^{+}-\mathrm{K}^{+}$-ATPase (39). For a comprehensive update on molecular identities of all isoforms and subunits of $\mathrm{Na}^{+}-\mathrm{K}^{+}-$ ATPase, please consult with http://www.genenames.org.

\section{Expression and localization of $\mathrm{Na}^{+}-\mathrm{K}^{+}-\mathrm{ATPase}$ in proximal tubules of the} nephron-In the kidney tubules, $\mathrm{Na}^{+}-\mathrm{K}^{+}$-ATPase is expressed $(96 ; 444)$ and localized primarily on the basolateral plasma membranes (Fig. 4) $(20 ; 353)$, where it is more active in proximal convoluted tubules than in proximal straight tubules $(129 ; 132 ; 263 ; 264 ; 434$; 489). $\mathrm{Na}^{+}-\mathrm{K}^{+}$-ATPase is also expressed in basolateral membranes of other nephron segments including the loop of Henle, distal tubules and collecting ducts. Although it has been suggested that the $a_{1} \beta_{1}$ heterodimer is the exclusive $\mathrm{Na}^{+}-\mathrm{K}^{+}$-ATPase in proximal tubules of the kidney (132), up to eight different $\mathrm{Na}^{+}-\mathrm{K}^{+}$-ATPase isoforms may be expressed in the kidney $(96 ; 444)$.

Effects of $\mathrm{Na}^{+}-\mathrm{K}^{+}-\mathrm{ATPase}$ on sodium transport in proximal tubules-The role of $\mathrm{Na}^{+}-\mathrm{K}^{+}$-ATPase in active sodium transport has been studied extensively since the $1970 \mathrm{~s}$. $\mathrm{Na}^{+}-\mathrm{K}^{+}$-ATPase is very sensitive to the inhibition by ouabain, a natural inhibitor and thus ouabain has been widely used to inhibit $\mathrm{Na}^{+}-\mathrm{K}^{+}$-ATPase in epithelial transport studies (132). Using in vivo micropuncture, Gyory and Kinne showed, as early as in the 1970s, that inhibition of $\mathrm{Na}^{+}-\mathrm{K}^{+}$-ATPase by ouabain effectively abolished sodium and fluid reabsorption in proximal tubules (181). The effect of ouabain on sodium and fluid reabsorption by blocking $\mathrm{Na}^{+}-\mathrm{K}^{+}$-ATPase was later confirmed in the in vitro microperfusion studies in proximal tubules $(149 ; 166)$. It is now understood that sodium transport across the proximal tubular epithelia is mediated by a two-step mechanism. First, $\mathrm{Na}^{+}-\mathrm{K}^{+}-\mathrm{ATPase}$ provides necessary energy to drive active sodium extrusion from basolateral plasma membranes, which facilitates passive entry of sodium into proximal tubular cells via various 
sodium antiporter or cotransporters expressed or localized on apical membranes (132). However, the role of $\mathrm{Na}^{+}-\mathrm{K}^{+}$-ATPase or its $a$ or $\beta$ subunits in the regulation of active sodium transport has not been studied in transgenic mice with either global or tissue-specific deletion of $\mathrm{Na}^{+}-\mathrm{K}^{+}$-ATPase in proximal tubules. The reasons may be due to the fact that mice with genetic deletion of the $a_{1}$ subunit gene die during embryogenesis, and mice with deletion of the $a_{2}$ subunit gene also die immediately after birth $(28 ; 119 ; 236 ; 247 ; 357)$. Accordingly, nephron segment- or cell-specific deletion or overexpression of $a$ or $\beta$ subunits of $\mathrm{Na}^{+}-\mathrm{K}^{+}$-ATPase may provide new insights and perspectives in this field.

$\mathrm{Na}^{+}-\mathrm{K}^{+}-\mathrm{ATPase}$ as a signal transducer in proximal tubules-There is evidence that $\mathrm{Na}^{+}-\mathrm{K}^{+}$-ATPase not only regulates active sodium transport, but also acts as a signal transducer via intracellular calcium (3). Many humoral factors, high salt intake, or hormones regulate proximal tubular sodium transport at least in part by altering the expression and activity of $\mathrm{Na}^{+}-\mathrm{K}^{+}$-ATPase or by inducing the endocytosis of $\mathrm{Na}^{+}-\mathrm{K}^{+}$-ATPase into proximal tubule cells $(95 ; 132 ; 324)$. For example, Yingst et al. demonstrated that the vasoactive peptide angiotensin II (ANG II) directly stimulates the activity and alters the phosphorylation of $\mathrm{Na}^{+}-\mathrm{K}^{+}$-ATPase in rat proximal tubules with a rapid time course (561; 562). Similar effects of ANG II on $\mathrm{Na}^{+}-\mathrm{K}^{+}$-ATPase activity were reported in proximal tubule cells or proximal straight tubules in vitro $(126 ; 152)$. Most of ANG II-stimulated effects on $\mathrm{Na}^{+}-\mathrm{K}^{+}$-ATPase activity are mediated by $\mathrm{AT}_{1}$ receptors $(47 ; 132 ; 185 ; 185)$. Periyasamy et al. fed Sprague-Dawley rats a high $(4 \% \mathrm{NaCl})$ or normal diet for one week, and found that high salt diet significantly decreased proximal tubular $\mathrm{Na}^{+}-\mathrm{K}^{+}$-ATPase $\mathrm{a}_{1}$ subunit proteins and activity in the plasmalemmal fraction containing basolateral membranes (406). These responses were correlated with the increased natriuretic responses in rats (80). Liu et al. demonstrated that ouabain stimulated the clathrin-dependent endocytic pathway, which translocates $\mathrm{Na}^{+}-\mathrm{K}^{+}$-ATPase into intracellular endosomal compartments (322). Likewise, caveolin-1, dopamine, or a adducin have also been shown to modulate the internalization of $\mathrm{Na}^{+}-\mathrm{K}^{+}$-ATPase in proximal tubular cells $(133 ; 161 ; 323 ; 499)$. Finally, pressure natriuresis may also involve suppression of $\mathrm{Na}^{+}-\mathrm{K}^{+}$-ATPase activity during hypertension (344).

\section{Role of apical membrane $\mathrm{Na}^{+}-\mathrm{H}^{+}$-antiporters or $\mathrm{Na}^{+}-\mathrm{H}^{+}$exchangers (NHEs)}

Molecular characteristics of NHEs in proximal tubules-While $\mathrm{Na}^{+}-\mathrm{K}^{+}$-ATPase on the basolateral plasma membranes provides the driving force for extrusion of intracellular sodium into the peritubular interstitial fluid compartment and thus into the circulation, luminal $\mathrm{Na}^{+}$entry into proximal tubular cells from apical membranes is mediated by various antiporters or exchangers, and cotransporters. One of these important antiporters is the sodium and hydrogen antiporter or exchanger 3 (NHE3) $(118 ; 567)$. The early evidence for the presence of a sodium and hydrogen exchanger or antiporter in the proximal tubular epithelium was provided by Murer et al. more than three decades ago in renal brush border membrane vesicles (361). The findings of Murer et al. led to extensive studies on this antiporter and subsequent recognition that the apical membrane of proximal tubules in mammals has the unique ability to acidify the tubular fluid by secreting hydrogen ions in exchange for luminal sodium $(6 ; 14 ; 16 ; 60 ; 423)$. A gene encoding a Na$/ \mathrm{H}^{+}$exchanger was cloned in 1989 by Sardet et al. (440), which was followed by subsequent cloning of additional members of the NHE gene family in renal and intestinal epithelial cells (389; $500-503 ; 532)$. It is now understood that NHE3 belongs to one of nine isoforms of the mammalian $\mathrm{Na}^{+} / \mathrm{H}^{+}$exchanger (NHE) gene family $(118 ; 567)$. Characterization of the NHE gene family showed that the isoforms of NHE1-5 are localized primarily in plasma membranes of epithelial cells, where the isoforms of NHE3 and NHE5 may traffic from the plasma membranes to intracellular organelles, primarily of recycling endosomes, under physiological conditions $(19 ; 23 ; 48 ; 50 ; 118 ; 389 ; 500)$. Unlike NHE3 and NHE5, the 
isoforms of NHE 1, 2 and 4 mainly stay on plasma membranes and appear not to traffic from plasma membranes into recycling endosomes (118). Thus trafficking of NHE3 between the plasma membranes and recycling endosomes plays an important physiological role in regulating sodium reabsorption in proximal tubules (Fig. 5) (103). The remaining four isoforms of NHEs, NHE6, 7, 8, and 9 are localized mainly intracellularly, where they are present in the membranes of organelles and play an important role in the regulation of intraorganellar $\mathrm{pH}(169 ; 170 ; 351 ; 366 ; 555)$.

Expression and localization of NHEs in proximal tubules-Although there are nine members of the NHE gene family, only the NHE3 isoform is most relevant to the proximal tubules due to its unique expression and localization. Indeed, NHE1 has not been localized in the apical membrane of proximal tubules cells, such as opossum kidney cells and S1 and S2 proximal tubular segments of the rat renal cortex (289). Interestingly, immunohistochemical staining of NHE1 proteins was localized in basolateral rather than apical membranes of rabbit proximal tubules, distal convoluted tubules, thick ascending limbs of the loops of Henle, and the collecting ducts (49). Likewise, NHE2 and NHE4 mRNAs may be expressed in the kidney, but their expression is localized mainly in the medulla, perhaps on basolateral membranes of inner medullary collecting ducts, where they may be involved in volume or osmolality regulation $(57 ; 475)$. Both NHE1 and NHE2 are sensitive to the inhibition of amiloride and its analogue ethylisopropyl amiloride (EIPA) $(100 ; 388)$, whereas NHE4 is not responsive to the inhibition by amiloride (57). Yun et al. has suggested that NHE1 may play a "housekeeper" role (567). By contrast, molecular, biochemical, immunohistochemical, and transgenic mouse studies all point to the important roles of NHE3 in the regulation of proximal tubule sodium reabsorption and blood pressure homeostasis. In the kidney, most of NHE3 mRNA is expressed in the cortex of rabbit (500), rat (389), and humans (389). Immunohistochemical studies localize NHE3 protein primarily in the apical, or brush border, membranes of proximal tubules (48). The proximal portion of the descending thin limb and the thick ascending limb of the loop of Henle may also express small amount of NHE3 proteins, but the level of NHE3 expression in the loop of Henle pales in comparison with that in the apical membranes of proximal tubules (118).

\section{Regulation of NHE3 activity in proximal tubules}

The NHE3 activity in proximal tubules of the kidney is regulated by a complex of humoral factors and signaling mechanisms $(210 ; 254 ; 313 ; 343 ; 352 ; 535)$. The $\mathrm{Na}^{+}-\mathrm{H}^{+}$exchanger regulatory factor-1, NHERF-1, is one of these factors $(534 ; 535)$. NHERF-1 is expressed and localized in apical membranes of proximal tubules (520), binds to NHE3 and the sodium-dependent phosphate transporter $2 \mathrm{a}(\mathrm{Npt} 2 \mathrm{a})$, and plays an important role in cAMPmediated phosphorylation and inhibition of NHE3 activity $(215 ; 534 ; 535)$. Studies in NHERF1(-/-) mice suggest that both the exchanger protein directly activated by cAMP (EPAC)-dependent and protein kinase A (PKA)-dependent mechanisms are involved in the NHERF-1-mediated regulation of NHE3 activity in proximal tubules $(363 ; 461)$. The vasoactive peptide ANG II is another major factor that may actively regulate NHE3 activity in proximal tubules $(25 ; 54 ; 123 ; 210 ; 223 ; 302 ; 313 ; 425 ; 530)$. The effects of ANG II on NHE3 activity in proximal tubules are likely mediated by protein kinase C (PKC) $(87 ; 122$; $223 ; 255 ; 261 ; 262 ; 313 ; 320)$, inositol 1,4,5-triphosphate $\left(\mathrm{IP}_{3}\right)$ receptor binding protein released with $\mathrm{IP}_{3}$ (IRBIT) and $\mathrm{Ca}^{2+} /$ calmodulin-dependent protein kinase II (210), or oxidative stress (25). In vivo, the effects of ANG II on NHE3 activity in proximal tubules may be blood pressure-dependent $(302 ; 313 ; 343 ; 428)$. For example, we have recently demonstrated that infusion of a pressor or nonpressor dose of ANG II for 2 weeks induced differential NHE-3 responses and distribution in proximal tubules of the rat kidney, with increased membrane phospho-NHE3 proteins during infusion of the nonpressor dose of ANG II, and vice versa during infusion of the pressor does of ANG II (Fig. 6 \& Fig. 7) 
(313). Finally, dopamine $(21 ; 55 ; 124 ; 227 ; 531)$, glucocorticoid $(400 ; 526)$, insulin (145), glucagon (7) have been shown to alter NHE3 activity in proximal tubule cells in vitro or proximal tubules in vivo.

\section{New insights and perspectives into the roles of NHE3 in the regulation of proximal tubule sodium transport and blood pressure, as revealed from studies on NHE3 transgenic mice-Most of previous studies on the roles of NHE3} were primarily performed in isolated proximal tubules or cultured proximal tubule cells using isoform-specific or non-specific inhibitors of NHEs. It is difficult to deduce whether NHE3 plays a critical role in mediating sodium reabsorption in proximal tubules of the entire kidney and whether NHE3 plays an important role in the physiological regulation of blood pressure. Global and proximal tubule-specific deletion of the NHE3 gene may provide new insights and perspectives on the role of NHE3 proteins in the physiological regulation of sodium reabsorption in the kidney. Gary Shull's group first generated mice lacking the NHE3 gene (Slc9a3-/- or Nhe3-/-) with or without the NHE3 gene rescue in small intestines, and demonstrated for the first time that.NHE3 indeed plays an important role in the regulation of proximal tubule sodium reabsorption in the kidney, body sodium and fluid balance, and blood pressure homeostasis $(8 ; 50 ; 536)$. These elegant studies confirmed that approximately $50 \%$ to $60 \%$ of filtered $\mathrm{NaCl}$ and $70 \%$ to $80 \%$ of filtered $\mathrm{HCO}_{3}{ }^{-}$reabsorption in proximal tubules are mediated by NHE3 proteins $(5 ; 14 ; 352 ; 451)$. Furthermore, virtually all of the measured $\mathrm{Na}^{+} / \mathrm{H}^{+}$exchanger activity in renal apical membrane vesicles are dependent on NHE3 $(530 ; 554)$. Knockout of the NHE3 gene in mice (Nhe3-/-) leads to $60 \%$ to $70 \%$ decreases in fluid, $\mathrm{Na}^{+}$and $\mathrm{HCO}_{3}{ }^{-}$absorption in proximal convoluted tubules, causes renal salt wasting, and significantly decreases basal blood pressure (Fig. 8) (300; 380; 451; 550). These phenotypes are accompanied by absorptive defects in the intestines resulting in mild diarrhea due to intestinal NHE3 deletion. Although $\mathrm{Nhe}^{3^{--}}$mice with rescue of the NHE3 transgene in small intestines ( $\operatorname{tg} N \mathrm{Nh}^{-/-}$) tolerate sodium depletion or loading better than the nontransgenic Nhe $3^{-/-}$mice, basal blood pressure was similar to $N h e 3^{-/}$(550). Renin expression in the kidney and circulating aldosterone level are increased in $N \mathrm{Nhe}^{-/}$mice by $\sim 5$-fold, suggesting that ANG II is markedly activated in these mice as a result of salt wasting and volume depletion (451). When fed a normal salt diet, blockade of $\mathrm{AT}_{1}$ receptors with losartan markedly decreased basal blood pressure further in both $N$ he $3^{-/}$and $\operatorname{tg} N$ he $3^{-/}$mice (380). However, when fed a high salt intake, blood pressure-reducing effect of losartan was blunted to the wild-type levels in $\operatorname{tg} N h 3^{-/-}$ but not in $\mathrm{Nhe}^{-{ }^{--}}$mice (380). These results may be interpreted in three ways. First, NHE3 indeed plays a critical role in the physiological regulation of proximal tubular sodium transport and blood pressure by ANG II, because deletion of the NHE-3 gene decreases proximal tubular sodium and fluid reabsorption by $>60 \%$, increases fractional sodium excretion by 4-fold, and decreases basal blood pressure in the presence of marked activation of the renin-angiotensin system (RAS) $(300 ; 451)$. Second, further blood pressure-reducing responses to losartan below their basal levels in both $N$ he $3^{-/}$and $\operatorname{tg} N$ he $3^{-/-}$mice may be due to blockade of the vascular effect of ANG II (380). Third, since basal blood pressure is similar in $\mathrm{Nhe}^{-/-}$and $\operatorname{tg} \mathrm{Nhe}^{-/-}$mice and the RAS is activated under normal salt intake $(380 ; 451 ; 550)$, intestinal NHE3 may not play a significant physiological role in blood pressure regulation. Whether blood pressure responses to long-term administration of ANG II would be different in $N$ he $3^{-/}$and $\operatorname{tg} N h e 3^{-/-}$mice with or without intestinal NHE3 transgene is not known. Thus $\mathrm{Nhe}^{3^{--}}$and $\operatorname{tg} \mathrm{Nhe} 3^{-/}$mice may be excellent models to further determine the interactions between ANG II and NHE3 in proximal tubules of the kidney. 


\section{Sodium and glucose cotransporters and the role of apical membrane SGLT2}

Expression and localization of SGLT2 in proximal tubules-It is now understood that the sodium and glucose cotransporter gene family includes six members, namely SGLT1 to SGLT6, but not all of these SGLTs are expressed in proximal tubules (24; 552; 553). SGLT1 is a low-capacity, high affinity sodium and glucose cotransporter and is expressed and functions mainly in the small intestines of the digestive system $(552 ; 553)$. By contrast, SGLT2 is a high-capacity, low affinity sodium and glucose cotransporter, and is localized almost exclusively in the apical membranes of proximal convoluted tubules (Fig. 9) $(24 ; 155 ; 301 ; 552 ; 553)$. Unlike SGLT1, which mediates sodium and glucose cotransport in a 2:1 ratio, SGLT2 mediates sodium and glucose cotransport in a 1:1 ratio $(211 ; 552 ; 553$; 564). The remaining members of the SGLT gene family, SGLT1 to SGL6, are expressed widely in the kidney or other tissues, but their physiological roles in the sodium and glucose cotransport remain incompletely understood $(552 ; 553)$.

Effects of SGLT1 on glucose transport in proximal tubules-The important role of the kidney, proximal tubules in particular, in the regulation of body glucose metabolism and homeostasis has long been overlooked by endocrinologists and diabetic researchers. A widely-held dogma is that insulin alone, controls glucose metabolism, and its deficiency contributes most, if not exclusively, to the development of type 1 and type 2 diabetes. However, recent studies on the role of SGLT2 in the regulation of glucose transport and metabolism in proximal tubules and the potential of its inhibitors in treating type 2 diabetes may challenge this century-old dogma $(24 ; 155 ; 339 ; 365 ; 552 ; 553)$. The kidneys of a normal adult human filter approximately $180 \mathrm{~L}$ of plasma a day. Given a normal blood glucose concentration of $100 \mathrm{mg} / \mathrm{dL}$, this means that $180 \mathrm{~g}$ glucose will be filtered by the glomeruli daily. However, $99.9 \%$ of the filtered glucose is taken up by proximal convoluted and straight tubules $(552 ; 553)$. As a result, virtually no glomerularly filtered glucose will appear in urine. In addition to being responsible for glucose uptake by proximal tubules, SGLT2 also plays an important role in sodium and glucose cotransport through apical membranes.

Effects of SGLT2 on sodium transport in proximal nephrons-The presence of sodium and glucose cotransporters in the intestinal epithelium was proposed more than 50 years ago (553), and in proximal tubules in 1980s $(17 ; 213)$. There was early evidence that luminal $\mathrm{Na}^{+}$not only enters proximal tubular cells from apical membranes through the actions of NHE3, but also does so through a number of $\mathrm{Na}^{+}$and glucose cotransporters (see the review on Glucose transport in the renal proximal tubule and Genetic models of diabetes insipidus for a comprehensive review) $(17 ; 213)$. In isolated brush border membrane vesicle preparations, D-glucose was found to be cotransported with sodium into and diffuse out of proximal tubule cells down an electrochemical gradient $(29 ; 30 ; 36 ; 37 ; 354 ; 506)$. These cotransport processes are highly sodium-dependent $(213 ; 511)$. If sodium is replaced by other cations such as lithium, the co-transport process ceases (71). For instance, Burg et al. perfused proximal convoluted tubules with artificial solutions containing glucose, lactate, alanine, and citrate. The effect of these solutes on sodium transport was examined by selective removal or replacement of the solutes individually or in combination from the perfusate $(70 ; 71)$. It was found that complete removal of these solutes from the luminal perfusate decreased the rate of sodium reabsorption by $45-75 \%$; whereas adding glucose or alanine individually induced a small, but significant, increase in sodium reabsorption (70). Alternatively, phlorizin, a glucose transport inhibitor, decreased the transepithelial voltage and the rate of sodium and fluid reabsorption in proximal tubules of the kidney. These early studies indicate that the sodium and glucose cotransport system indeed plays an important role in isosmotic fluid reabsorption by proximal tubules of the kidney. 
New insights and perspectives into the roles of SGLT2 in proximal tubules from studies on SGLT2 ${ }^{-/-}$mice-Recently, the important role of SGLT2 in the regulation of glucose reabsorption in the kidney was determined in SGLT2-deficient mice $\left(\mathrm{SGLT2}^{-/-}\right)(329 ; 515 ; 516)$. The complete knockout of the SGLT2 gene was verified by the complete absence of SGLT2 immunostaining in the brush border membranes of the early proximal tubules (516). SGLT2 ${ }^{-/}$mice developed glucosuria and polyuria with significantly lower fractional glucose reabsorption, as showed in whole-kidney clearance and free-flow micropuncture studies (Fig. 10) (516). No significant differences in GFR and fractional excretion of sodium, potassium and chloride were observed between wild-type and SGLT2 ${ }^{-1-}$ mice, probably due to substantial increases in food and fluid intake in $\mathrm{SGLT}^{-/-}$mice (516). However, since absolute and fractional sodium reabsorption has not been determined by free-flow micropuncture, it remains unknown whether deletion of the SGLT2 gene would impair sodium reabsorption in these mice. Nevertheless, SGLT2 inhibitors have been recently used to inhibit glucose reabsorption by the proximal tubules and therefore to lower blood glucose for treating type 2 diabetes in animals and humans (24; $155 ; 339 ; 365 ; 552 ; 553)$. These mutant mice may also be used as a novel tool to further study interactions between SGLT2 and $\mathrm{Na}^{+}$transport in proximal tubules in addition to SGLT2 inhbitors.

\section{Role of basolateral membrane $\mathrm{Na}^{+} / \mathrm{Ca}^{2+}$ exchanger in sodium transport}

Molecular characteristics of $\mathrm{Na}^{+} / \mathrm{Ca}^{2+}$ exchanger-The molecular and protein structures and physiological implications of the sodium and calcium exchanger $\left(\mathrm{Na}^{+} / \mathrm{Ca}^{2+}\right.$ exchanger) in the kidney and other physiological systems have been reviewed elsewhere $(53 ; 140 ; 243 ; 330 ; 409)$. This section only reviews the role of basolateral membrane $\mathrm{Na}^{+} /$ $\mathrm{Ca}^{2+}$ exchanger in sodium transport in proximal tubules. The $\mathrm{Na}^{+} / \mathrm{Ca}^{2+}$ exchanger gene was first cloned from the dog and human cardiac muscle $(286 ; 378)$. The super family of the $\mathrm{Na}^{+} / \mathrm{Ca}^{2+}$ exchangers (the NCX family) consists of three gene members, NCX1, NCX2 and NCX3 $(286 ; 378)$. The NCX gene family is widely expressed in different mammalian tissues (286; 378). While the localization and functional significance of the $\mathrm{Na}^{+} / \mathrm{Ca}^{2+}$ exchanger have been extensively studied in cardiac tissues and vascular smooth muscle cells (286; 378 ), its role in the regulation of sodium transport in proximal tubules remains poorly understood. In the kidney, localization of the $\mathrm{Na}^{+} / \mathrm{Ca}^{2+}$ exchanger in the basolateral membranes of proximal tubules remains an issue of debate $(116 ; 117 ; 426 ; 427)$.

\section{Effects of $\mathrm{Na}^{+} / \mathrm{Ca}^{2+}$ exchanger on sodium transport in proximal tubules-Most} of our current understanding of the $\mathrm{Na}^{+} / \mathrm{Ca}^{2+}$ exchanger in the regulation of sodium and fluid reabsorption in proximal tubules of the kidney is still largely based on earlier studies in the 1960s to 1990s. It has been suggested that the changes in intracellular calcium concentrations $\left(\left[\mathrm{Ca}^{2+}\right]_{\mathrm{i}}\right)$ play an important role in the regulation of sodium transport in absorptive epithelia $(142 ; 492)$. Gmaj et al. appeared to first demonstrate that two pathways of $\mathrm{Ca}^{2+}$ transport might exist in the basolateral membranes of proximal tubule cells, one via the $\mathrm{Ca}^{2+}$-ATPase and the other involving a Na$/ \mathrm{Ca}^{2+}$ exchanger (164). Studies on the properties of the $\mathrm{Na}^{+} / \mathrm{Ca}^{2+}$ exchanger revealed that this system operates in an electrogenic manner and is very sensitive to the changes in intracellular and peritubular $\mathrm{Na}^{+}$ concentrations ( 326 ; 492). Unlike the $\mathrm{Ca}^{2+}$-ATPase, the $\mathrm{Na}^{+} / \mathrm{Ca}^{2+}$ counter-transport is not directly coupled to ATP hydrolysis, but rather is dependent on the electrochemical potential gradient of sodium generated from $\mathrm{Na}^{+}-\mathrm{K}^{+}$-ATPase $(52 ; 164 ; 359)$. It was further suggested that $\mathrm{Na}^{+}$entry into proximal tubular cells across the apical membranes and $\mathrm{Na}^{+}$uptake from the basolateral membranes into peritubular capillaries are tightly linked to the $\mathrm{Na}^{+} / \mathrm{Ca}^{2+}$ exchanger via the changes in $\left[\mathrm{Ca}^{2+}\right]_{I}$ concentrations (492). 


\section{Mechanisms underlying $\mathrm{Na}^{+} / \mathrm{Ca}^{2+}$ exchanger-regulated sodium transport in} proximal tubules-The mechanisms whereby the changes in $\left[\mathrm{Ca}^{2+}\right]_{\mathrm{i}}$ concentrations mediate transepithelial $\mathrm{Na}^{+}$transport remain incompletely understood. The widely held view is that increases in cytosolic free $\mathrm{Ca}^{2+}$ inhibit sodium and fluid reabsorption in proximal tubules whereas decreases in cytosolic free $\mathrm{Ca}^{2+}$ would have opposite effects $(142 ; 192$; $359 ; 492)$. Friedman et al. perfused isolated rabbit proximal tubules with quinidine and A23187, compounds known to selectively increase intracellular free $\mathrm{Ca}^{2+}$ concentrations in other epithelia, and demonstrated that these compounds inhibited proximal tubular sodium reabsorption $(140 ; 141)$. In other studies, increases in $\left[\mathrm{Ca}^{2+}\right]_{\mathrm{i}}$ concentrations were also found to inhibit $\mathrm{Na}^{+}-\mathrm{K}^{+}$-ATPase in vitro (563), or to alter apical membrane permeability to $\mathrm{Na}^{+}$ via the $\mathrm{Na}^{+} / \mathrm{Ca}^{2+}$ exchanger (492). Furthermore, $\left[\mathrm{Ca}^{2+}\right]_{\mathrm{i}}$ may also act as a second messenger in the regulation of proximal tubular sodium transport in response to certain neurotransmitter or peptide hormones. For instance, acethylcholine is known to elevate intracellular calcium and inhibit proximal tubular sodium reabsorption in vivo (484). The effects of the vasoactive peptide hormone ANG II on proximal tubular sodium transport are well documented to involve the changes in $\left[\mathrm{Ca}^{2+}\right]_{\mathrm{i}}$ (Fig. 11) $(99 ; 120 ; 193 ; 590 ; 591)$. However, whether the $\mathrm{Na}^{+} / \mathrm{Ca}^{2+}$ exchanger plays an important role in the regulation of proximal tubular sodium and fluid reabsorption in the kidney has not been studied in transgenic animals with global or cell-specific deletion or expression of the $\mathrm{Na}^{+} / \mathrm{Ca}^{2+}$ exchangers $(53 ; 573 ; 574)$. Generation of transgenic mice with deficiency or overexpression of the $\mathrm{Na}^{+} / \mathrm{Ca}^{2+}$ exchangers, NCX1, NCX2 or NCX3, selectively in proximal tubules of the kidney may be necessary to further determine the role of these $\mathrm{Na}^{+} / \mathrm{Ca}^{2+}$ exchangers in proximal tubules.

\section{Role of basolateral membrane eletrogenic $\mathrm{Na}^{+} / \mathrm{HCO}_{3}{ }^{-}$co-transporters}

Expression of carbonic anhydrases in proximal tubules-Carbonic anhydrases (CA) are a family of enzymes that catalyze the rapid interconversion of carbon dioxide $\left(\mathrm{CO}_{2}\right)$ and $\mathrm{H}_{2} \mathrm{O}$ to proton $\left(\mathrm{H}^{+}\right)$and bicarbonate $\left(\mathrm{HCO}_{3}{ }^{-}\right)$or vice versa (Wikipedia). The $\mathrm{CA}$ family includes at least five distinct sub-families $(\alpha, \beta, \gamma, \delta$ and $\varepsilon$ ). The $a$-CA enzymes, expressed primarily in mammals, are divided broadly into membrane CAs (CAIV, CAIX, CAXII, CAXIV and CAXV), cytosolic CAs (CAI, CAII, CAIII, CAVII and CAXIII), mitochondrial CAs (CAVA and CAVB), and secreted CAs (CAVI) (for details, please refer to http://www.genenames.org) (417). In the kidney, CAII, a $29 \mathrm{kDa}$ protein, and CAIV, a $\sim 35 \mathrm{kDa}$ protein, are predominantly expressed in humans and rabbits, while CAXII and CAXIV are also expressed in rodents $(67 ; 356 ; 416 ; 417 ; 455 ; 504)$. CAII is localized in the cytoplasm of most nephron segments including proximal convoluted tubules, proximal straight tubules, the thick ascending limbs, distal tubules and collecting ducts (417). In proximal tubules, CAIV is localized in both apical and basolateral membranes of the S1 and S2 segments $(67 ; 417)$, where CAXII is expressed primarily in basolateral membranes (417). Approximately $95 \%$ of total CA activity in the kidney is mediated by the cytosolic CAII, while the remaining $5 \%$ of the CA activity in the kidney is mediated by the membraneassociated CAIV and CAXII (416; 417).

\section{Role of $\mathrm{CAll}$ and $\mathrm{Na}^{+} / \mathrm{HCO}_{3}{ }^{-}$co-transporters in proximal tubule sodium and} fluid reabsorption-The kidney plays a critical role in the maintenance of intracellular $\mathrm{pH}$ by regulating acid-base transport in proximal tubules $(59 ; 401)$. Proximal tubules are responsible for reabsorbing $~ 80 \%$ of the filtered $\mathrm{HCO}_{3}{ }^{-}$load from the kidney. Although the acid-base transport process is primarily associated with the regulation of intracellular and blood $\mathrm{pH}$, it also indirectly regulates sodium transport by proximal tubules through apical membrane NHE3 (59). $\mathrm{HCO}_{3}{ }^{-}$transport in proximal tubules involves three major steps (Fig. 12) (59). First, $\mathrm{CO}_{2}$ and $\mathrm{H}_{2} \mathrm{O}$ are converted by the cytosolic enzyme $\mathrm{CAII}$ into $\mathrm{H}_{2} \mathrm{CO}_{3}$, which subsequently dissociates to $\mathrm{H}^{+}$and $\mathrm{HCO}_{3}{ }^{-}$within proximal tubule cells $(265 ; 472)$. 
Second, proximal tubule cells exchange luminal $\mathrm{Na}^{+}$for cytosolic $\mathrm{H}^{+}$through the action of NHE3 $(15 ; 522)$. Third, the electrogenic $\mathrm{Na}^{+} / \mathrm{HCO}_{3}{ }^{-}$co-transporter NBCe1-A, expressed on basolateral membranes, transports $\mathrm{Na}^{+} / \mathrm{HCO}_{3}{ }^{-}$into the interstitial fluid compartment and blood $(59 ; 217 ; 433)$. Thus, the factors that stimulate the expression and activity of basolateral membrane NBCe1-A are expected to indirectly promote sodium and fluid reabsorption in proximal tubules $(15 ; 59 ; 554)$. Alternatively, the factors that regulate CAII expression and activity are expected to alter NHEs and NBCe1-A expression and proximal tubule sodium and fluid reabsorption. Indeed, humans with genetic CAII enzyme defect or mice with CAII deficiency develop metabolic renal tubular acidosis with markedly impaired $\mathrm{Na}^{+} / \mathrm{HCO}_{3}{ }^{-}$reabsorption $(61 ; 303 ; 471 ; 473)$. However, the precise roles of CAII or other CAs and $\mathrm{Na}^{+} / \mathrm{HCO}_{3}{ }^{-}$-cotransporters in proximal tubule sodium and fluid reabsorption should be further studied in mutant mice with deficiency of a specific CA enzyme selectively in proximal tubules.

\section{Isotonic fluid absorption in proximal tubules}

Historical considerations-The classic dogma of isosmotic fluid reabsorption in mammalian proximal tubules remains well recognized by epithelial transport physiologists. The early evidence for isosmotic fluid reabsorption in proximal tubules of the kidney was first obtained from the pioneering micropuncture studies of Walker and colleagues (523; 524). These early investigators used the micropuncture technique to collect proximal tubular fluid in rats and guinea pigs, and demonstrated that the osmolalities of proximal tubular fluid and plasma were virtually identical. These findings led them to conclude that "... This fluid reabsorption is an isosmotic process, accomplished without producing any increase in osmotic pressure of the fluid remaining within the tubule; ...". Using a microcryoscopic technique, Gottschalk \& Mylle measured the osmolality of tubular fluid samples collected from the proximal convoluted tubules by micropuncture under the conditions of hydropenia, hypertonic mannitol infusion, urea and sodium diuresis, and confirmed that proximal tubular fluid was essentially isosmotic to plasma with or without superimposed osmotic diuresis (168). Similar conclusions were reached by Kokko and colleagues $(283 ; 284)$, who found that during fluid reabsorption, the cryoscopic luminal fluid osmolality remained unchanged in superficial proximal convoluted tubules. Schafer and associates further demonstrated that fluid reabsorption from proximal straight tubules of the rabbit kidney was also an isosmotic process (443). However, it should be pointed out that there were disagreements on the concept of isosmotic fluid reabsorption in proximal tubules in $1980 \mathrm{~s}(31 ; 172 ; 173 ; 442)$.

The mechanisms underlying isosmotic fluid reabsorption may involve several hypotheses. As in other leaky epithelia such as small intestines and gall bladder, it was widely thought early that fluid transport by proximal tubular epithelium is a passive process as a result of active sodium and solute reabsorption. This is because active sodium and solute transport across proximal tubular epithelium creates an effective transepithelial osmotic gradient that drives water down an osmotic gradient. However, this explanation may be too simplistic, given the complexity of sodium and fluid reabsorption in proximal tubules of the kidney especially in vivo. Over the last 50 years, several hypotheses have been put forwarded to explain isosmotic fluid reabsorption in proximal tubules of the kidney, as discussed below.

Role of lateral intercellular space hypertonicity-The so-called lateral intercellular space is defined as that at the luminal side, apical membranes of proximal tubular cells are joined together via tight junctions, whereas at the peritubular side, basolateral membranes of two adjacent proximal tubular cells are closely opposed to each other, forming an intercellular space between tight junctions and basolateral membranes of two adjacent cells $(291 ; 336)$. According to the lateral intercellular hypertonicity hypothesis, the active $\mathrm{Na}^{+}$ transport process is powered by the activity of $\mathrm{Na}^{+}-\mathrm{K}^{+}$-ATPase at the basolateral 
membranes and transport of $\mathrm{Na}^{+}$into the lateral intercellular space, which creates a hypertonic intercellular compartment $(102 ; 113)$. A hypertonic fluid compartment in the lateral intercellular space serves as a driving force promoting water transport from the tubular lumen into the peritubular capillaries, and therefore may be an important factor in the regulation of proximal tubular fluid reabsorption by the so-called peritubular physical factors.

To test the lateral intercellular hypertonicity hypothesis in the regulation of isosmotic fluid transport in leaky epithelia, Curran \& McIntosh designed a model system for water transport, which consisted of three compartments separated by two membranes with different reflection coefficients (102). These investigators established an osmotic pressure gradient and a hydrostatic pressure gradient across the membranes and were able to demonstrate isosmotic water transport in this model system, which provided a possible mechanism or explanation for water transport in small intestine and proximal tubules of the kidney (102). Diamond and Bossert extended Curran \& McIntosh's work further by proposing a standing-gradient osmotic flow hypothesis, which retained the basic concept of Curran \& McIntosh, but with some modifications based on the presence of $\mathrm{Na}^{+}-\mathrm{K}^{+}$-ATPase on the lateral basolateral membranes (113). The hypothesis of Diamond and Bossert was based on several assumptions, namely: a) sodium and solutes are continuously transported into the lateral intercellular compartment, b) the lateral basolateral membranes are not permeable to solutes, so back-diffusion of solutes across lateral basolateral membranes into proximal tubular cells would not occur, and c) water permeability across apical, lateral basolateral and basement membranes remain high. Thus, a standing osmotic gradient or hypertonicity would be established within the lateral intercellular compartment as a result of active sodium transport into this compartment, which would provide an osmotic driving force for isosmotic water movement from the lumen into the lateral intercellular space either through tubular cells or tight junctions. According to Diamond and Bossert, the accumulation of solute and water within the lateral intercellular compartment will generate a sufficient hydrostatic pressure gradient to move water out of the space across the high waterpermeable basolateral and basement membranes into peritubular capillaries (113).

While the lateral intercellular hypertonicity hypothesis remains debatable since the 1960s, there is some evidence suggesting that the lateral intercellular hypertonicity may indeed play an important role in water transport in proximal tubules. For instance, Maunsbach and Boulpaep observed that in Necturus and rabbit proximal tubules, the dilatation or collapse of the lateral intercellular space was closely associated with the presence or cessation of water reabsorptive volume flux (342). It has also been long recognized that the changes in peritubular physical forces resulting from aortic constriction $(64 ; 424)$, volume expansion $(33 ; 62)$, or increased renal venous pressure (304) may directly or indirectly alter the osmolality and hydrostatic pressure within the lateral intercellular compartment, thereby altering fluid reabsorption by proximal tubules.

Role of $\mathrm{Na}^{+}$recirculation-The role of the $\mathrm{Na}^{+}$recirculation hypothesis in the regulation of solute-coupled fluid reabsorption in proximal tubules has been recently reviewed by Larsen and Moberg, and Larsen et al., respectively (297; 298). The hypothesis appears to be an expansion of the standing-gradient osmotic flow hypothesis proposed by Diamond \& Bossert (113). To help explain isosmotic fluid transport in adsorptive epithelia, Ussing \& Eskesen proposed the alternative so-called $\mathrm{Na}^{+}$-recirculation hypothesis $(512 ; 513)$. The latter theory suggests that the recirculation of $\mathrm{Na}^{+}$ions, or the "surplus of solutes" may be returned to the lateral space via the action of the lateral membrane $\mathrm{Na}^{+}-\mathrm{K}^{+}$-ATPase, and may regulate the osmolality of the absorbate and promote fluid absorption in absorptive epithelia, such as small intestines and proximal tubules of the kidney. Although this hypothesis may predict isosmotic or hyposmotic transport, solvent drag, or the remaining 
hydraulic permeability in proximal tubules of $\mathrm{AQP} 1^{-/-}$mice, they appear to be inadequate to explain the markedly decreased water reabsorption in AQP1 $1^{-/}$mice $(297 ; 298)$.

Role of intraluminal hypotonicity-An alternative hypothesis in explaining isosmotic fluid reabsorption in proximal tubules was proposed in the late 1970s and through the 1980s $(31 ; 172 ; 173 ; 184 ; 321 ; 441 ; 442)$. This hypothesis argues that the lateral intercellular compartment lacks sufficient restraint for solutes and water diffusion, because it is physically very narrow and has remarkably low diffusion resistance, and therefore, it is unlikely can provide enough diffusion resistance to maintain a significant hypertonicity in the compartment for water transport (441). Instead, water reabsorption in proximal tubules may be driven by a relatively small but effective osmotic pressure difference, i.e., luminal hypotonicity, between the tubular lumen and the peritubular capillaries $(10 ; 172 ; 441)$. To test the role of intraluminal hypotonicity in driving water reabsorption, Green and Giebisch simultaneously perfused proximal convoluted tubules and peritubular capillaries with isotonic $\mathrm{NaCl}$. These authors demonstrated that intraluminal hypotonicity developed proportionally to the perfusion rate and the rate of volume reabsorption (172). Barfuss and Schafer (31) perfused isolated rabbit proximal convoluted and straight tubules with an ultrafiltrate of rabbit serum or a similar artificial solution, and found that the osmolality of the absorbate was significantly higher than that of the luminal perfusate and a positive correlation between fluid reabsorption and the osmolality differences between the absorbate and luminal perfusate. These studies provided support to the hypothesis of intraluminal hypotonicity, or a small transepithelial osmotic gradient, in driving fluid reabsorption in proximal tubules of the kidney. Further evidence in favoring luminal hypotonicity as a driving force for isosmotic fluid reabsorption in proximal tubules was obtained in in vivo micropuncture studies in rats $(172 ; 184 ; 321)$. It was estimated that approximately $50 \%$ of water is reabsorbed transcellularly due to luminal hypotonicity (41). Nevertheless, due to the difficulty in measuring such a small luminal hypotonicity in proximal tubular fluid $(<5$ mosmol $/ \mathrm{kg} \mathrm{H}_{2} \mathrm{O}$ ), which is close to the limitation of the methodology for detection, the luminal hypotonicity is also unlikely the sole driving force for isosmotic fluid reabsorption in proximal tubules.

Role of axial anion asymmetry-As both lateral intercellular hypertonicity and intraluminal hypotonicity are insufficient to drive transepithelial fluid reabsorption in proximal tubules, it has also been proposed that preferential reabsorption of organic solutes or anions and bicarbonate in the early proximal convoluted tubules, i.e., axial anion asymmetry, may create an effective osmotic gradient and therefore a driving force for water transport across proximal tubular epithelium $(172 ; 173 ; 321 ; 333 ; 377 ; 441 ; 443)$. The axial anion asymmetry hypothesis suggests that the luminal bicarbonate concentrations would fall due to preferential reabsorption of bicarbonate in early proximal convoluted tubules, while chloride concentrations would rise along the proximal tubule. A transepithelial chloride concentration gradient would develop between the tubular lumen and peritubular capillaries, which may drive proximal tubular sodium and fluid reabsorption (443). If a tubular lumen to peritubular capillary chloride concentration gradient is maintained, proximal tubular sodium and fluid reabsorption would be maintained as well $(172 ; 174)$. Likewise, this hypothesis can also only partially account for isosmotic fluid reabsorption in proximal tubules.

Role of Aquaporin 1-Aquaporin 1 (AQP1) is a major water channel protein, which was cloned by Jung et al. in 1994 (256). The cloned AQP1 gene contains six putative transmembrane domains, but lacks cysteines at the known mercury-sensitive sites (256). The expression of the cloned AQP1 gene in Xenopus oocytes was found to induce 20-fold increase in osmotic water permeability. Northern blot and RNase protection assays demonstrated abundant mRNA expression in rat brain, and to less extent in the kidney and 
other tissues (410). High levels of AQP1 expression were later localized in proximal tubules and the loop of Henle, where AQP1 may be physiologically responsible for up to $80 \%$ of water reabsorption from these nephron segments $(331 ; 447 ; 517)$.

Studies in AQP1-knockout mice have provided new insights and perspectives on the important role of AQP1 in the regulation of water reabsorption in proximal tubules (331; 447; 517). Ma et al. showed that in membrane vesicles isolated from AQP1-knockout mouse kidneys, osmotic water permeability was decreased 8-fold compared with vesicles from wild-type mice (331). AQP1-knockout mice became severely dehydrated after water deprivation for $36 \mathrm{~h}$, with serum osmolality increasing to $500 \mathrm{mOsm} / \mathrm{kg} \mathrm{H}_{2} \mathrm{O}$ and urine osmolality remained decreased (331). Using in vitro proximal tubule microperfusion and in vivo micropuncture, Schnermann et al. specifically determined the role of AQP1 in water reabsorption in AQP1-knockout mice (447). The authors demonstrated that transepithelial osmotic water permeability ( $\mathrm{Pf}$ ) in isolated $\mathrm{S} 2$ segments of proximal tubules from AQP1 knockout mice was markedly decreased, compared with wild-type mice. Spontaneous fluid absorption rates in AQP1-knockout mice were decreased to approximately $50 \%$ of wildtype. Further free-flow micropuncture studies showed that the percentage of fluid absorption in proximal tubules was decreased in AQP1-knockout mice ( $26 \pm 3 \%$ vs. $48 \pm 2 \%, p<0.01$ ) (447). Vallon et al. compared osmolalities in micropuncture fluid samples collected from late proximal tubules and confirmed marked luminal hypotonicity in proximal tubules of AQP1-knockout mice (Fig. 13) (517). Taken together, these results strongly suggest that AQP1 in proximal tubules play an important role in the regulation of proximal tubular fluid reabsorption,

\section{MECHANISMS OF GLOMERULO-TUBULAR BALANCE}

\section{Glomerulo-tubular balance}

A constancy of electrolyte composition and fluid volume in the extracellular space is essential for survival of all mammals. Approximately $99 \%$ of filtered sodium and fluid load from the glomeruli is returned to the circulation by the renal tubular reabsorptive processes. Proximal tubules play a key role in the maintenance of the fine balance between the rate of glomerular filtration (GFR) and absolute proximal tubular reabsorption (APR) in response to spontaneous variations in GFR. This inherent property of proximal tubules in which APR is closely coupled to GFR has long been recognized as glomerulo-tubular balance (GTB) (184; $235 ; 523 ; 524 ; 539 ; 546 ; 549)$. Although the interest in studying this phenomenon appears to have decreased during last couple of decades, GTB remains one of the most important mechanisms whereby proximal tubular transport of sodium and fluid is regulated $(184 ; 497$; 546).

Historical evidence of GTB - The phenomenon of GTB has a long history in the renal physiology and pathophysiology, and excellent reviews on GTB have been published in detail elsewhere $(156 ; 184 ; 497 ; 546)$. The evidence for the existence of proportionality between the rate of GFR and APR was reported as early as 1941 (523; 524). The classical micropuncture study by Walker et al. demonstrated for the first time that “... at least $t w o-$ thirds of the fluid are reabsorbed. This fluid reabsorption is an isosmotic process, accomplished without producing any increase in osmotic pressure of the fluid remaining within the tubule; ..."(523). These investigators also observed a parallel relationship between glomerular and proximal tubular function during spontaneous changes in GFR and concluded that ".. the percentage rather than the amount of reabsorption remained constant; ...". This was followed by Wesson et al. who appeared to first use the expression of GTB in their article entitled "The excretion of strong electrolytes" (541). In his 1951 landmark monograph "The Kidney: Structure and Function in Health and Disease", Homer Smith further introduced and extended the concept of GTB (474). Smith referred to GTB as a 
physiological phenomenon involving the entire nephron population as an integration of glomerular filtration and proximal tubular reabsorption of sodium chloride, fluid, glucose, phosphate and sulphate etc. (474). However, most contemporary renal physiologists continue to focus GTB primarily to the relationship between GFR and absolute APR of sodium and fluid reabsorption.

Gold-standard micropuncture technique to study GTB-The concept of GTB as developed and advocated by Walker et al. (523), Wesson et al. (541), and Smith in the 1940s and 1950s (474) has led to extensive efforts to elucidate this phenomenon and underlying mechanisms. The early micropuncture findings by Walker et al. was subsequently confirmed by others in the 1960 s and 1970 s $(114 ; 156 ; 159 ; 160 ; 316)$. Thus, in vivo micropuncture became the technique of choice to study proximal tubule transport and GTB in subsequent years. In fact, the technique remains a gold-standard tool for renal physiologists to elucidate this phenomenon in health and diseases today. The micropuncture technique has many advantages for studying GTB compared to other approaches. First, the tubular fluid can be collected directly from the end of a single proximal convoluted tubule via a fine glass micropipette for analysis of the changes of its compositions $(156 ; 157 ; 514)$. Second, the structural and biochemical relationship between a proximal tubule, the interstitium and a peritubular capillary is well maintained during the collection of proximal tubular fluid. Third, perhaps more importantly agonists, hormones and their inhibitor(s) or blocker(s) may be applied directly into the tubular lumen or the peritubular capillary to study their roles in the regulation of proximal tubular transport and the cellular mechanisms $(167 ; 200 ; 418)$.

However, the micropuncture technique may also have some limitations. Proximal straight tubules of superficial nephrons and the entire proximal tubular segments in mid-cortical and juxtamedullary nephrons are inaccessible to in vivo micropuncture collection of the tubular fluid $(156 ; 157 ; 514)$. This limitation is significant, because there are clear structural and functional heterogeneities between superficial and juxtamedullary nephrons $(246 ; 248 ; 249$; $291 ; 291 ; 336 ; 551)$. Thus the observations and conclusions obtained using this technique on a single proximal convoluted tubule of a single superficial nephron may not necessarily be applicable to all proximal tubules in the kidney. The other limitation is that the technique is so technically challenging and laborious that very few investigators in the world have the required expertise and resolve to continue to use the technique in their research $(40 ; 269$; $325 ; 399 ; 498 ; 514)$. This technical challenge may in part contribute to the diminished interest in studying GTB today. Recent generation of diverse transgenic mice with knockout, knockin, or overexpression of a particular gene appear to have revived the interest in using the in vivo micropuncture technique to study the physiological roles of these genes in mice $(40 ; 206 ; 269 ; 325)$. Nevertheless, to accurately and reliably perform in vivo micropuncture experiments in superficial proximal tubules of the mouse kidney is even more technically challenging. It is not surprising that some of unexpected observations have been reported between micropuncture studies in the rat and mouse kidneys $(40 ; 206 ; 269 ; 325)$. In spite of these limitations, in vivo micropuncture will remain the gold standard approach to study single proximal tubule function.

Indirect approaches to evaluate GTB in the entire kidney-Since GTB is a phenomenon only occurred under euvolemic conditions in the intact kidney, isolated perfusion of proximal tubules may not be suitable for studying the phenomenon of GTB. To determine whether or not GTB occurs in the entire kidney, several indirect approaches have been proposed. However, their usefulness or validity in evaluating GTB in the entire kidney is often controversial. For example, Leyssac proposed a simple occlusion time and transit time technique for measurement of absolute proximal tubular reabsorption in anesthetized rats $(56 ; 305)$. But the assumptions and validity of the technique have been questioned (156; 157). Other indirect methods include the renal clearance of phosphate, calcium, solute-free 
water clearance during maximal water diuresis to determine total proximal reabsorption of sodium and water in the kidney. But these substances are either reabsorbed or secreted in or beyond proximal tubules, and therefore not ideal for studying GTB (454).

We and others have attempted to use the lithium clearance technique to indirectly estimate absolute proximal reabsorption and thus GTB in the 1980s and 1990s $(66 ; 196 ; 197 ; 202$; $582 ; 587 ; 589)$. The theoretical assumption and validity of this method are primarily based on the observations that the concentration of endogenous lithium is negligible in humans and rodents, and that the reabsorption of exogenous lithium by proximal tubules of the kidney occurs in parallel with sodium and water (Fig. 14) $(449 ; 494 ; 496)$. These include proximal convoluted and straight tubules. No significant lithium secretion or reabsorption was observed beyond the end of proximal tubules $(209 ; 449 ; 483 ; 494 ; 496)$. It has been suggested that the lithium clearance technique may obtain information on the entire kidney proximal tubule function as reliable as the gold standard in vivo micropuncture technique on a single proximal convoluted tubule in rats with normal sodium intake $(463 ; 495)$. It is cautioned, however, that some investigators have questioned the validity of the lithium clearance technique for estimating absolute proximal reabsorption in the entire proximal tubule function $(288 ; 374)$, because lithium reabsorption in distal nephrons may occur under the conditions of sodium depletion or restriction $(271 ; 288)$. In spite of this limitation, the lithium clearance technique has been used as an indirect tool to determine the roles of various humoral factors in the regulation of proximal tubule function and GTB in animals and humans $(66 ; 75 ; 338 ; 386 ; 414 ; 438 ; 476 ; 576)$.

\section{Mechanisms regulating glomerulo-tubular balance}

Although GTB has been demonstrated consistently in rats, it still remains a puzzle how proximal tubules adjust their transport capacity to the physiological changes in GFR. It is well recognized that GTB is present in euvolemic but not in volume-expanded animals. If proximal tubules are isolated from the kidney and perfused in vitro, GTB is either impaired or abolished. This characteristic of GTB has led to the development of several hypotheses to explain the phenomenon of GTB, which include: a) peritubular physical factors $(274 ; 364)$, b) intraluminal factors (274), and c) humoral factors $(51 ; 183 ; 274 ; 364 ; 547)$. These factors are reviewed and discussed below (Fig. 15).

\section{Role of peritubular physical factors}

Peritubular capillary and interstitial oncotic pressure-The coupling of sodium, solute and fluid reabsorption from the lumen of proximal tubules into the lateral intercellular compartment may be mediated or regulated by a combination of active sodium transport, intercellular hypertonicity $(102 ; 113)$, intraluminal hypotonicity $(172 ; 441)$, or axial anion asymmetry $(321 ; 442)$. Thereafter, the reabsorbate is either taken up by peritubular capillaries or leaks back into the tubular lumen via tight junctions due to paracellular back leak of solutes and fluid. The direction of solutes and fluid movement is then determined by the reabsorptive pressure, which is the balance of peritubular capillary and intrarenal interstitial oncotic pressure and hydrostatic pressure. Specifically, peritubular capillary oncotic and interstitial hydrostatic pressure promote fluid reabsorption from the intrarenal interstitium into peritubular capillaries, whereas peritubular capillary hydrostatic and interstitial oncotic pressure reduce fluid reabsorption by forcing fluid and solutes to leak back into the tubular lumen. In addition to peritubular physical forces, absolute fluid absorption in proximal tubules is also regulated by peritubular capillary reabsorptive coefficient, a product of effective reabsorptive area, hydraulic permeability, and tight junctions of proximal tubules. 
Historically, the determinants of peritubular physical factors have been proposed as the dominant, if not sole, mechanism controlling proximal tubular fluid reabsorption, and hence the major mediator of GTB $(32 ; 33 ; 64 ; 304 ; 419 ; 505)$. Indeed, a perfect GTB was demonstrated in studies using aortic artery constriction or release to alter peritubular physical factors $(157 ; 163 ; 234 ; 429)$, or changes in peritubular and interstitial oncotic pressure during and after intra-aortic infusion of colloid-free, isooncotic or hyperoncotic solutions $(62 ; 64 ; 172 ; 283 ; 419)$. Nevertheless, conflicting findings have also been reported in studies using similar microperfusion techniques $(32 ; 214 ; 218)$. Thus, the role of peritubular and interstitial oncotic pressure in modulating GTB is still not well understood.

\section{Peritubular capillary and interstitial hydrostatic pressure-The effects of} peritubular capillary and interstitial hydrostatic pressure on absolute proximal tubular reabsorption and GTB were extensively studied throughout the 1970s to 1980s by altering hydrostatic pressure within peritubular capillaries and the renal interstitium due to alteration of blood pressure, constriction or dilatation of afferent and efferent arterioles, saline volume expansion and increased renal venous pressure $(33 ; 93 ; 156 ; 182 ; 274 ; 430 ; 505 ; 546)$. Acute volume expansion or increase in renal perfusion pressure was closely associated with an increase in peritubular and interstitial hydrostatic pressure, resulting in a decrease in absolute proximal reabsorption and impairment of GTB $(171 ; 430 ; 546)$. If the increases in renal perfusion pressure and therefore, hydrostatic pressure in peritubular capillaries and the renal interstitium were prevented by aortic constriction before volume expansion, GTB would be maintained. By contrast, GTB would be impaired if the aorta was clamped during or after acute volume expansion $(139 ; 234 ; 258)$. It is now well understood that pressure diuresis and natriuresis occur largely due to increases in peritubular capillary and interstitial hydrostatic pressure, which impairs proximal tubular reabsorption and disrupts GTB.

\section{Role of intraluminal factors}

Flow-dependent fluid reabsorption-Flow-dependent fluid reabsorption in proximal tubules remains a well-recognized phenomenon today. Wiederholt et al. first showed that absolute proximal reabsorption changed in direct proportion to tubular flow or perfusion rate. These authors observed a constancy of proximal tubular fluid to plasma inulin concentration ratio, under conditions in which proximal tubular flow rate was altered without changes in single nephron GFR or peritubular physical factors (545). This phenomenon was later confirmed by many others $(32 ; 69 ; 174 ; 184 ; 527)$, providing evidence of flow-dependent of proximal tubular fluid reabsorption.

The mechanisms by which the changes in absolute proximal tubular flow induce parallel changes in proximal tubular fluid absorption remain incompletely understood (527). One of the most recognized hypotheses is that glomerular-borne factors such as filtered sodium bicarbonate, glucose, organic acids, amino acids, and unidentified humoral factors act on proximal tubules $(174 ; 184 ; 270)$. This hypothesis suggests that when the proximal tubular flow rate is increased, more glomerular-borne factors will be presented to the proximal tubular epithelium, which will stimulate proximal tubular reabsorption proportionally. For instance, Bartoli and Earley perfused proximal convoluted tubules with an ultrafiltrate of rat plasma and demonstrated flow-dependent fluid reabsorption, but not during perfusion of a Ringer solution alone (32). Haberle et al. perfused proximal tubules with proximal tubular fluid harvested previously and demonstrated a perfect GTB, which disappeared when the same tubule was perfused with an artificial fluid (184). These early elegant studies strongly suggested that natural glomerular filtrates contain glomerular-borne factors that regulate GTB by stimulating sodium and fluid reabsorption in proximal tubules. 
However, the nature of glomerular-borne factors still remains to be determined. One of possible glomerular-borne factors may be $\mathrm{HCO}_{3}{ }^{-}$. Mathisen and coworkers used ethacrynic acid to inhibit proximal tubular carbonic anhydrase and reported a direct proportionality between $\mathrm{HCO}_{3}{ }^{-}$and absolute proximal fluid reabsorption (340). Green et al. perfused proximal tubular lumen with $\mathrm{HCO}_{3}{ }^{-}$-Ringer solution and obtained $80 \%$ effective GTB (174). Other potential glomerular-borne factors may include organic solutes such as glucose, lactate, alanine, or citrate. Removal of these organic solutes from proximal tubular perfusates impaired GTB by almost $45-75 \%$, whereas addition of these solutes in the perfusates increased absolute proximal reabsorption $(30 ; 70 ; 174)$. These studies suggest that glomerular-borne factors may at least account for up to one-third of a perfect GTB.

An alternative intraluminal factor may involve the so-called tubular geometry. Gertz et al. suggested that GTB is closely associated with the tubular geometry or diameter (156). Indeed, decreased proximal tubular diameter induced by aortic constriction or increased proximal tubular diameter induced by ureteral occlusion was accompanied by parallel changes in absolute proximal reabsorption (424). Alternatively, absolute proximal tubular reabsorption was shown to be proportional to the cross-sectional diameter or area (448). However, the hypothesis of the tubular geometry was not supported by many others ( 72 ; $355 ; 429)$. Thus it appears that flow-dependent fluid reabsorption in proximal nephrons may be associated with glomerular filtered load or constituents of proximal tubular fluid rather than the diameter of proximal tubules.

Recently, it has been suggested that solitary (or primary) cilia of proximal tubular epithelia may play a role in flow-dependent fluid reabsorption in proximal tubules of the kidney, therefore in GTB $(216 ; 285)$. Primary cilia are microtubule-based organelles that extrude from the cell surface such as the brush border membranes of epithelial cells (216). In cultured proximal tubule cells, the cilia may sense the fluid-mechanical stimuli to regulate the trafficking of apical membrane proteins, G protein-coupled receptors (GPCRs), or transcriptional factors between the cilia, cytoplasm and nucleus $(216 ; 285)$. However, the presence and ultrastructure of primary cilia and their potential role in the regulation of proximal tubular transport have not been studied.

Roles of systemic and intrarenal humoral factors-Glomerulotubular balance was recognized between the 1970s and 1980s as an intrinsic physiological process that is regulated by either peritubular physical factors, $(64 ; 234 ; 419 ; 505)$ or intraluminal factors $(32 ; 33 ; 184 ; 214 ; 218 ; 270)$. This process requires little if any external neural or humoral influences. However, neither peritubular and interstitial physical factors nor intraluminal factors alone, or in combination, was firmly established as the sole mechanism(s) responsible for GTB $(184 ; 546)$. Through the 1980s and the early 1990s, we reasoned that humoral mediators which have direct actions on GFR and sodium and fluid reabsorption in proximal tubules may play additional and important roles in the regulation of GTB. Among these humoral factors or mediators, ANG II $(202 ; 527 ; 582 ; 587)$, atrial natriuretic peptide $(105 ; 107 ; 196 ; 197 ; 332 ; 376 ; 398 ; 519 ; 589)$, endothelin $1(201 ; 292 ; 293 ; 314 ; 560)$, and dopamine $(11 ; 104)$ appear to directly or indirectly affect GFR and absolute proximal reabsorption and therefore GTB. This section of review focuses primarily on the roles of these systemic and intrarenal humoral factors or mediators in the regulation of absolute proximal reabsorption and GTB.

\section{Roles of ANG II and its G protein-coupled receptors}

Expression and localization of the major components of the renin-angiotensin system (RAS) in proximal tubules: Among various systemic and intrarenal humoral mediators, angiotensins, especially ANG II, play important roles in the regulation of GFR and proximal 
tubular reabsorption of sodium and water $(99 ; 186 ; 193 ; 276 ; 368 ; 528 ; 590)$. All major components of the RAS, including the substrate angiotensinogen $(239 ; 275 ; 276 ; 371 ; 491)$, the rate-limiting enzyme renin $(239 ; 276 ; 491)$, the angiotensin 1 -converting enzyme (ACE) $(86 ; 205 ; 584 ; 585)$ are expressed in proximal tubules of the kidney (Fig. 16). Thus ANG II can be formed not only systemically, but also locally in the kidney $(77 ; 78 ; 250 ; 345 ; 346$; $369 ; 372 ; 518)$. There is new evidence, however, that angiotensinogen expressed in the liver may be the primary source of angiotensinogen and ANG II in the kidney (341), Matsusaka et al. demonstrated that liver-specific knockout of angiotensinogen nearly abolished plasma and renal angiotensinogen protein and renal tissue angiotensin II (341). This study strongly suggests that under physiological conditions, hepatic angiotensinogen plays a dominant role in the generation of systemic and renal angiotensinogen and ANG II. However, increased local angiotensinogen expression in proximal tubules may partly contribute to high intrarenal or intratubular ANG II levels in ANG II-induced hypertension (373).

Angiotensin II acts on three different GPCRs, $\mathrm{AT}_{1 \mathrm{a}}, \mathrm{AT}_{1 \mathrm{~b}}$ and $\mathrm{AT}_{2}$, in rodents, which are expressed in the apical and basolateral membranes of proximal tubules (Fig. 16) $(82 ; 205$; $391 ; 577 ; 578 ; 586)$. In humans, ANG II acts on two GPCRs, $\mathrm{AT}_{1}\left(\mathrm{AT}_{1 \mathrm{a}}\right)$ and $\mathrm{AT}_{2}$, because humans do not express $\mathrm{AT}_{1 \mathrm{~b}}$. Recent studies using $\mathrm{AT}_{1 \mathrm{a}}$ receptor mutant mice showed that deletion of $\mathrm{AT}_{1 \mathrm{a}}$ receptors selectively from proximal tubules of the kidney is associated with significant decreases in proximal tubular reabsorption and basal blood pressure $(177 ; 307)$. ANG II can be metabolized by aminopeptidases APA and APN to form ANG III and ANG $\mathrm{IV}$, which are also biologically active in proximal tubules via $\mathrm{AT}_{1} / \mathrm{AT}_{2}$ or $\mathrm{AT}_{4}$ receptors, respectively. $(13 ; 189 ; 190 ; 308 ; 393 ; 579)$. Alternatively, ANG II can be degraded by ACE2 to form ANG (1-7), which activates ANG (1-7) or Mas receptors $(88 ; 134 ; 180)$. ANG II and its major metabolites have been shown to alter proximal tubular transport and therefore may serve as mediators of GTB $(90 ; 146 ; 189 ; 395 ; 486)$. The scope of this section focuses mainly on the roles of ANG II and its receptors.

Effects of ANG II on single nephron GTB: Although ANG II is well recognized to be a powerful regulator of sodium, bicarbonate and fluid reabsorption in proximal tubules (99; $186 ; 193 ; 276 ; 368 ; 590)$, few studies have tested the hypothesis whether ANG II is directly involved in the regulation of GTB. Leyssac appears to be the $1^{\text {st }}$ investigator to suggest that angiotensin (probably refer to ANG II) regulates GTB in the mid 1960s by specifically and directly inhibiting fluid reabsorption in proximal tubules (306). Horster et al. subsequently determined whether angiotensin regulates proximal sodium reabsorption and came to a completely different conclusion that angiotensin did not have any direct effect on proximal tubular sodium reabsorption (220). Burg and Orloff investigated GTB in isolated, perfused rabbit proximal tubules in vitro (72). In that study, angiotensin was added into the bath rather than the lumen at the concentration of $2.5 \mu \mathrm{M}$ and fluid reabsorption in proximal tubules was not significantly changed from the control (72). The authors concluded that “... On the basis of the evidence, it appears unlikely that angiotensin is directly involved in this fashion in glomerulotubular balance. The possibility remains, however, that glomerulotubular balance might be regulated by a feedback system involving a hormone other than angiotensin." Finally, Ichikawa and Brenner performed in vivo micropuncture studies to determine the role of efferent arteriolar tone in the regulation of proximal tubular fluid reabsorption and GTB in the rats (234). These authors observed that the subtypenonselective ANG II antagonist saralasin reduced SNGFR and absolute proximal reabsorption proportionally possibly by altering the efferent arteriolar tone (234). In volumedepleted Munich-Wistar rats, Liu and Cogan reported that saralasin caused a small increase in SNGFR and parallel decreases in bicarbonate and chloride reabsorption in proximal convoluted tubules, implying an impairment of GTB (319). Thus whether ANG II regulates GTB remains incompletely understood. 
Effects of ANG II and ANG III on the whole-kidney GTB: Using the whole-kidney integrative approach, we tested the hypothesis that ANG II or ANG III modulates GTB in anesthetized rats by altering GFR and increasing proximal sodium and fluid reabsorption (Fig. 17) $(202 ; 582 ; 587)$. In our studies, the effects of ANG II and ANG III on GTB were evaluated by altering the whole-kidney GFR with the ACE inhibitor enalaprilat to suppress endogenous ANG II formation, and subsequently by replacing equimolar exogenous ANG II or ANG III. Simultaneous changes in absolute and fractional proximal reabsorption were determined by the lithium clearance method as an indirect marker of proximal sodium and fluid reabsorption in the entire kidney (494). We demonstrated that the diuresis and natriuresis induced by enalaprilat were due to the decreases in absolute and fractional proximal tubular reabsorption of sodium and fluid and the disruption of GTB to $48 \%$ of a perfect GTB $(202 ; 582 ; 587)$. We further found that subsequent replacement of exogenous ANG II or ANG III largely restored GTB impaired by enalaprilat to $90 \%$ of a perfect GTB. Impairment of GTB was also observed in anesthetized rats treated with the $\mathrm{AT}_{1}$ receptor antagonist losartan (587). These results may be interpreted to indicate that endogenous ANG II and ANG III may exert a direct stimulatory action on proximal tubular sodium and fluid reabsorption, and may act as a modulator of GTB by coupling the glomerular filtration and absolute proximal reabsorption. In contrast to our early studies $(202 ; 582 ; 587)$, however, Carey et al. have suggested that ANG III may be the predominant agonist for $\mathrm{AT}_{2}$ receptors in proximal tubules of the kidney, activation of which induces natriuresis via a GMPdependent mechanism $(268 ; 392 ; 393)$.

The conclusion that GTB may be modulated by ANG II is supported by the diverse effects of ANG II via $\mathrm{AT}_{1}$ receptors in cultured proximal tubular cells, isolated perfusion of proximal convoluted tubules in vitro, as well as in free-flow micropuncture of proximal convoluted tubules in vivo $(99 ; 186 ; 193 ; 276 ; 368 ; 528 ; 590 ; 591)$. In vitro, we have shown that ANG II stimulates the expression and activation of NHE3 in cultured rabbit and mouse proximal tubule cells $(309 ; 311 ; 312)$. Both in vitro isolated perfusion and in vivo micropuncture studies have established that ANG II exerts biphasic effects on proximal tubular reabsorption with fentomolar concentrations stimulating whereas with nanomolar concentrations inhibiting proximal tubular transport $(152 ; 200 ; 317 ; 453 ; 528 ; 529)$. In vivo, we have recently demonstrated in ANG II-infused rats that at the pressor dose, ANG II induced natriuresis by inhibiting phosphorylation or activation of NHE3 proteins (Fig. 6), whereas the non-pressor dose of ANG II stimulated activation of NHE3 in freshly isolated proximal tubules via protein kinase $\mathrm{Ca}$ (Fig. 7) (313). Both exogenous and endogenous ANG II also stimulates bicarbonate $(59 ; 153 ; 575)$ and phosphate reabsorption (428), increases $\mathrm{Na}^{+}-\mathrm{K}^{+}$-ATPase activity (562), gluconeogenesis (175), and ammoniagenesis (92) in proximal tubules. These diverse effects of ANG II will promote $\mathrm{Na}^{+} / \mathrm{H}^{+}$exchange, $\mathrm{Na}^{+}$/ glucose and $\mathrm{Na}^{+} /$amino acid cotransport on the apical membranes, while increasing $\mathrm{Na}^{+} /$ $\mathrm{HCO}_{3}{ }^{-}$cotransport and $\mathrm{Na}^{+} / \mathrm{K}^{+}$-ATPase activity on the basolateral membranes $(59 ; 153$; 575). Hence, the stimulation by ANG II (and ANG III) of $\mathrm{Na}^{+} / \mathrm{HCO}_{3}{ }^{-}$, and other $\mathrm{Na}^{+}-$ dependent solute cotransport may subsequently create a luminal hypotonicity and a lateral intercellular hypertonicity environment for promoting proximal tubular sodium and fluid reabsorption. Furthermore, by its preferential vasoconstrictive actions on efferent arterioles, ANG II and ANG III may also create a favorable peritubular physical force, i.e., increased oncotic pressure and decreased hydrostatic pressure, for peritubular capillary uptake of sodium and fluid into the circulation.

\section{Roles of dopamine and its GPCRs}

Dopamine synthesis in proximal tubules: Dopamine is best known as a catecholamine and neurotransmitter, but is now widely recognized to play an important paracrine role in the regulation of proximal tubular sodium transport in the kidney and arterial blood pressure 
homeostasis (Fig. 18) (so see the review on Dopamine for a comprehensive review on the topic) $(81 ; 233 ; 253 ; 570 ; 572)$. Dopamine is synthesized not only in noradrenergic and dopaminergic nerves in the central and peripheral nervous systems but also in the kidney. All major components of the entire dopamine system have been reported especially in proximal tubules $(81 ; 572)$. How dopamine is synthesized, metabolized, and trafficking in proximal tubules of the kidney is still not fully understood. Dopamine synthesis in neurons involves hydroxylation of tyrosine by tyrosine hydroxylase to L-dihydroxyphenylalanine (LDOPA), followed by decarboxylation via aromatic amino acid decarboxylase. However, tyrosine hydroxylase is not expressed in proximal tubules, which means dopamine may not be synthesized via the tyrosine hydroxylase $(81 ; 572)$. There is also no evidence that LDOPA is synthesized by proximal tubule cells, and instead its presence within proximal tubular cells is dependent mainly on the glomerular filtrate and taken up by proximal tubule cells via an apical membrane sodium transporter $(81 ; 253 ; 410)$. The uptake of L-DOPA by the proximal tubule cells appears to increase during high salt loading, but the mechanisms involved remain poorly understood $(81 ; 253 ; 390 ; 410 ; 456)$. Nevertheless, this suggests that dopamine synthesis is increased by high salt intake, therefore increased dopamine synthesis in proximal tubules may in part be responsible for high salt-induced natriuresis. Following its synthesis from L-DOPA in proximal tubules, dopamine is thought to be degraded by catechol-o-methyl-transferase and monoamine oxidase A or secreted into either interstitial or luminal fluid compartment, where dopamine activates either apical or basolateral membrane GPCRs $(81 ; 253 ; 572)$, Recently, a novel flavin adenine dinucleotide-dependent amine oxidase, or renalase, has been identified in the kidney $(327 ; 556)$. Renalase has been shown to efficiently metabolize catecholamines including dopamine, epinephrine, and norepinephrine $(111 ; 556)$. Mice with renalase-knockout are hypertensive, suggesting that renalse may play a physiological role in proximal tubule transport and blood pressure regulation $(111 ; 112)$.

Dopamine GPCRs in proximal tubules: The roles of dopamine in the regulation of proximal sodium reabsorption, urinary excretion and blood pressure are mediated by multiple GPCRs (Fig. 19) $(81 ; 253 ; 566 ; 570)$. Dopamine GPCRs belong to the super family of $\mathrm{G}$ protein-coupled hepta-helical membrane receptors, and include at least five distinct members based on their molecular, structural and pharmacological properties $(81 ; 253 ; 570$; 572). Dopamine receptors are further classified into two subfamily groups, the $D_{1}$-like and $\mathrm{D}_{2}$-like sub-families. The $\mathrm{D}_{1}$-like group includes two members, $\mathrm{D}_{1}\left(\right.$ or $\left.\mathrm{D}_{1 \mathrm{~A}}\right)$ and $\mathrm{D}_{5}\left(\mathrm{D}_{1 \mathrm{~B}}\right)$, whereas the $\mathrm{D}_{2}$-like sub-family has three members, $\mathrm{D}_{2}, \mathrm{D}_{3}$ and $\mathrm{D}_{4}$. The $\mathrm{G}$ protein-coupled signaling for the $\mathrm{D}_{1}$-like and $\mathrm{D}_{2}$-like dopamine receptors is strikingly different in that activation of the $\mathrm{D}_{1}$-like receptors by dopamine stimulates adenylate cyclase by coupling to the stimulatory $G$ protein, $G_{s a}$, whereas activation of the $D_{2}$-like receptors inhibits adenylate cyclase by coupling to the inhibitory $\mathrm{G}_{i}$ protein $(81 ; 253 ; 570 ; 572)$. Although all five members of dopamine receptors have been localized in the kidney, only $\mathrm{D}_{1}$-like $\left(\mathrm{D}_{1 \mathrm{~A}}\right.$ and $\left.\mathrm{D}_{1 \mathrm{~B}}\right)$ and $\mathrm{D}_{3}$ of the $\mathrm{D}_{2}$-like dopamine receptors have been demonstrated in proximal tubules $(382 ; 383 ; 390 ; 487 ; 557)$. Light and high resolution electron microscopic immunohistochemical studies have localized $\mathrm{D}_{3}$ dopamine receptors in both apical and basolateral membranes of proximal tubules $(81 ; 572)$. However, it remains poorly understood how apical/basolateral membrane and intracellular/nuclear dopamine receptor expression, localization or distribution are physiologically regulated by high salt intake, pressure natriuresis, and ANG II-dependent hypertension. High resolution electron microscopic immunohistochemistry or in situ hybridization should be ideal approaches to further investigate dopamine GPCRs in proximal tubules. .

Effects of dopamine on proximal tubule function and blood pressure homeostasis: Although whether dopamine and its receptor signaling directly regulate GTB in the kidney 
has not been studied, it has long been recognized that intravenous or intrarenal administration of dopamine induces renal vasodilatation, diuresis and natriuresis, thereby resulting a decrease in arterial blood pressure $(81 ; 253 ; 570 ; 572)$. While the effects of exogenous dopamine on renal hemodynamic responses including GFR and RBF remain inconclusive, dopamine does induce significant diuresis and natriuresis, when it was systemically or intrarenally administered $(81 ; 229)$. Alternatively, the effects of dopamine on urinary sodium excretion of water and sodium could also be deduced from studies in which animals were treated with different dopamine receptor agonists or antagonists (81; $191 ; 229 ; 402 ; 533$ ). If dopamine induces significant diuresis and natriuresis independent of the glomerular filtered load, this strongly suggests that dopamine inhibits proximal tubular sodium transport, since the majority of dopamine GPCRs are expressed or localized in proximal tubules. However, not all dopamine-induced diuresis and natriuresis are due to the inhibition of proximal tubular sodium and fluid reabsorption. In proximal tubules, the inhibitory effects of dopamine are primarily mediated by the $\mathrm{D}_{1}$-like receptors to inhibit $\mathrm{Na}^{+} / \mathrm{K}^{+}$-ATPase and/or NHE3 activity, whereas the $\mathrm{D}_{2}$-like receptors may act synergistically with the $\mathrm{D}_{1}$-like receptors to either increase or decrease sodium reabsorption $(81 ; 89 ; 533 ; 572)$. Activation of the $\mathrm{D}_{1}$-like receptors localized in apical membranes by dopamine leads to the inhibition of NHE3 activity via stimulation of adenylyl cyclase, cAMP production and protein kinase $A$, while stimulation of basolateral membrane $\mathrm{D}_{1}$ receptors inhibits $\mathrm{Na}^{+} / \mathrm{K}^{+}$-ATPase activity through activation of protein kinase $\mathrm{C}(55 ; 81$; $533 ; 572)$.

New insights in the role of dopamine in dopamine GPCR transgenic mice: A significant role of $\mathrm{D}_{1}\left(\mathrm{D}_{1 \mathrm{~A}}\right)$ receptors in the regulation of blood pressure was studied by Albrecht et al. (4). Mice with $\mathrm{D}_{1 \mathrm{~A}}$ receptor knockout $\left(\mathrm{D}_{1 \mathrm{~A}} \mathrm{R}-\mathrm{KO}\right)$ showed markedly elevation of basal systolic and diastolic blood pressures without significantly altering cAMP accumulation in renal tubules or urinary sodium excretion (4). The absence of changes in basal urinary sodium excretion and intrarenal cAMP accumulation in $\mathrm{D}_{1 \mathrm{~A}} \mathrm{R}-\mathrm{KO}$ mice is unexpected. This suggests that dopamine may not play an important role in the regulation of basal renal function, but may become important under pathophysiological conditions such as sodium excess. Nevertheless, the ability of dopamine to increase renal cAMP production, induce sodium excretion, and inhibit NHE activity is decreased in $\mathrm{D}_{1 \mathrm{~A}} \mathrm{R}-\mathrm{KO}$ mice. $\mathrm{D}_{1 \mathrm{~A}} \mathrm{R}-\mathrm{KO}$ mice also develop fatal growth defects and died shortly after weaning age unless their diet is supplemented with hydrated food $(4 ; 121)$. Alternatively, there may be compensatory responses to other dopamine GPCRs following genetic deletion of $\mathrm{D}_{1 \mathrm{~A}}$ receptors. $\mathrm{D}_{3}$ dopamine receptors are also expressed in proximal tubules and they are expected to regulate sodium excretion and blood pressure, because they negatively interact with ANG II and/or $\mathrm{AT}_{1}$ receptors $(381 ; 383 ; 569 ; 571)$. Indeed, Jose and associates generated $\mathrm{D}_{3} \mathrm{R}-\mathrm{KO}$ mice and demonstrated that $\mathrm{D}_{3} \mathrm{R}-\mathrm{KO}$ mice developed renin-dependent hypertension, also accompanied by insignificant changes in basal urinary sodium excretion (18). By contrast, in a different study $\mathrm{D}_{3} \mathrm{R}-\mathrm{KO}$ mice showed no significant differences from wild-type mice in urinary sodium excretion and blood pressure under basal conditions and during high saltdiet, salt-loading or volume expansion (482). Thus, the ideal approach may be to generate $\mathrm{D}_{1 \mathrm{~A}} \mathrm{R}-\mathrm{KO}$ or $\mathrm{D}_{3} \mathrm{R}-\mathrm{KO}$ mice selectively in proximal tubules or to use in vivo micropuncture to study proximal tubular sodium transport responses in wild-type and dopamine receptor mutant mice. Nevertheless, it is estimated that the inhibition of NHE3 and $\mathrm{Na}^{+} / \mathrm{K}^{+}$-ATPase activities in proximal tubules and perhaps in more distal tubules by endogenous dopamine may be responsible for up to $50 \%$ of the basal urinary sodium excretion in the kidney (81; $253 ; 570 ; 572$ ). Although the effects of dopamine and the receptors involved in GTB have not been studied, it is likely that dopamine, via interaction with ANG II $\mathrm{AT}_{2}$ receptors and dopamine $\mathrm{D}_{1}$ receptors, may physiologically impairs GTB and lower basal blood pressure 
by inhibiting proximal tubular sodium and fluid reabsorption in animals and humans (162; 394).

Roles of atrial natriuretic factor (ANF) and natriuretic peptide receptors-In 1961, de Wardener and associates observed that intravenous infusion of saline led to a marked diuresis and natriuresis independent of changes in RBF, GFR and plasma aldosterone level (108). These investigators hypothesized that in addition to the already known GFR and aldosterone, a "third factor" might be involved in the regulation of renal sodium excretion. This observation sparked a great deal of interest and unsuccessful attempts to identify such a natriuretic factor in following years. It was two decades later when de Bold and colleagues first demonstrated that intravenous injection of atrial extracts cause a potent and rapid diuresis and natriuresis in anesthestized rats, which was named atrial natriuretic factor (ANF) or peptide (ANP) $(105 ; 107)$. The discovery of de Bold et al. was soon confirmed by many others $(58 ; 65 ; 76 ; 148)$. The molecular biology and cardiovascular and renal hemodynamic actions of ANF have been comprehensively reviewed elsewhere $(105 ; 106 ; 165 ; 332 ; 376 ; 397 ; 398)$. Although many renal physiologists or nephrologists have recently lost interest in further studying the physiological and pathophysiological roles of ANF in the kidney and other tissues, it may still be relevant to briefly review the effects and mechanisms of ANF in the regulation of proximal tubular sodium and fluid reabsorption and GTB.

Effects of ANF on glomerular hemodynamics: In the kidney, ANF receptors are abundantly expressed in the glomeruli and proximal tubules in the cortex and the inner stripe of the outer medulla and inner medulla (Fig. 20) $(85 ; 347 ; 458)$. The principal actions of ANF are to induce marked diuresis and natriuresis, but the mechanisms by which it increases urinary sodium and water excretion were quite controversial during 1980s to 1990s $(165 ; 332 ; 376)$. A careful review of the ANF research field for last three decades since its discovery reveals at least two major hypotheses, with one being predominantly of the hemodynamic nature and the other involving inhibition of sodium and fluid reabsorption in proximal tubules $(76 ; 98 ; 195 ; 228 ; 318 ; 332)$. While the effects of ANF on RBF have been inconsistent, its effects on GFR appear to be well recognized with the exception when crude atrial extracts or low doses of synthetic ANF were administered $(75 ; 76 ; 332)$. Increases in glomerular filtered load of sodium and water may exceed the reabsorptive capacity of proximal and distal tubules, thereby leading to diuresis and natriuresis. However, pronounced diuresis and natriuresis still occurred in response to low doses of ANF in anesthetized animals without any detectable increases in GFR $(27 ; 107 ; 362 ; 477 ; 594)$. These results strongly suggest that direct actions of ANF on renal tubular transport of sodium and fluid may be indicated.

Effects of ANF on proximal tubular sodium and fluid reabsorption: In addition to the diverse renal hemodynamic effects of ANF, there are also conflicting observations on the effects of ANF on the tubular transport of sodium and fluid reported by many renal physiologists. ANF has been shown to inhibit sodium reabsorption in distal tubules including cortical and medullary collecting ducts $(65 ; 379 ; 478 ; 479 ; 568)$. However, in vitro microperfusion studies later found no direct effects of ANF in the medullary collecting duct $(137 ; 138)$, or in the loop of Henle $(287 ; 408)$. Since fractional sodium excretion was consistently demonstrated during ANF administration with or without changes in GFR, which cannot be entirely attributed to the inhibition of sodium reabsorption in distal nephron segments, a direct or indirect action of ANF on proximal tubules should be explored. Indeed, up to $65 \%$ of glomerular filtered sodium and fluid are reabsorbed by proximal tubules, any inhibition of proximal tubular reabsorption of sodium and fluid by a few percentages will likely result in a significant increase in the end proximal tubular delivery and thereby 
urinary sodium and water excretion. This occurs especially if the distal tubules do not adequately compensate by reabsorbing more sodium and fluid delivered from the end of proximal tubules. For example, Burnett et al showed that ANF significantly increased fractional lithium and phosphate excretion in dog (74). Itabashi and associates demonstrated that ANF infusion caused increases in end-proximal tubular delivery of sodium and free water clearance in isolated perfused rat kidney (242). Finally, Hammond et al. showed that ANF impaired $\mathrm{Na}^{+}$-dependent phosphate symporter and $\mathrm{Na}^{+} / \mathrm{H}^{+}$antiporter activity in brush border membranes of rat proximal tubules (188). Interestingly, ANF had no effects on transepithelial volume flux or potential differences in isolated perfused rabbit proximal tubules $(9 ; 35)$. The reasons underlying these conflicting reports on the renal tubular effects of ANF remained unresolved until Harris et al., who used split-droplet micropuncture technique to study whether ANF has a direct effect on proximal tubular transport (198). These investigators demonstrated for the first time that although ANF alone does not directly inhibit proximal reabsorption when it was perfused into peritubular capillaries, it significantly inhibited ANG II-induced increased proximal tubular reabsorption in a dosedependent manner (198). These results were confirmed by Garvin two year later in isolated perfused proximal straight tubules (151). These results suggest that under physiological conditions, ANF may interact with ANG II in proximal tubules by antagonizing the stimulatory effects of endogenous ANG II on proximal tubular sodium and fluid reabsorption and therefore modulate GTB. The study of Harris et al. may at least explain why ANF does not have direct effects in isolated perfused proximal tubules $(9 ; 35)$, loops of Henle $(287 ; 408)$, and collecting tubules in vitro $(137 ; 138)$.

Effects of ANF on GTB: We have investigated whether ANF inhibits proximal tubular sodium and fluid reabsorption and impairs GTB in anesthetized rats in late 1980s. We infused both low and high doses of synthetic ANF intravenously and simultaneously determined both renal hemodynamic and proximal tubular responses to ANF using the lithium clearance technique $(196 ; 197 ; 199 ; 589)$. At low doses $(0.1-5 \mathrm{ng} / \mathrm{min})$, ANF induced diuresis and natriuresis without concomitant changes in GFR (197). At higher doses (30 ng/kg/min), ANF markedly increased both GFR and the magnitude of diuresis and natriuresis (196). Thus, while GFR was increased by $33 \%$ during ANF administration, absolute APR was increased by only $10 \%$. Consequently, GTB was reduced to $30 \%$ of a perfect GTB $(196 ; 197)$. In parallel experiments, we infused the pancreatic hormone glucagon, which is a known to induce glomerular hyperfiltration in the kidney, to raise GFR to the level seen during ANF infusion, and surprisingly found a proportionally increase in APR and a well-maintained GTB (196). In further studies, we investigated the interactions between ANG II and ANF on the whole-kidney proximal tubular reabsorption in anesthetized rats (Fig. 21) (589). We first treated the rats with the ACE inhibitor enalaprilat to suppress endogenous ANG II formation before ANF was infused intravenously. The effects of ANF on APR and GTB were prevented in rats pretreated with enalaprilat. These whole-kidney studies on the effects of ANF on APR and GTB are consistent with the shrinking split-droplet micropuncture study of Harris et al in rat proximal convoluted tubules (198) or in isolated perfused proximal straight tubules as reported by Garvin (151). The other indirect evidence supporting our observations includes that ANF-induced increases in fractional lithium and phosphate excretion were abolished by combined administration of an ACE inhibitor and ANG II (420; 421; 438). However, it should be pointed out that Liu and Cogan failed to demonstrate a proximal tubular effect of ANF when it was administered at a pharmacological dose $(5 \mu \mathrm{g} / \mathrm{kg}$ as a bolus dose followed by a constant infusion rate of $0.5 \mu \mathrm{g} / \mathrm{kg} / \mathrm{min}$ ) (318). These differences may only be further resolved in the future by using transgenic mice with genetic deletion of ACE $(206 ; 269)$, $\mathrm{AT}_{1 \mathrm{a}}$ receptor for ANG II $(177 ; 299 ; 307)$, natriuretic peptide receptor A (NPRA) and B (NPRB) for ANF $(397 ; 398)$ selectively in proximal tubules of the kidney. 
Roles of endothelin-1 and $\mathrm{ET}_{\mathbf{A}}$ and $\mathrm{ET}_{\mathbf{B}}$ receptors-Endothelin-1 (ET-1) is known as one of the most potent vasoactive polypeptides initially derived from cultured porcine endothelial cells (560), but it is now well recognized to be synthesized or expressed in the kidney including proximal tubules $(278 ; 280)$. Endothelin-1 belongs to the mammalian ET gene family, which includes two additional members, ET-2 and ET-3 $(278 ; 280)$. The molecular biology, tissue-specific expression or production, and its physiological and pathophysiological roles in the regulation of salt and fluid balance and therefore blood pressure has recently been comprehensively reviewed by Kohan et al. $(278 ; 280)$. This section therefore only devotes to the potential roles of ET-1 and its receptors in the physiological regulation of proximal tubular function and GTB.

Production of ET-1 in proximal tubules-It is important to emphasize that very low levels of ET-1 are present in the circulation under physiological situations and therefore ET-1 may be viewed as a local tissue paracrine or autocrine peptide $(280 ; 457 ; 462 ; 560)$. The evidence that proximal tubules express and synthesize ET-1 primarily came from molecular biology and immunohistochemical studies. For example, there is evidence that ET-1 mRNA is expressed in cultured proximal tubules cell lines, including rabbit proximal tubule cells $(207 ; 277)$ and human proximal tubule cells (387). By contrast, ET-1 mRNAs are either expressed $(91 ; 314)$ or not expressed in rat proximal tubules $(507 ; 509)$. Although immunohistochemical staining of ET-1 was detected in proximal tubules (548), these studies may only serve as an indirect evidence for proximal tubular production of ET-1 under physiological conditions. It may be necessary to determine the physiological levels of ET-1 concentrations in freshly isolated proximal tubules.

Expression and localization of ET-1 receptors in proximal tubules-Two classes of ET-1 receptors, $\mathrm{ET}_{\mathrm{A}}$ and $\mathrm{ET}_{\mathrm{B}}$, have been molecularly cloned in humans and other mammals $(2 ; 12 ; 128 ; 222 ; 315 ; 367 ; 384 ; 436 ; 437)$. The human $\mathrm{ET}_{\mathrm{A}}$ receptor gene encodes 427 amino acids $(2 ; 222)$, whereas the human $\mathrm{ET}_{\mathrm{B}}$ receptor gene encodes 442 amino acids, respectively $(367 ; 384 ; 436)$. The $\mathrm{ET}_{\mathrm{A}}$ receptor has much higher affinity in binding to ET-1 than to ET-2 and ET-3 $(2 ; 222)$, whereas the ET $_{\mathrm{B}}$ receptor appears to bind three ET peptides equally $(367 ; 384 ; 436)$. Both ET receptors belong to the GPCR family and have been shown to involve several $G$ proteins, including $G_{i}, G_{s}, G_{q}$ and $G_{a 12 / 13}(125$; $272 ; 280 ; 315 ; 367 ; 384 ; 436 ; 437)$. Depending on the tissues or cells, activation of both receptors by ET- 1 induces a variety of signaling responses $(208 ; 279 ; 280 ; 412 ; 445)$. In the kidney, mRNAs for $\mathrm{ET}_{\mathrm{A}}$ and $\mathrm{ET}_{\mathrm{B}}$ receptors are widely expressed in different cells, including glomerular mesangial cells, vascular smooth muscle cells, proximal and distal tubular epithelial cells and inner collecting duct cells (280). Low levels of specific ET-1 and ET-3 receptor binding have been demonstrated in microdissected proximal tubular segments $(490 ; 508)$, whereas both $\mathrm{ET}_{\mathrm{A}}$ and $\mathrm{ET}_{\mathrm{B}}$ receptor immunostaining were localized in proximal tubules of the rat kidney $(538 ; 558 ; 559)$. Using in vitro and in vivo autoradiography, we and others have localized ET-1 receptor binding to the glomeruli, cortical inter-glomerular regions corresponding to proximal tubules, inner stripe of the outer medulla, and inner medulla $(109 ; 110 ; 281 ; 282 ; 581 ; 583)$. Using $\mathrm{ET}_{\mathrm{A}}$ receptor-selective antagonist $\mathrm{BQ} 123$ or $\mathrm{ET}_{\mathrm{B}}$ receptor-selective agonist sarafotoxin $6 \mathrm{C}(\mathrm{S} 6 \mathrm{C})$ as a binding displacer/inhibitor, we demonstrated that most of intrarenal ET-1 receptor binding is of the $\mathrm{ET}_{\mathrm{B}}$ receptor $(109 ; 110$; $581 ; 583 ; 588)$. However, in vitro autoradiographic studies suggest that levels of ET-1 or $\mathrm{ET}_{\mathrm{B}}$ receptors are much lower in proximal tubules, than those in the glomeruli, inner stripe of the outer medulla, and inner medulla in the rat kidney (Fig. 22).

Effects of ET-1 on proximal sodium and fluid reabsorption and GTB-Although both ET-1 synthesis and its receptor expression are relatively lower in proximal tubules, ET-1 appears to have diverse effects on proximal tubular sodium and fluid transport in the 
kidney (280). Depending on the experimental settings or tissue preparations, two different modes of ET-1-induced effects have been reported. In vitro, ET-1 appears to exert positive or stimulatory effects, which are associated with increases in proximal tubular sodium and fluid reabsorption. For example, ET-1 increases the activities of NHE3 via an autocrine action $(176 ; 292 ; 293 ; 314)$ and $\mathrm{Na}^{+} / \mathrm{HCO}_{3}{ }^{-}$symporter in rabbit renal cortical vesicles $(127)$ or opossum kidney proximal tubular cells (OKP) (525), and $\mathrm{Na}^{+} / \mathrm{P}_{\mathrm{i}}$ cotransporter in rat renal cortical slices (176). ET-1 also induces activation and/or phosphorylation and exocytic insertion of NHE3 in OKP cells via $\mathrm{ET}_{\mathrm{B}}$ receptors and activation of protein kinase $\mathrm{C}$ (PKC) and cAMP-dependent protein kinase A (PKA) $(94 ; 403 ; 404)$. Furthermore, increased activities of NHE3, $\mathrm{Na}^{+} / \mathrm{HCO}_{3}{ }^{-}$symporter, and $\mathrm{Na}^{+} / \mathrm{P}_{\mathrm{i}}$ cotransporter in proximal tubular cells are associated with enhanced proximal tubular sodium and fluid reabsorption. The stimulatory effects of ET-1 in proximal tubule cells in vitro were elicited at $\mathrm{nM}$ of concentrations, which are probably above physiological levels of ET-1 in proximal tubules. However, it is quite common that higher concentrations of ET-1 or any other agonists would be required to induce biological effects in the in vitro preparations or cultured cells.

Although there have been more than 20,000 publications on ET-1 and $\mathrm{ET}_{\mathrm{A}}$ and $\mathrm{ET}_{\mathrm{B}}$ receptors since ET-1 was discovered more than two decades ago, there is limited information on whether ET-1 and its receptors regulate proximal tubular sodium and fluid reabsorption in the kidney in vivo or in isolated perfused proximal tubules in vitro (147; $150 ; 201 ; 405 ; 432)$. Using the lithium clearance technique, we intravenously infused low doses of ET-1 (1 and $10 \mathrm{ng} / \mathrm{kg} / \mathrm{min}$ ) in anesthetized rats, which did not alter the wholekidney GFR (201). We demonstrated that ET-1 induced transient increases in blood pressure followed by sustained hypotension and decreased renal vascular resistance, accompanied by 5 -fold increases in fractional water and 10-fold increases in fractional sodium excretion (201). Interestingly, we found that the end-proximal tubular delivery as estimated by the lithium clearance technique doubled and fractional sodium reabsorption was decreased by $\sim 20 \%$ by ET- 1 infusion. APR also fell significantly indicating an impairment of GTB by ET-1. These findings were subsequently confirmed in a different lithium clearance study by Perico et al. who also demonstrated that ET-1 (150 pmol, i.v.) induced marked diuresis and natriuresis primarily by decreasing both APR and fractional proximal tubular reabsorption of sodium (405). Thus these two reports were the first demonstration of an inhibitory effect of low concentrations of ET-1 on proximal tubular sodium and fluid transport and GTB in the rat kidney in vivo. By contrast, in healthy human subjects ET-1 did not have any effect on APR, when it was infused at a dose that significantly increased blood pressure, caused renal vascular constriction, and induced marked anti-diuresis and anti-natriuresis (480). In an in vivo micropuncture study in which ET-1 was administered intraluminally at $10^{-7} \mathrm{M}$, APR was increased by more than 3 -fold whereas fractional proximal tubular sodium reabsorption was increased by $30 \%$ (432). Whether ET-1 exerts such profound stimulatory effects on proximal tubular reabsorption in the kidney remains controversial, since pharmacological concentrations of ET-1 were used $(280 ; 432)$. Similarly, the mechanisms by which ET-1 inhibits proximal tubular sodium and fluid reabsorption in the rat kidney are also not well understood. However, it has been shown that ET-1 inhibited fluid and bicarbonate reabsorption in isolated perfused rat proximal straight tubules by decreasing $\mathrm{Na}^{+}-\mathrm{K}^{+}$ATPase activity (150). Furthermore, activation of $\mathrm{ET}_{\mathrm{B}}$ receptors by an $\mathrm{ET}_{\mathrm{B}}$ receptor agonist in proximal tubules of the WKY rat kidney also inhibits $\mathrm{Na}^{+}-\mathrm{K}^{+}$-ATPase activity (565).

\section{PROXIMAL TUBULAR FUNCTIONS AND GLOMERULO-TUBULAR BALANCE IN GENE-TARGETED ANIMALS}

Over the last two decades, gene silencing or deletion has been increasingly used to generate unique animal models in which a gene encoding a particular enzyme, protein, GPCR, or transporter is silenced or deleted globally throughout the body or in a cell- or tissue-specific 
manner. These novel animal models has provided a powerful tool to further study the proximal tubular function and determine the genetic and signaling mechanisms by which the proximal tubular function is regulated. However, some interesting but unexpected findings and/or insights on the proximal tubular function and GTB have emerged during recent years. Several examples are briefly reviewed below.

\section{NHE3}

NHE3 is the major $\mathrm{Na}^{+} / \mathrm{H}^{+}$exchanger expressed in proximal tubules of the kidney $(48 ; 118$; $389 ; 500)$ and small intestines of the digestive system, and is responsible for the majority of sodium reabsorption in proximal tubules $(5 ; 14 ; 352 ; 451)$. One would expect an imbalance between the glomerular filtered load and urinary excretion of sodium in mice with deficiency of the NHE3 gene. In these mutant mice, absolute reabsorption of fluid and bicarbonate in proximal tubules was reduced by more than $60 \%$ in NHE3-knockout mice (Nhe3-/-) $(325 ; 451 ; 530)$. This suggests that the end-proximal tubular fluid and sodium delivery should be increased by a similar extent into the distal nephrons, and may induce marked diuresis and natriuresis, because the distal nephrons are only responsible for reabsorbing about $30 \%$ of the filtered load. However, urinary water and sodium excretion was reduced rather than increased in Nhe3-/- mice $(325 ; 451 ; 530)$. This is because NHE3 is also expressed in abundance in small intestines and global deletion of NHE3 in these mice not only markedly impairs fluid and sodium reabsorption from proximal tubules but also from small intestines. There is a marked fluid and sodium wasting from the digestive system due to fluid and sodium retaining inside the lumen of intestines and moderate to severe diarrhea $(325 ; 451 ; 530)$. Further studies on transgenic rescue of the NHE3 gene in small intestines led to improvement of fluid and sodium wasting from the digestive system (380; 550). Thus severe fluid and sodium wasting in the gut may stimulate compensatory responses to retain fluid and sodium from proximal tubules and the kidney by reducing single nephron and whole-kidney GFR (325).

\section{ACE}

ACE is expressed in abundance in apical membranes of proximal tubules (Fig. 15B), and play an important role in the regulation of proximal tubular transport of fluid and sodium by converting ANG I to ANG II $(130 ; 194 ; 205 ; 206 ; 269 ; 372 ; 584 ; 587)$. Previous studies in anesthetized rats or in vivo micropuncture studies using ACE inhibitors confirmed the important roles of ACE and by implication, endogenous ANG II (194; 205; 372; 584; 587). To determine the role of ACE in renal function, Hashimoto et al. performed in vivo micropuncture on two lines of ACE-KO mice, in which ACE expression in the kidney was markedly reduced (ACE1/3) or eliminated (ACE2/2), respectively (206). In ACE1/3 mice, total GFR and SNGFR and fractional proximal reabsorption were similar to those of wildtype mice, In ACE2/2 mice, total GFR and SNGFR were significantly reduced while fractional proximal tubular reabsorption was increased significantly (206). These authors concluded that the chronic lack of ACE, and presumably endogenous ANG II generation, in the proximal tubule was not associated with sustained proximal fluid transport defects (Fig. 23) (206). Similar results were reported by Kesseler et al. in mice with or without expression of renal ACE (14). These results again suggest that in the absence of ANG II-stimulated proximal tubular transport, other vasoactive systems may compensate for the loss of the effects induced by ACE or ANG II in proximal tubules, therefore maintaining GTB.

\section{ANG II and/or $\mathrm{AT}_{1}\left(\mathrm{AT}_{1 \mathrm{a}}\right)$ receptors}

In contrast to $\mathrm{ACE}-\mathrm{KO}$ mice, $\mathrm{AT}_{1}\left(\mathrm{AT}_{1 \mathrm{a}}\right)$ receptors in proximal tubules appear to play an important role in the regulation of proximal tubular reabsorption and blood pressure in transgenic mouse models. Gurley et al. generated transgenic mice with deficiency of $\mathrm{AT}_{1 \mathrm{a}}$ receptors selectively in proximal tubules, and demonstrated that ANG II in the epithelium of 
the proximal tubule plays a critical and nonredundant role in determining the basal level of blood pressure. Abrogation of $\mathrm{AT}_{1 \mathrm{a}}$ receptor signaling in the proximal tubule alone reduced proximal fluid reabsorption and altered expression of key sodium transporters, modified pressure-natriuresis and protected the animals against hypertension (177). Li et al. used a proximal tubule specific, androgen-dependent promoter construct (KAP2) to generate mice with either over-expression of a constitutively active $\mathrm{AT}_{1 \mathrm{a}}$ receptor transgene or depletion of endogenous $\mathrm{AT}_{1 \mathrm{a}}$ receptors (307). Androgen administration to female transgenic mice caused a robust induction of the transgene in the kidney and increased baseline blood pressure. In the receptor depleted mice, androgen administration to females resulted in a Cre recombinase-mediated deletion of $\mathrm{AT}_{1 \mathrm{a}}$ receptors in the proximal tubule and reduced blood pressure (307). Using the in vivo intrarenal adenoviral gene transfer approach, we expressed an intracellular cyan fluorescent fusion of ANG II (ECFP/ANG II), selectively in proximal tubules of the rat and mouse kidneys with a proximal tubule-specific SGLT2 gene promoter (Fig. 24) (310). In our study, systolic blood pressure was increased in ECFP/ANG IItransferred rats, whereas fractional sodium and lithium excretion was reduced significantly. These suggest that intracellular ECFP/ANG II expression selectively in proximal tubules of the kidney led to increased basal blood pressure by increasing proximal tubular sodium reabsorption. The effects of ECFP/ANG II on blood pressure were blocked by losartan and prevented in $\mathrm{AT}_{1 \mathrm{a}}$ receptor knockout mice (Fig. 25). Thus our results provide evidence that proximal tubule-selective transfer of an intracellular ANG II fusion protein increases blood pressure by activating $\mathrm{AT}_{1 \mathrm{a}}$ receptors and increasing sodium reabsorption in proximal tubules (310). Taken together, $\mathrm{AT}_{1}\left(\mathrm{AT}_{1 \mathrm{a}}\right)$ receptors in proximal tubules appear to play an important role in mediating both extracellular and intracellular ANG II-regulated proximal tubular reabsorption and blood pressure.

\section{SUMMARY AND CONCLUSIONS}

In summary, the kidney no doubt plays a central role in the maintenance of a delicate extracellular electrolyte and fluid balance and blood pressure homeostasis largely through the function of proximal tubules. Proximal convoluted and straight tubules appear to exert a more prominent role than other nephron segments by reabsorbing $65 \%$ to $70 \%$ of the entire glomerularly filtered load and most, if not all, of filtered amino acids, solutes and low molecular weight proteins. Proximal tubules also contribute to the regulation of body acidbase balance and glucose metabolism. Great progress has been made in almost all aspects of proximal tubular function, especially with recent advances acquired from studies using molecular biology, gene silencing, and transgenic approaches in proximal tubules of the kidney. However, some basic tenets of the proximal tubule including the ultrastructures, intrinsic properties of proximal tubular sodium and fluid transport, and the regulatory mechanisms involved remain surprisingly intact. These include nearly isosmotic transport of two-thirds of the glomerular filterd load, the proportionality of APR to GFR (or GTB), and the roles of apical membrane NHE3, basolateral membrane $\mathrm{Na}^{+}-\mathrm{K}^{+}$-ATPase and NBCe1-A, peritubular physical and intraluminal humoral factors. However, recent studies showed that global or proximal tubule-specific deficiency of a particular transporter protein, a GPCR, or a peptide hormone that has profound effects on proximal tubular transport may not lead to significant body sodium and fluid imbalance in transgenic animals, but may lead to lower basal blood pressure $(206 ; 269 ; 325 ; 446 ; 517 ; 530)$. This is because the defects in the proximal transport function due to the knockout of a gene or protein of interest are alleviated by appropriate compensatory responses in dietary intake, the glomerular filtered load and distal nephron segments (446). When a transporter protein is deleted from the proximal tubule, the same transporter expressed in other nephron segments or other solute transporters in proximal and distal nephron segments respond by increasing their expression or activities. Thus the body can largely adapt to the changes in proximal tubule functional defects in order to maintain body salt and fluid balance. 
Although our understanding of the proximal tubular function has greatly improved with the use of novel approaches, new agonists or inhibitors, and global or proximal tubule-specific gene-targeting animals, the proximal tubular function and its physiological regulatory mechanisms may still be further studied using complementary approaches in the future. First, the traditional approach using a particular pharmacological compound to target an enzyme, a protein kinase, or a GPCR etc., still has a place in studying a particular tubular transport mechanism in proximal tubule cell cultures, in vitro isolated perfused or in vivo micropuncture of proximal tubules. However, better inhibitors or antagonists which have fewer nonspecific effects need to be developed. Second, in vitro isolated perfused and in vivo micropuncture of proximal tubules remain the gold standard techniques to study the proximal tubular transport and underlying physiological mechanisms. Third, gene silencing of a particular transporter or protein using siRNAs is increasingly used in the cell culture studies, but its usefulness for elucidating proximal tubule-specific effects in animals remains to be confirmed. The question remains as to how a particular siRNA may be delivered specifically and efficiently to proximal tubules to knockdown a gene or protein expression. There are also major concerns on the off-target effects or nonspecific consequences of this gene-silencing approach (257). Fourth, it is no longer sufficient to use global knockout animals to study proximal tubule physiology, and novel animal models with proximal tubule-specific knockout or knockin should be developed. Finally, with recent advances in gene microarrays and proteomics, an integrative approach should be used to uncover or explore the complex signaling transduction pathways and their interactions responsible for the regulation of the proximal tubular function in health and disease. Together, future studies with these complementary and innovative approaches will no doubt provide further new insights and perspectives in our understanding how proximal tubular transport is regulated by humoral factors, and how proximal tubular transport contributes to blood pressure homeostasis, and therefore becomes a therapeutic target in the prevention and treatment of hypertension and progressive kidney diseases.

\section{Acknowledgments}

The work of this laboratory cited in this manuscript before 2001 was supported by grants from National Health and Medical Research Council of Australia, National Heart Foundation, and Australian Kidney Foundation; whereas the work cited here after 2001 was supported by grants from National Institute of Diabetes and Digestive and Kidney Disease grants (5RO1DK067299, 2R56DK067299, and 2RO1DK067299), National Kidney Foundation of Michigan, American Heart Association, American Society of Nephrology M. James Scherbenske Grant, and Hearin Foundation Medical Research Scholar Award to Dr. Jia L. Zhuo. We wish to thank our Australian mentors Drs. Sandford L. Skinner and Peter J. Harris of the Department of Physiology, and Dr. Frederick A.O. Mendelsohn of Howard Florey Institute of Experimental Physiology and Medicine at the University of Melbourne, Australia, and American mentors Dr. L. Gabriel Navar of the Department of Physiology at Tulane University School of Medicine in New Orleans and Dr. Oscar A. Carretero of the Division of Hypertension and Vascular Research at Henry Ford Hospital in Detroit, We also thank our past and present collaborators, postdoctoral fellows, graduate students, and technicians for their support. We sincerely apologize to all other outstanding investigators whose work on all aspects of proximal tubules has not been included in this review due to the topic confined to proximal tubules of the kidney and space restriction.

\section{REFERENCES}

1. Abuladze N, Lee I, Newman D, Hwang J, Pushkin A, Kurtz I. Axial heterogeneity of sodiumbicarbonate cotransporter expression in the rabbit proximal tubule. Am J Physiol. 1998; 274:F628F633. [PubMed: 9530281]

2. Adachi M, Yang YY, Furuichi Y, Miyamoto C. Cloning and characterization of cDNA encoding human A-type endothelin receptor. Biochem Biophys Res Commun. 1991; 180:1265-1272. [PubMed: 1719979]

3. Aizman O, Aperia A. Na,K-ATPase as a signal transducer. Ann N Y Acad Sci. 2003; 986:489-496. 489-496. [PubMed: 12763869] 
4. Albrecht FE, Drago J, Felder RA, Printz MP, Eisner GM, Robillard JE, Sibley DR, Westphal HJ, Jose PA. Role of the D1A dopamine receptor in the pathogenesis of genetic hypertension. J Clin Invest. 1996; 97:2283-2288. [PubMed: 8636408]

5. Alpern RJ. Cell mechanisms of proximal tubule acidification. Physiol Rev. 1990; 70:79-114. [PubMed: 2404291]

6. Alpern RJ, Chambers M. Cell pH in the rat proximal convoluted tubule. Regulation by luminal and peritubular $\mathrm{pH}$ and sodium concentration. J Clin Invest. 1986; 78:502-510. [PubMed: 3016029]

7. Amemiya M, Kusano E, Muto S, Tabei K, Ando Y, Alpern RJ, Asano Y. Glucagon acutely inhibits but chronically activates $\mathrm{Na}(+) / \mathrm{H}(+)$ antiporter 3 activity in OKP cells. Exp Nephrol. 2002; 10:2633. [PubMed: 11803202]

8. Amemiya M, Loffing J, Lotscher M, Kaissling B, Alpern RJ, Moe OW. Expression of NHE-3 in the apical membrane of rat renal proximal tubule and thick ascending limb. Kidney Int. 1995; 48:12061215. [PubMed: 8569082]

9. Ando R, Sasaki S, Shiigai T, Takeuchi J. Lack of effect of alpha-human atrial natriuretic polypeptide on volume reabsorption and p-aminohippuric acid secretion in the rabbit proximal straight tubule. Jpn J Physiol. 1987; 37:81-91. [PubMed: 2956445]

10. Andreoli TE, Schafer JA, Troutman SL. Perfusion rate-dependence of transepithelial osmosis in isolated proximal convoluted tubules: estimation of the hydraulic conductance. Kidney Int. 1978; 14:263-269. [PubMed: 723152]

11. Aperia AC. Intrarenal dopamine: a key signal in the interactive regulation of sodium metabolism. Annu Rev Physiol. 2000; 62:621-647. 621-647. [PubMed: 10845105]

12. Arai H, Hori S, Aramori I, Ohkubo H, Nakanishi S. Cloning and expression of a cDNA encoding an endothelin receptor. Nature. 1990; 348:730-732. [PubMed: 2175396]

13. Ardaillou R, Chansel D. Synthesis and effects of active fragments of angiotensin II. Kidney Int. 1997; 52:1458-1468. [PubMed: 9407491]

14. Aronson PS. Mechanisms of active H+ secretion in the proximal tubule. Am J Physiol. 1983; 245:F647-F659. [PubMed: 6318566]

15. Aronson PS. Ion exchangers mediating $\mathrm{Na}+, \mathrm{HCO} 3-$ and $\mathrm{Cl}-$ transport in the renal proximal tubule. J Nephrol. 2006; 19(Suppl 9):S3-S10. [PubMed: 16736438]

16. Aronson PS, Nee J, Suhm MA. Modifier role of internal $\mathrm{H}+$ in activating the $\mathrm{Na}+\mathrm{H}+$ exchanger in renal microvillus membrane vesicles. Nature. 1982; 299:161-163. [PubMed: 7110335]

17. Aronson PS, Sacktor B. The Na+ gradient-dependent transport of D-glucose in renal brush border membranes. J Biol Chem. 1975; 250:6032-6039. [PubMed: 1150669]

18. Asico LD, Ladines C, Fuchs S, Accili D, Carey RM, Semeraro C, Pocchiari F, Felder RA, Eisner GM, Jose PA. Disruption of the dopamine D3 receptor gene produces renin-dependent hypertension. J Clin Invest. 1998; 102:493-498. [PubMed: 9691085]

19. Attaphitaya S, Park K, Melvin JE. Molecular cloning and functional expression of a rat $\mathrm{Na}+\mathrm{H}+$ exchanger (NHE5) highly expressed in brain. J Biol Chem. 1999; 274:4383-4388. [PubMed: 9933642]

20. Avner ED, Sweeney WE Jr, Nelson WJ. Abnormal sodium pump distribution during renal tubulogenesis in congenital murine polycystic kidney disease. Proc Natl Acad Sci U S A. 1992; 89:7447-7451. [PubMed: 1323837]

21. Bacic D, Kaissling B, McLeroy P, Zou L, Baum M, Moe OW. Dopamine acutely decreases apical membrane $\mathrm{Na} / \mathrm{H}$ exchanger NHE3 protein in mouse renal proximal tubule. Kidney Int. 2003; 64:2133-2141. [PubMed: 14633135]

22. Baines AD, de RC. Functional heterogeneity of nephrons. II. Filtration rates, intraluminal flow velocities and fractional water reabsorption. Pflugers Arch. 1969; 308:260-276. [PubMed: 5813954]

23. Baird NR, Orlowski J, Szabo EZ, Zaun HC, Schultheis PJ, Menon AG, Shull GE. Molecular cloning, genomic organization, and functional expression of $\mathrm{Na}+\mathrm{H}+$ exchanger isoform 5 (NHE5) from human brain. J Biol Chem. 1999; 274:4377-4382. [PubMed: 9933641]

24. Bakris GL, Fonseca VA, Sharma K, Wright EM. Renal sodium-glucose transport: role in diabetes mellitus and potential clinical implications. Kidney Int. 2009; 75:1272-1277. [PubMed:

19357717] 
25. Banday AA, Lokhandwala MF. Angiotensin II-mediated biphasic regulation of proximal tubular $\mathrm{Na}+\mathrm{H}+$ exchanger 3 is impaired during oxidative stress. Am J Physiol Renal Physiol. 2011; 301:F364-F370. [PubMed: 21593187]

26. Bankir L, Farman N. [Heterogeneity of the glomeruli in the rabbit]. Arch Anat Microsc Morphol Exp. 1973; 62:281-291. [PubMed: 4794446]

27. Banks RO. Effects of a physiological dose of ANP on renal function in dogs. Am J Physiol. 1988; 255:F907-F910. [PubMed: 2973245]

28. Barcroft LC, Moseley AE, Lingrel JB, Watson AJ. Deletion of the Na/K-ATPase alpha1-subunit gene (Atp1a1) does not prevent cavitation of the preimplantation mouse embryo. Mech Dev. 2004; 121:417-426. [PubMed: 15147760]

29. Barfuss DW, Schafer JA. Collection and analysis of absorbate from proximal straight tubules. Am J Physiol. 1981; 241:F597-F604. [PubMed: 7325231]

30. Barfuss DW, Schafer JA. Differences in active and passive glucose transport along the proximal nephron. Am J Physiol. 1981; 241:F322-F332. [PubMed: 7282931]

31. Barfuss DW, Schafer JA. Rate of formation and composition of absorbate from proximal nephron segments. Am J Physiol. 1984; 247:F117-F129. [PubMed: 6331196]

32. Bartoli E, Conger JD, Earley LE. Effect of intraluminal flow on proximal tubular reabsorption. J Clin Invest. 1973; 52:843-849. [PubMed: 4693649]

33. Bartoli E, Earley LE. Effects of saline infusion on glomerulotubular balance. Kidney Int. 1972; 1:67-77. [PubMed: 4671222]

34. Basgen JM, Steffes MW, Stillman AE, Mauer SM. Estimating glomerular number in situ using magnetic resonance imaging and biopsy. Kidney Int. 1994; 45:1668-1672. [PubMed: 7933814]

35. Baum M, Toto RD. Lack of a direct effect of atrial natriuretic factor in the rabbit proximal tubule. Am J Physiol. 1986; 250:F66-F69. [PubMed: 2934992]

36. Beck JC, Sacktor B. Membrane potential-sensitive fluorescence changes during Na+-dependent Dglucose transport in renal brush border membrane vesicles. J Biol Chem. 1978; 253:7158-7162. [PubMed: 701240]

37. Beck JC, Sacktor B. The sodium electrochemical potential-mediated uphill transport of D-glucose in renal brush border membrane vesicles. J Biol Chem. 1978; 253:5531-5535. [PubMed: 670213]

38. Beeman SC, Zhang M, Gubhaju L, Wu T, Bertram JF, Frakes DH, Cherry BR, Bennett KM. Measuring glomerular number and size in perfused kidneys using MRI. Am J Physiol Renal Physiol. 2011; 300:F1454-F1457. [PubMed: 21411479]

39. Beguin P, Wang X, Firsov D, Puoti A, Claeys D, Horisberger JD, Geering K. The gamma subunit is a specific component of the Na,K-ATPase and modulates its transport function. EMBO J. 1997; 16:4250-4260. [PubMed: 9250668]

40. Bell TD, Luo Z, Welch WJ. Glomerular tubular balance is suppressed in adenosine type 1 receptordeficient mice. Am J Physiol Renal Physiol. 2010; 299:F1158-F1163. [PubMed: 20810615]

41. Berry CA. Water permeability and pathways in the proximal tubule. Am J Physiol. 1983; 245:F279-F294. [PubMed: 6351634]

42. Berry CA, Rector FC Jr. Electroneutral $\mathrm{NaCl}$ absorption in the proximal tubule: mechanisms of apical Na-coupled transport. Kidney Int. 1989; 36:403-411. [PubMed: 2687567]

43. Berry CA, Rector FC Jr. Mechanism of proximal $\mathrm{NaCl}$ reabsorption in the proximal tubule of the mammalian kidney. Semin Nephrol. 1991; 11:86-97. [PubMed: 2034928]

44. Bertram JF. Counting in the kidney. Kidney Int. 2001; 59:792-796. [PubMed: 11168963]

45. Bertram JF, Soosaipillai MC, Ricardo SD, Ryan GB. Total numbers of glomeruli and individual glomerular cell types in the normal rat kidney. Cell Tissue Res. 1992; 270:37-45. [PubMed: 1423523]

46. Bevensee, MO; Boron, WF. Control of intracellular pH. In: Alpern, RJ.; Hebert, SC., editors. The Kidney: Physiology and Pathophysiology. Vol. Chapter 51. Burlington, San Diego, and London: Academic Press; 2008. p. 1429-1480.

47. Bharatula M, Hussain T, Lokhandwala MF. Angiotensin II AT1 receptor/signaling mechanisms in the biphasic effect of the peptide on proximal tubular Na+,K+-ATPase. Clin Exp Hypertens. 1998; 20:465-480. [PubMed: 9607407] 
48. Biemesderfer D, Pizzonia J, Abu-Alfa A, Exner M, Reilly R, Igarashi P, Aronson PS. NHE3: a Na +/H+ exchanger isoform of renal brush border. Am J Physiol. 1993; 265:F736-F742. [PubMed: 8238556]

49. Biemesderfer D, Reilly RF, Exner M, Igarashi P, Aronson PS. Immunocytochemical characterization of $\mathrm{Na}(+)-\mathrm{H}+$ exchanger isoform NHE-1 in rabbit kidney. Am J Physiol. 1992; 263:F833-F840. [PubMed: 1279986]

50. Biemesderfer D, Rutherford PA, Nagy T, Pizzonia JH, bu-Alfa AK, Aronson PS. Monoclonal antibodies for high-resolution localization of NHE3 in adult and neonatal rat kidney. Am J Physiol. 1997; 273:F289-F299. [PubMed: 9277590]

51. Blantz RC. The glomerular and tubular actions of angiotensin II. Am J Kidney Dis. 1987; 10:2-6. [PubMed: 2886045]

52. Blaustein MP. The interrelationship between sodium and calcium fluxes across cell membranes. Rev Physiol Biochem Pharmacol. 1974; 70:33-82. 33-82. [PubMed: 4618920]

53. Blaustein MP, Lederer WJ. Sodium/calcium exchange: its physiological implications. Physiol Rev. 1999; 79:763-854. [PubMed: 10390518]

54. Bloch RD, Zikos D, Fisher KA, Schleicher L, Oyama M, Cheng JC, Skopicki HA, Sukowski EJ, Cragoe EJ Jr, Peterson DR. Activation of proximal tubular $\mathrm{Na}(+)-\mathrm{H}+$ exchange by angiotensin II. Am J Physiol. 1992; 263:F135-F143. [PubMed: 1322054]

55. Bobulescu IA, Quinones H, Gisler SM, Di SF, Hu MC, Shi M, Zhang J, Fuster DG, Wright N, Mumby M, Moe OW. Acute Regulation of Renal Na+/H+ Exchanger NHE3 by Dopamine: Role of Protein Phosphatase 2A. Am J Physiol Renal Physiol. 2010; 298(5):F1205-F1213. [PubMed: 20181665]

56. Bojesen E, LEYSSAC PP. Proximal tubular reabsorption in the rat kidney as studied by the occlusion time and lissamine green transit time technique. Acta Physiol Scand. 1969; 76:213-235. [PubMed: 5823382]

57. Bookstein C, Musch MW, DePaoli A, Xie Y, Villereal M, Rao MC, Chang EB. A unique sodiumhydrogen exchange isoform (NHE-4) of the inner medulla of the rat kidney is induced by hyperosmolarity. J Biol Chem. 1994; 269:29704-29709. [PubMed: 7961960]

58. Borenstein HB, Cupples WA, Sonnenberg H, Veress AT. The effect of a natriuretic atrial extract on renal haemodynamics and urinary excretion in anaesthetized rats. J Physiol. 1983; 334:133140. 133-140. [PubMed: 6864555]

59. Boron WF. Acid-base transport by the renal proximal tubule. J Am Soc Nephrol. 2006; 17:23682382. [PubMed: 16914536]

60. Boron WF, Boulpaep EL. The electrogenic Na/HCO3 cotransporter. Kidney Int. 1989; 36:392402. [PubMed: 2687566]

61. Brechue WF, Kinne-Saffran E, Kinne RK, Maren TH. Localization and activity of renal carbonic anhydrase (CA) in CA-II deficient mice. Biochim Biophys Acta. 1991; 1066:201-207. [PubMed: 1906751]

62. Brenner BM, Bennett CM, Berliner RW. The relationship between glomerular filtration rate and sodium reabsorption by the proximal tubule of the rat nephron. J Clin Invest. 1968; 47:1358-1374. [PubMed: 5653214]

63. Brenner BM, Garcia DL, Anderson S. Glomeruli and blood pressure. Less of one, more the other? Am J Hypertens. 1988; 1:335-347. [PubMed: 3063284]

64. Brenner BM, Troy JL. Postglomerular vascular protein concentration: evidence for a causal role in governing fluid reabsorption and glomerulotublar balance by the renal proximal tubule. J Clin Invest. 1971; 50:336-349. [PubMed: 5540173]

65. Briggs JP, Steipe B, Schubert G, Schnermann J. Micropuncture studies of the renal effects of atrial natriuretic substance. Pflugers Arch. 1982; 395:271-276. [PubMed: 7155801]

66. Brochner-Mortensen J, Stockel M, Sorensen PJ, Nielsen AH, Ditzel J. Proximal glomerulo-tubular balance in patients with type 1 (insulin-dependent) diabetes mellitus. Diabetologia. 1984; $27: 189$ 192. [PubMed: 6489654]

67. Brown D, Zhu XL, Sly WS. Localization of membrane-associated carbonic anhydrase type IV in kidney epithelial cells. Proc Natl Acad Sci U S A. 1990; 87:7457-7461. [PubMed: 2120700] 
68. Bruns FJ, Alexander EA, Riley AL, Levinsky NG. Superficial and juxtamedullary nephron function during saline loading in the dog. J Clin Invest. 1974; 53:971-979. [PubMed: 4815088]

69. Buentig WE, Earley LE. Demonstration of independent roles of proximal tubular reabsorption and intratubular load in the phenomenon of glomerulotubular balance during aortic constriction in the rat. J Clin Invest. 1971; 50:77-89. [PubMed: 5543884]

70. Burg M, Patlak C, Green N, Villey D. Organic solutes in fluid absorption by renal proximal convoluted tubules. Am J Physiol. 1976; 231:627-637. [PubMed: 961916]

71. Burg MB, Green N. Role of monovalent ions in the reabsorption of fluid by isolated perfused proximal renal tubules of the rabbit. Kidney Int. 1976; 10:221-228. [PubMed: 972442]

72. Burg MB, Orloff J. Control of fluid absorption in the renal proximal tubule. J Clin Invest. 1968; 47:2016-2024. [PubMed: 4300070]

73. Burg MB, Orloff J. Electrical potential difference across proximal convoluted tubules. Am J Physiol. 1970; 219:1714-1716. [PubMed: 5485689]

74. Burnett JC Jr, Granger JP, Opgenorth TJ. Effects of synthetic atrial natriuretic factor on renal function and renin release. Am J Physiol. 1984; 247:F863-F866. [PubMed: 6238539]

75. Burnett JC Jr, Opgenorth TJ, Granger JP. The renal action of atrial natriuretic peptide during control of glomerular filtration. Kidney Int. 1986; 30:16-19. [PubMed: 2943930]

76. Camargo MJ, Kleinert HD, Atlas SA, Sealey JE, Laragh JH, Maack T. Ca-dependent hemodynamic and natriuretic effects of atrial extract in isolated rat kidney. Am J Physiol. 1984; 246:F447-F456. [PubMed: 6720901]

77. Campbell DJ. Circulating and tissue angiotensin systems. J Clin Invest. 1987; 79:1-6. [PubMed: 3025255]

78. Campbell DJ. Tissue renin-angiotensin system: sites of angiotensin formation. J Cardiovasc Pharmacol. 1987; 10(Suppl 7):S1-S8. [PubMed: 2485038]

79. Candido, R.; Burrell, LM.; Jandeleit, K.; Cooper, ME. Vasoactive peptides and the kidney. In: Brenner, BM., editor. Brenner: Brenner and Rector's The Kidney. St. Louis: Saunders; 2007.

80. Capuano P, Bacic D, Roos M, Gisler SM, Stange G, Biber J, Kaissling B, Weinman EJ, Shenolikar S, Wagner CA, Murer H. Defective coupling of apical PTH receptors to phospholipase C prevents internalization of the $\mathrm{Na}$-phosphate cotransporter NaPi-IIa in Nherf1-deficient mice. Am J Physiol Cell Physiol. 2007; 292:C927-C934. [PubMed: 16987995]

81. Carey RM. Theodore Cooper Lecture: Renal dopamine system: paracrine regulator of sodium homeostasis and blood pressure. Hypertension. 2001; 38:297-302. [PubMed: 11566894]

82. Carey RM, Wang ZQ, Siragy HM. Novel actions of angiotensin II via its renal type-2 (AT(2)) receptor. Curr Hypertens Rep. 1999; 1:151-157. [PubMed: 10981059]

83. Carriere S, Desrosiers M, Friborg J, Brunette MG. The effect of furosemide on the intrarenal blood flow distribution in the dog. Can J Physiol Pharmacol. 1972; 50:774-783. [PubMed: 5053789]

84. Casellas D, Navar LG. In vitro perfusion of juxtamedullary nephrons in rats. Am J Physiol. 1984; 246:F349-F358. [PubMed: 6703068]

85. Chai SY, Sexton PM, Allen AM, Figdor R, Mendelsohn FA. In vitro autoradiographic localization of ANP receptors in rat kidney and adrenal gland. Am J Physiol. 1986; 250:F753-F757. [PubMed: 3008578]

86. Chai SY, Zhuo J, Mendelsohn FA. Localization of components of the renin-angiotensin system and site of action of inhibitors. Arzneimittelforschung. 1993; 43:214-221. [PubMed: 8498967]

87. Chan YL, Wang T. The role of protein kinase $\mathrm{C}$ in mediating the stimulatory effect of angiotensin II on renal tubular transport. Contrib Nephrol. 1991; 95:216-221. [PubMed: 1807911]

88. Chappell MC. Emerging evidence for a functional angiotensin-converting enzyme 2-angiotensin(1-7)-MAS receptor axis: more than regulation of blood pressure? Hypertension. 2007; 50:596599. [PubMed: 17785634]

89. Chen C, Beach RE, Lokhandwala MF. Dopamine fails to inhibit renal tubular sodium pump in hypertensive rats. Hypertension. 1993; 21:364-372. [PubMed: 8386702]

90. Chen JK, Zimpelmann J, Harris RC, Burns KD. Angiotensin IV induces tyrosine phosphorylation of focal adhesion kinase and paxillin in proximal tubule cells. Am J Physiol Renal Physiol. 2001; 280:F980-F988. [PubMed: 11352837] 
91. Chen M, Todd-Turla K, Wang WH, Cao X, Smart A, Brosius FC, Killen PD, Keiser JA, Briggs JP, Schnermann J. Endothelin-1 mRNA in glomerular and epithelial cells of kidney. Am J Physiol. 1993; 265:F542-F550. [PubMed: 8238383]

92. Chobanian MC, Julin CM. Angiotensin II stimulates ammoniagenesis in canine renal proximal tubule segments. Am J Physiol. 1991; 260:F19-F26. [PubMed: 1992777]

93. Chou CL, Marsh DJ. Role of proximal convoluted tubule in pressure diuresis in the rat. Am J Physiol. 1986; 251:F283-F289. [PubMed: 3740275]

94. Chu TS, Peng Y, Cano A, Yanagisawa M, Alpern RJ. Endothelin(B) receptor activates NHE-3 by a Ca2+-dependent pathway in OKP cells. J Clin Invest. 1996; 97:1454-1462. [PubMed: 8617878]

95. Cinelli AR, Efendiev R, Pedemonte CH. Trafficking of Na-K-ATPase and dopamine receptor molecules induced by changes in intracellular sodium concentration of renal epithelial cells. Am J Physiol Renal Physiol. 2008; 295:F1117-F1125. [PubMed: 18701625]

96. Clapp WL, Bowman P, Shaw GS, Patel P, Kone BC. Segmental localization of mRNAs encoding $\mathrm{Na}(+)-\mathrm{K}(+)$-ATPase alpha- and beta-subunit isoforms in rat kidney using RT-PCR. Kidney Int. 1994; 46:627-638. [PubMed: 7996786]

97. Clausen T, Persson AE. Jens Christian Skou awarded the Nobel prize in chemistry for the identification of the Na+, K(+)-pump. Acta Physiol Scand. 1998; 163:1-2. [PubMed: 9648616]

98. Cogan MG. Atrial natriuretic factor can increase renal solute excretion primarily by raising glomerular filtration. Am J Physiol. 1986; 250:F710-F714. [PubMed: 2938484]

99. Cogan MG. Angiotensin II: a powerful controller of sodium transport in the early proximal tubule. Hypertension. 1990; 15:451-458. [PubMed: 2185149]

100. Counillon L, Scholz W, Lang HJ, Pouyssegur J. Pharmacological characterization of stably transfected $\mathrm{Na}+\mathrm{H}+$ antiporter isoforms using amiloride analogs and a new inhibitor exhibiting anti-ischemic properties. Mol Pharmacol. 1993; 44:1041-1045. [PubMed: 8246907]

101. Crowley SD, Gurley SB, Oliverio MI, Pazmino AK, Griffiths R, Flannery PJ, Spurney RF, Kim HS, Smithies O, Le TH, Coffman TM. Distinct roles for the kidney and systemic tissues in blood pressure regulation by the renin-angiotensin system. J Clin Invest. 2005; 115:1092-1099. [PubMed: 15841186]

102. CURRAN PF, MACINTOSH JR. A model system for biological water transport. Nature. 1962; 193:347-348. [PubMed: 13882705]

103. D'Souza S, Garcia-Cabado A, Yu F, Teter K, Lukacs G, Skorecki K, Moore HP, Orlowski J, Grinstein $\mathrm{S}$. The epithelial sodium-hydrogen antiporter $\mathrm{Na}+\mathrm{H}+$ exchanger 3 accumulates and is functional in recycling endosomes. J Biol Chem. 1998; 273:2035-2043. [PubMed: 9442041]

104. Danser AH, van Kats JP, Verdouw PD, Schalekamp MA. Evidence for the existence of a functional cardiac renin-angiotensin system in humans. Circulation. 1997; 96:3795-3796. [PubMed: 9396499]

105. de Bold AJ. Atrial natriuretic factor: a hormone produced by the heart. Science. 1985; 230:767770. [PubMed: 2932797]

106. de Bold AJ. Thirty years of research on atrial natriuretic factor: historical background and emerging concepts. Can J Physiol Pharmacol. 2011; 89(8):527-531. [PubMed: 21671768]

107. de Bold AJ, Borenstein HB, Veress AT, Sonnenberg H. A rapid and potent natriuretic response to intravenous injection of atrial myocardial extract in rats. Life Sci. 1981; 28:89-94. [PubMed: 7219045]

108. DE WARDENER HE, MILLS IH, CLAPHAM WF, HAYTER CJ. Studies on the efferent mechanism of the sodium diuresis which follows the administration of intravenous saline in the dog. Clin Sci. 1961; 21:249-258. [PubMed: 13884596]

109. Dean R, Zhuo JL, Alcorn D, Casley D, Mendelsohn FA. Cellular distribution of 125Iendothelin-1 binding in rat kidney following in vivo labeling. Am J Physiol. 1994; 267:F845F852. [PubMed: 7977789]

110. Dean R, Zhuo JL, Alcorn D, Casley D, Mendelsohn FA. Cellular localization of endothelin receptor subtypes in the rat kidney following in vitro labelling. Clin Exp Pharmacol Physiol. 1996; 23:524-531. [PubMed: 8800578]

111. Desir GV. Regulation of blood pressure and cardiovascular function by renalase. Kidney Int. 2009; 76:366-370. [PubMed: 19471322] 
112. Desir GV. Role of renalase in the regulation of blood pressure and the renal dopamine system. Curr Opin Nephrol Hypertens. 2011; 20:31-36. [PubMed: 21099685]

113. Diamond JM, Bossert WH. Standing-gradient osmotic flow. A mechanism for coupling of water and solute transport in epithelia. J Gen Physiol. 1967; 50:2061-2083. [PubMed: 6066064]

114. DIRKS JH, CIRKSENA WJ, Berliner RW. The effects of saline infusion on sodium reabsorption by the proximal tubule of the dog. J Clin Invest. 1965; 44:1160-1170. [PubMed: 14328393]

115. Dlouha H, Bibr B, Jezek J, Zicha J. Single nephron glomerular filtration rate ratios of superficial, intercortical and juxtamedullary nephrons in rats during development. Pflugers Arch. 1976; 366:277-279. [PubMed: 1033531]

116. Dominguez JH, Juhaszova M, Kleiboeker SB, Hale CC, Feister HA. Na(+)-Ca2+ exchanger of rat proximal tubule: gene expression and subcellular localization. Am J Physiol. 1992; 263:F945F950. [PubMed: 1443182]

117. Dominguez JH, Rothrock JK, Macias WL, Price J. Na+ electrochemical gradient and Na+-Ca2+ exchange in rat proximal tubule. Am J Physiol. 1989; 257:F531-F538. [PubMed: 2679143]

118. Donowitz M, Li X. Regulatory binding partners and complexes of NHE3. Physiol Rev. 2007; 87:825-872. [PubMed: 17615390]

119. Dostanic-Larson I, Lorenz JN, Van Huysse JW, Neumann JC, Moseley AE, Lingrel JB. Physiological role of the alpha1- and alpha2-isoforms of the Na+-K+-ATPase and biological significance of their cardiac glycoside binding site. Am J Physiol Regul Integr Comp Physiol. 2006; 290:R524-R528. [PubMed: 16467499]

120. Douglas JG, Hopfer U. Novel aspect of angiotensin receptors and signal transduction in the kidney. Annu Rev Physiol. 1994; 56:649-669. [PubMed: 8010754]

121. Drago J, Gerfen CR, Lachowicz JE, Steiner H, Hollon TR, Love PE, Ooi GT, Grinberg A, Lee EJ, Huang SP. Altered striatal function in a mutant mouse lacking D1A dopamine receptors. Proc Natl Acad Sci U S A. 1994; 91:12564-12568. [PubMed: 7809078]

122. Du Z, Ferguson W, Wang T. Role of PKC and calcium in modulation of effects of angiotensin II on sodium transport in proximal tubule. Am J Physiol Renal Physiol. 2003; 284:F688-F692. [PubMed: 12527554]

123. Du Z, Wan L, Yan Q, Weinbaum S, Weinstein AM, Wang T. Regulation of glomerulotubular balance II: impact of angiotensin II on flow-dependent transport. Am J Physiol Renal Physiol. 2012

124. Du Z, Yan Q, Wan L, Weinbaum S, Weinstein AM, Wang T. Regulation of glomerulotubular balance. I Impact of dopamine on flow-dependent transport. Am J Physiol Renal Physiol. 2012; 303:F386-F395. [PubMed: 22552936]

125. Dulin NO, Sorokin A, Reed E, Elliott S, Kehrl JH, Dunn MJ. RGS3 inhibits G protein-mediated signaling via translocation to the membrane and binding to Galpha11. Mol Cell Biol. 1999; 19:714-723. [PubMed: 9858594]

126. Efendiev R, Budu CE, Cinelli AR, Bertorello AM, Pedemonte CH. Intracellular Na+ regulates dopamine and angiotensin II receptors availability at the plasma membrane and their cellular responses in renal epithelia. J Biol Chem. 2003; 278:28719-28726. [PubMed: 12759348]

127. Eiam-Ong S, Hilden SA, King AJ, Johns CA, Madias NE. Endothelin-1 stimulates the Na+/H+ and $\mathrm{Na}+\mathrm{HCO} 3-$ transporters in rabbit renal cortex. Kidney Int. 1992; 42:18-24. [PubMed: 1321928]

128. Elshourbagy NA, Lee JA, Korman DR, Nuthalaganti P, Sylvester DR, Dilella AG, Sutiphong JA, Kumar CS. Molecular cloning and characterization of the major endothelin receptor subtype in porcine cerebellum. Mol Pharmacol. 1992; 41:465-473. [PubMed: 1312214]

129. Ernst SA. Transport ATPase cytochemistry: ultrastructural localization of potassium-dependent and potassium-independent phosphatase activities in rat kidney cortex. J Cell Biol. 1975; 66:586608. [PubMed: 125760]

130. Esther CR, Marino EM, Howard TE, Machaud A, Corvol P, Capecchi MR, Bernstein KE. The critical role of tissue angiotensin-converting enzyme as revealed by gene targeting in mice. J Clin Invest. 1997; 99:2375-2385. [PubMed: 9153279]

131. Eysenhardt CW. De structura renum observationes microscopiac. Berolinensis. :1818. 
132. Feraille E, Doucet A. Sodium-potassium-adenosinetriphosphatase-dependent sodium transport in the kidney: hormonal control. Physiol Rev. 2001; 81:345-418. [PubMed: 11152761]

133. Ferrandi M, Salardi S, Tripodi G, Barassi P, Rivera R, Manunta P, Goldshleger R, Ferrari P, Bianchi G, Karlish SJ. Evidence for an interaction between adducin and $\mathrm{Na}(+)-\mathrm{K}(+)$-ATPase: relation to genetic hypertension. Am J Physiol. 1999; 277:H1338-H1349. [PubMed: 10516168]

134. Ferrario CM, Chappell MC, Tallant EA, Brosnihan KB, Diz DI. Counterregulatory actions of angiotensin-(1-7). Hypertension. 1997; 30:535-541. [PubMed: 9322978]

135. FETTERMAN GH, SHUPLOCK NA, PHILIPP FJ, GREGG HS. The growth and maturation of human glomeruli and proximal convolutions from term to adulthood: studies by microdissection. Pediatrics. 1965; 35:601-619. [PubMed: 14269712]

136. Finco DR, Duncan JR. Relationship of glomerular number and diameter to body size of the dog. Am J Vet Res. 1972; 33:2447-2450. [PubMed: 4641201]

137. Fitzgibbon W, Morgan T. Effect of atrial natriuretic peptide on collecting duct function evaluated by stop-flow in rabbits. Clin Exp Pharmacol Physiol. 1987; 14:169-174. [PubMed: 2959417]

138. Fitzgibbon W, Morgan T. Effect of atrial peptide on collecting duct function. Clin Exp Pharmacol Physiol. 1988; 15:845-855. [PubMed: 2976327]

139. Fitzgibbons JP, Gennari FJ, Garfinkel HB, Cortell S. Dependence of saline-induced natriuresis upon exposure of the kidney to the physical effects of extracellular fluid volume expansion. $\mathrm{J}$ Clin Invest. 1974; 54:1428-1436. [PubMed: 4436441]

140. Friedman PA. Codependence of renal calcium and ransport. Annu Rev Physiol. 1998; 60:179_ 197. [PubMed: 9558460]

141. Friedman PA, Figueiredo JF, Maack T, Windhager EE. Sodium-calcium interactions in the renal proximal convoluted tubule of the rabbit. Am J Physiol. 1981; 240:F558-F568. [PubMed: 6787932]

142. Frindt G, Lee CO, Yang JM, Windhager EE. Potential role of cytoplasmic calcium ions in the regulation of sodium transport in renal tubules. Miner Electrolyte Metab. 1988; 14:40-47. [PubMed: 3279295]

143. Fromter E. The Feldberg Lecture 1976. Solute transport across epithelia: what can we learn from micropuncture studies in kidney tubules? J Physiol. 1979; 288:1-31. [PubMed: 381634]

144. Fulladosa X, Moreso F, Narvaez JA, Grinyo JM, Seron D. Estimation of total glomerular number in stable renal transplants. J Am Soc Nephrol. 2003; 14:2662-2668. [PubMed: 14514746]

145. Fuster DG, Bobulescu IA, Zhang J, Wade J, Moe OW. Characterization of the regulation of renal $\mathrm{Na} / \mathrm{H}+$ exchanger NHE3 by insulin. Am J Physiol Renal Physiol. 2007; 292:F577-F585. [PubMed: 17018843]

146. Garcia NH, Garvin JL. Angiotensin 1-7 has a biphasic effect on fluid absorption in the proximal straight tubule. J Am Soc Nephrol. 1994; 5:1133-1138. [PubMed: 7849254]

147. Garcia NH, Garvin JL. Endothelin's biphasic effect on fluid absorption in the proximal straight tubule and its inhibitory cascade. J Clin Invest. 1994; 93:2572-2577. [PubMed: 8200994]

148. Garcia R, Cantin M, Thibault G, Ong H, Genest J. Relationship of specific granules to the natriuretic and diuretic activity of rat atria. Experientia. 1982; 38:1071-1073. [PubMed: 7128752]

149. Garg LC, Knepper MA, Burg MB. Mineralocorticoid effects on Na-K-ATPase in individual nephron segments. Am J Physiol. 1981; 240:F536-F544. [PubMed: 6264796]

150. Garvin J, Sanders K. Endothelin inhibits fluid and bicarbonate transport in part by reducing Na+/ K+ ATPase activity in the rat proximal straight tubule. J Am Soc Nephrol. 1991; 2:976-982. [PubMed: 1662089]

151. Garvin JL. Inhibition of Jv by ANF in rat proximal straight tubules requires angiotensin. Am J Physiol. 1989; 257:F907-F911. [PubMed: 2556043]

152. Garvin JL. Angiotensin stimulates bicarbonate transport and $\mathrm{Na}+\mathrm{K}+$ ATPase in rat proximal straight tubules. J Am Soc Nephrol. 1991; 1:1146-1152. [PubMed: 1662990]

153. Geibel J, Giebisch G, Boron WF. Angiotensin II stimulates both $\mathrm{Na}(+)-\mathrm{H}+$ exchange and Na+/ HCO3- cotransport in the rabbit proximal tubule. Proc Natl Acad Sci U S A. 1990; 87:79177920. [PubMed: 2172967] 
154. Gennari, FJ.; Maddox, DA. Renal regulation of acid-base homeostasis: integrative response. In: Seldin, DW.; Giebisch, G., editors. The Kidney: Physiology and Pathophysiology. New York: Raven Press; 1992.

155. Gerich JE. Role of the kidney in normal glucose homeostasis and in the hyperglycaemia of diabetes mellitus: therapeutic implications. Diabet Med. 2010; 27:136-142. [PubMed: 20546255]

156. Gertz, KH.; Boylan, JW. Glomerulo-tubular balance. In: Orloff, J.; Berliner, RW., editors. Handbook of Physiology. Bethesda: American Physiological Society; 1973.

157. Gertz KH, Mangos JA, Braun G, Pagel HD. On the glomerular tubular balance in the rat kidney. Pflugers Arch Gesamte Physiol Menschen Tiere. 1965; 285:360-372.

158. Giebisch G. Measurements of electrical potential differences on single nephrons of the perfused Necturus kidney. J Gen Physiol. 1961; 44:659-678. [PubMed: 13705146]

159. Giebisch G, KLOSE RM, Windhager EE. Micorpuncture study of hypertonic sodium chloride loading in the rat. Am J Physiol. 1964; 206:687-693. [PubMed: 14166158]

160. Giebisch G, Windhager EE. Renal tubular transfer of sodium, chloride and potassium. Am J Med. 1964; 36:643-669. [PubMed: 14141446]

161. Gildea JJ, Israel JA, Johnson AK, Zhang J, Jose PA, Felder RA. Caveolin-1 and dopaminemediated internalization of NaKATPase in human renal proximal tubule cells. Hypertension. 2009; 54:1070-1076. [PubMed: 19752292]

162. Gildea JJ, Wang X, Shah N, Tran H, Spinosa M, Van SR, Sasaki M, Yatabe J, Carey RM, Jose PA, Felder RA. Dopamine and angiotensin type 2 receptors cooperatively inhibit sodium transport in human renal proximal tubule cells. Hypertension. 2012

163. GLABMAN S, AYNEDJIAN HS, BANK N. Micropuncture study of the effect of acute reductions in glomerular filtration rate on sodium and water reabsorption by the proximal tubules of the rat. J Clin Invest. 1965; 44:1410-1416. [PubMed: 14322045]

164. Gmaj P, Murer H, Kinne R. Calcium ion transport across plasma membranes isolated from rat kidney cortex. Biochem J. 1979; 178:549-557. [PubMed: 454364]

165. Goetz KL. Atrial natriuretic peptide and atrial pressure. N Engl J Med. 1987; 316:485-486. [PubMed: 2949153]

166. Goldman ID, Fyfe JM, Bowen D, Loftfield S, Schafer JA. The effect of microtubular inhibitors on transport of alpha-aminoisobutyric acid. Inhibition of uphill transport without changes in transmembrane gradients of $\mathrm{Na}+\mathrm{K}+$, or $\mathrm{H}+$ Biochim Biophys Acta. 1977; 467:185-191. [PubMed: 18176]

167. Gottschalk, CW.; Lassiter, WE. Micropuncture methodology. In: Orloff, J.; Berliner, RW., editors. Handbook of Physiology. Washington DC: American Physiological Society; 1973.

168. Gottschalk CW, MYLLE M. Micropuncture study of the mammalian urinary concentrating mechanism: evidence for the countercurrent hypothesis. Am J Physiol. 1959; 196:927-936. [PubMed: 13637248]

169. Goyal S, Mentone S, Aronson PS. Immunolocalization of NHE8 in rat kidney. Am J Physiol Renal Physiol. 2005; 288:F530-F538. [PubMed: 15522984]

170. Goyal S, Vanden Heuvel G, Aronson PS. Renal expression of novel Na+/H+ exchanger isoform NHE8. Am J Physiol Renal Physiol. 2003; 284:F467-F473. [PubMed: 12409279]

171. Granger JP, Haas JA, Pawlowska D, Knox FG. Effect of direct increases in renal interstitial hydrostatic pressure on sodium excretion. Am J Physiol. 1988; 254:F527-F532. [PubMed: 3354685]

172. Green R, Giebisch G. Luminal hypotonicity: a driving force for fluid absorption from the proximal tubule. Am J Physiol. 1984; 246:F167-F174. [PubMed: 6696118]

173. Green R, Giebisch G. Osmotic forces driving water reabsorption in the proximal tubule of the rat kidney. Am J Physiol. 1989; 257:F669-F675. [PubMed: 2801964]

174. Green R, Moriarty RJ, Giebisch G. Ionic requirements of proximal tubular fluid reabsorption flow dependence of fluid transport. Kidney Int. 1981; 20:580-587. [PubMed: 7343708]

175. Guder WG. Stimulation of renal gluconeogenesis by angiotensin II. Biochim Biophys Acta. 1979; 584:507-519. [PubMed: 454678] 
176. Guntupalli J, DuBose TD Jr. Effects of endothelin on rat renal proximal tubule $\mathrm{Na}(+)-\mathrm{Pi}$ cotransport and $\mathrm{Na}+\mathrm{H}+$ exchange. Am J Physiol. 1994; 266:F658-F666. [PubMed: 8184900]

177. Gurley SB, Riquier-Brison AD, Schnermann J, Sparks MA, Allen AM, Haase VH, Snouwaert JN, Le TH, McDonough AA, Koller BH, Coffman TM. AT1A angiotensin receptors in the renal proximal tubule regulate blood pressure. Cell Metab. 2011; 13:469-475. [PubMed: 21459331]

178. Guyton, AC.; Hall, JE. Textbook of Medical Physiology. Philadelphia: Saunders, Elsevier; 2011. p. 305

179. Guyton, AC.; Hall, JE.; Coleman, TG.; Manning, RD., Jr; Norman, RAJ. The dominant role of the kidneys in long-term arterial pressure regulation in normal and hypertensive states. In: Laragh, JH.; Brenner, BM., editors. Hypertension: Pathophysiology, Diagnosis, and Management. New York: Raven Press; 1995.

180. Gwathmey TM, Pendergrass KD, Reid SD, Rose JC, Diz DI, Chappell MC. Angiotensin-(1-7)angiotensin-converting enzyme 2 attenuates reactive oxygen species formation to angiotensin II within the cell nucleus. Hypertension. 2010; 55:166-171. [PubMed: 19948986]

181. Gyory AZ, Kinne R. Energy source for transepithelial sodium transport in rat renal proximal tubules. Pflugers Arch. 1971; 327:234-260. [PubMed: 4254961]

182. Haas JA, Granger JP, Knox FG. Effect of renal perfusion pressure on sodium reabsorption from proximal tubules of superficial and deep nephrons. Am J Physiol. 1986; 250:F425-F429. [PubMed: 3953822]

183. Haberle D. [Significance of humoral factors in the tubulus fluid for maintenance of glomerulotubular balance in the proximal tubulus of the rat kidney]. Fortschr Med. 1978; 96:2337. [PubMed: 721009]

184. Haberle DA, von BH. Characteristics of glomerulotubular balance. Am J Physiol. 1983; 244:F355-F366. [PubMed: 6340526]

185. Hakam AC, Hussain T. Angiotensin II type 2 receptor agonist directly inhibits proximal tubule sodium pump activity in obese but not in lean Zucker rats. Hypertension. 2006; 47:1117-1124. [PubMed: 16618840]

186. Hall JE. Regulation of glomerular filtration rate and sodium excretion by angiotensin II. Fed Proc. 1986; 45:1431-1437. [PubMed: 3514280]

187. Hall JE, Brands MW, Shek EW. Central role of the kidney and abnormal fluid volume control in hypertension. J Hum Hypertens. 1996; 10:633-639. [PubMed: 9004086]

188. Hammond TG, Yusufi AN, Knox FG, Dousa TP. Administration of atrial natriuretic factor inhibits sodium-coupled transport in proximal tubules. J Clin Invest. 1985; 75:1983-1989. [PubMed: 2989338]

189. Handa RK. Characterization and signaling of the AT(4) receptor in human proximal tubule epithelial (HK-2) cells. J Am Soc Nephrol. 2001; 12:440-449. [PubMed: 11181791]

190. Handa RK, Krebs LT, Harding JW, Handa SE. Angiotensin IV AT4-receptor system in the rat kidney. Am J Physiol. 1998; 274:F290-F299. [PubMed: 9486224]

191. Hansell P, Fasching A. The effect of dopamine receptor blockade on natriuresis is dependent on the degree of hypervolemia. Kidney Int. 1991; 39:253-258. [PubMed: 2002639]

192. Harris PJ. Regulation of proximal tubule function by angiotensin. Clin Exp Pharmacol Physiol. 1992; 19:213-222. [PubMed: 1516268]

193. Harris PJ, Navar LG. Tubular transport responses to angiotensin II. Am J Physiol Renal Physiol. 1985; 248:F621-F630.

194. Harris PJ, Navar LG, Ploth DW. Evidence for angiotensin-stimulated proximal tubular fluid reabsorption in normotensive and hypertensive rats: effect of acute administration of captopril. Clin Sci (Lond). 1984; 66:541-544. [PubMed: 6368101]

195. Harris PJ, Skinner SL. Intra-renal interactions between angiotensin II and atrial natriuretic factor. Kidney Int Suppl. 1990; 30:S87-S91. [PubMed: 2175373]

196. Harris PJ, Skinner SL, Zhuo JL. The effects of atrial natriuretic peptide and glucagon on proximal glomerulo-tubular balance in anaesthetized rats. J Physiol. 1988; 402:29-42. [PubMed: 2976822]

197. Harris PJ, Skinner SL, Zhuo JL. Haemodynamic and renal tubular responses to low-dose infusion or bolus injection of the peptide ANF in anaesthetized rats. J Physiol. 1989; 412:309-320. [PubMed: 2532253] 
198. Harris PJ, Thomas D, Morgan TO. Atrial natriuretic peptide inhibits angiotensin-stimulated proximal tubular sodium and water reabsorption. Nature. 1987; 326:697-698. [PubMed: 2951600]

199. Harris PJ, Thomas D, Zhuo JL, Skinner SL. Regulation of proximal tubule sodium reabsorption by angiotensin II (AII) and atrial natriuretic factor (ANF). Acta Physiol Scand Suppl. 1990; 591:63-65. [PubMed: 2145724]

200. Harris PJ, Young JA. Dose-dependent stimulation and inhibition of proximal tubular sodium reabsorption by angiotensin II in the rat kidney. Pflugers Arch. 1977; 367:295-297. [PubMed: 556854]

201. Harris PJ, Zhuo JL, Mendelsohn FA, Skinner SL. Haemodynamic and renal tubular effects of low doses of endothelin in anaesthetized rats. J Physiol. 1991; 433:25-39. [PubMed: 1841941]

202. Harris PJ, Zhuo JL, Skinner SL. Effects of angiotensins II and III on glomerulotubular balance in rats. Clin Exp Pharmacol Physiol. 1987; 14:489-502. [PubMed: 3315334]

203. Harrison-Bernard LM, Cook AK, Oliverio MI, Coffman TM. Renal segmental microvascular responses to ANG II in AT1A receptor null mice. Am J Physiol Renal Physiol. 2003; 284:F538F545. [PubMed: 12429556]

204. Harrison-Bernard LM, Monjure CJ, Bivona BJ. Efferent arterioles exclusively express the subtype 1A angiotensin receptor: functional insights from genetic mouse models. Am J Physiol Renal Physiol. 2006; 290:F1177-F1186. [PubMed: 16332932]

205. Harrison-Bernard LM, Zhuo J, Kobori H, Ohishi M, Navar LG. Intrarenal AT(1) receptor and ACE binding in ANG II-induced hypertensive rats. Am J Physiol Renal Physiol. 2002; 282:F19 F25. [PubMed: 11739108]

206. Hashimoto S, Adams JW, Bernstein KE, Schnermann J. Micropuncture determination of nephron function in mice without tissue angiotensin-converting enzyme. Am J Physiol Renal Physiol. 2005; 288:F445-F452. [PubMed: 15494545]

207. Haug C, Grill C, Schmid-Kotsas A, Gruenert A, Jehle PM. Endothelin release by rabbit proximal tubule cells: modulatory effects of cyclosporine A, tacrolimus, HGF and EGF. Kidney Int. 1998; 54:1626-1636. [PubMed: 9844139]

208. Haynes WG, Webb DJ. Endothelin as a regulator of cardiovascular function in health and disease. J Hypertens. 1998; 16:1081-1098. [PubMed: 9794709]

209. Hayslett JP, Kashgarian M. A micropuncture study of the renal handling of lithium. Pflugers Arch. 1979; 380:159-163. [PubMed: 573443]

210. He P, Klein J, Yun CC. Activation of Na+/H+ exchanger NHE3 by angiotensin II is mediated by inositol 1,4,5-triphosphate (IP3) receptor-binding protein released with IP3 (IRBIT) and Ca2+/ calmodulin-dependent protein kinase II. J Biol Chem. 2010; 285:27869-27878. [PubMed: 20584908]

211. Hediger MA, Rhoads DB. Molecular physiology of sodium-glucose cotransporters. Physiol Rev. 1994; 74:993-1026. [PubMed: 7938229]

212. Heilmann M, Neudecker S, Wolf I, Gubhaju L, Sticht C, Schock-Kusch D, Kriz W, Bertram JF, Schad LR, Gretz N. Quantification of glomerular number and size distribution in normal rat kidneys using magnetic resonance imaging. Nephrol Dial Transplant. 2011; 27(1):100-107. [PubMed: 21642513]

213. Hilden S, Sacktor B. Potential-dependent D-glucose uptake by renal brush border membrane vesicles in the absence of sodium. Am J Physiol. 1982; 242:F340-F345. [PubMed: 7065244]

214. Holzgreve H, Schrier RW, Eigler J. Renal regulation of the sodium balance. Internist (Berl). 1971; 12:69-76. [PubMed: 4927713]

215. Honegger KJ, Capuano P, Winter C, Bacic D, Stange G, Wagner CA, Biber J, Murer H, Hernando N. Regulation of sodium-proton exchanger isoform 3 (NHE3) by PKA and exchange protein directly activated by cAMP (EPAC). Proc Natl Acad Sci U S A. 2006; 103:803-808. [PubMed: 16407144]

216. Hopfer U. Unraveling the complex mechanosensory machine of solitary cilia. Editorial Focus for Ms f657-2009. Am J Physiol Renal Physiol. 2010; 298(5):F1095. [PubMed: 20147369] 
217. Horita S, Zheng Y, Hara C, Yamada H, Kunimi M, Taniguchi S, Uwatoko S, Sugaya T, Goto A, Fujita T, Seki G. Biphasic regulation of Na+-HCO3- cotransporter by angiotensin II type 1A receptor. Hypertension. 2002; 40:707-712. [PubMed: 12411466]

218. Horster M, Burg M, Potts D, Orloff J. Fluid absorption by proximal tubules in the absence of a colloid osmotic gradient. Kidney Int. 1973; 4:6-11. [PubMed: 4723996]

219. Horster M, Kemler BJ, Valtin H. Intracortical distribution of number and volume of glomeruli during postnatal maturation in the dog. J Clin Invest. 1971; 50:796-800. [PubMed: 5547276]

220. Horster M, Nagel W, Schnermann J, Thurau K. On the problem of direct angiotensin effect on the resorption of sodium in the proximal tubule and Henle0027;s loop of the rat kidney. Pflugers Arch Gesamte Physiol Menschen Tiere. 1966; 292:118-128.

221. Horster M, Thurau K. Micropuncture studies on the filtration rate of single superficial and juxtamedullary glomeruli in the rat kidney. Pflugers Arch Gesamte Physiol Menschen Tiere. 1968; 301:162-181.

222. Hosoda K, Nakao K, Hiroshi A, Suga S, Ogawa Y, Mukoyama M, Shirakami G, Saito Y, Nakanishi S, Imura H. Cloning and expression of human endothelin-1 receptor cDNA. FEBS Lett. 1991; 287:23-26. [PubMed: 1652463]

223. Houillier P, Chambrey R, Achard JM, Froissart M, Poggioli J, Paillard M. Signaling pathways in the biphasic effect of angiotensin II on apical $\mathrm{Na} / \mathrm{H}$ antiport activity in proximal tubule. Kidney Int. 1996; 50:1496-1505. [PubMed: 8914015]

224. Hoy WE, Bertram JF, Denton RD, Zimanyi M, Samuel T, Hughson MD. Nephron number, glomerular volume, renal disease and hypertension. Curr Opin Nephrol Hypertens. 2008; 17:258-265. [PubMed: 18408476]

225. Hoy WE, Hughson MD, Diouf B, Zimanyi M, Samuel T, McNamara BJ, Douglas-Denton RN, Holden L, Mott SA, Bertram JF. Distribution of volumes of individual glomeruli in kidneys at autopsy: association with physical and clinical characteristics and with ethnic group. Am J Nephrol. 2011; 33(Suppl 1):15-20. [PubMed: 21659730]

226. Hoy WE, Hughson MD, Singh GR, Douglas-Denton R, Bertram JF. Reduced nephron number and glomerulomegaly in Australian Aborigines: a group at high risk for renal disease and hypertension. Kidney Int. 2006; 70:104-110. [PubMed: 16723986]

227. Hu MC, Fan L, Crowder LA, Karim-Jimenez Z, Murer H, Moe OW. Dopamine acutely stimulates $\mathrm{Na}+/ \mathrm{H}+$ exchanger (NHE3) endocytosis via clathrin-coated vesicles: dependence on protein kinase A-mediated NHE3 phosphorylation. J Biol Chem. 2001; 276:26906-26915. [PubMed: 11328806]

228. Huang CL, Lewicki J, Johnson LK, Cogan MG. Renal mechanism of action of rat atrial natriuretic factor. J Clin Invest. 1985; 75:769-773. [PubMed: 3156153]

229. Hughes JM, Ragsdale NV, Felder RA, Chevalier RL, King B, Carey RM. Diuresis and natriuresis during continuous dopamine-1 receptor stimulation. Hypertension. 1988; 11:I69-I74. [PubMed: 2894359]

230. Hughson M, Farris AB III, Douglas-Denton R, Hoy WE, Bertram JF. Glomerular number and size in autopsy kidneys: the relationship to birth weight. Kidney Int. 2003; 63:2113-2122. [PubMed: 12753298]

231. Hughson M, Farris AB III, Douglas-Denton R, Hoy WE, Bertram JF. Glomerular number and size in autopsy kidneys: the relationship to birth weight. Kidney Int. 2003; 63:2113-2122. [PubMed: 12753298]

232. Hughson MD, Gobe GC, Hoy WE, Manning RD Jr, Douglas-Denton R, Bertram JF. Associations of glomerular number and birth weight with clinicopathological features of African Americans and whites. Am J Kidney Dis. 2008; 52:18-28. [PubMed: 18514988]

233. Hussain T, Lokhandwala MF. Renal dopamine receptor function in hypertension. Hypertension. 1998; 32:187-197. [PubMed: 9719042]

234. Ichikawa I, Brenner BM. Importance of efferent arteriolar vascular tone in regulation of proximal tubule fluid reabsorption and glomerulotubular balance in the rat. J Clin Invest. 1980; 65:11921201. [PubMed: 7364945]

235. Ichikawa I, Hoyer JR, Seiler MW, Brenner BM. Mechanism of glomerulotubular balance in the setting of heterogeneous glomerular injury. Preservation of a close functional linkage between 
individual nephrons and surrounding microvasculature. J Clin Invest. 1982; 69:185-198. [PubMed: 7054238]

236. Ikeda K, Onimaru H, Yamada J, Inoue K, Ueno S, Onaka T, Toyoda H, Arata A, Ishikawa TO, Taketo MM, Fukuda A, Kawakami K. Malfunction of respiratory-related neuronal activity in Na ,$+ \mathrm{K}+$-ATPase alpha2 subunit-deficient mice is attributable to abnormal $\mathrm{Cl}$ - homeostasis in brainstem neurons. J Neurosci. 2004; 24:10693-10701. [PubMed: 15564586]

237. Imig JD, Cook AK, Inscho EW. Postglomerular vasoconstriction to angiotensin II and norepinephrine depends on intracellular calcium release. Gen Pharmacol. 2000; 34:409-415. [PubMed: 11483290]

238. Imig JD, Zhao X, Falck JR, Wei S, Capdevila JH. Enhanced renal microvascular reactivity to angiotensin II in hypertension is ameliorated by the sulfonimide analog of 11,12epoxyeicosatrienoic acid. J Hypertens. 2001; 19:983-992. [PubMed: 11393683]

239. Ingelfinger JR, Jung F, Diamant D, Haveran L, Lee E, Brem A, Tang SS. Rat proximal tubule cell line transformed with origin-defective SV40 DNA: autocrine ANG II feedback. Am J Physiol. 1999; 276:F218-F227. [PubMed: 9950952]

240. Inscho EW, Carmines PK, Cook AK, Navar LG. Afferent arteriolar responsiveness to altered perfusion pressure in renal hypertension. Hypertension. 1990; 15:748-752. [PubMed: 2351427]

241. Inscho EW, Imig JD, Deichmann PC, Cook AK. Candesartan cilexetil protects against loss of autoregulatory efficiency in angiotensin II-infused rats. J Am Soc Nephrol. 1999; 10(Suppl 11):S178-S183. [PubMed: 9892160]

242. Itabashi A, Chan L, Shapiro JI, Cheung C, Schrier RW. Comparison of the natriuretic response to atriopeptin III and loop diuretic in the isolated perfused rat kidney. Clin Sci (Lond). 1987; 73:143-150. [PubMed: 2958206]

243. Iwamoto T, Kita S. Hypertension, $\mathrm{Na}+\mathrm{Ca} 2+$ exchanger, and $\mathrm{Na}+, \mathrm{K}+-\mathrm{ATPase}$. Kidney Int. 2006; 69:2148-2154. [PubMed: 16641927]

244. Jacobson HR. Characteristics of volume reabsorption in rabbit superficial and juxtamedullary proximal convoluted tubules. J Clin Invest. 1979; 63:410-418. [PubMed: 429562]

245. Jacobson HR. Effects of $\mathrm{CO} 2$ and acetazolamide on bicarbonate and fluid transport in rabbit proximal tubules. Am J Physiol. 1981; 240:F54-F62. [PubMed: 6779638]

246. Jacobson HR, Kokko JP. Intrinsic differences in various segments of the proximal convoluted tubule. J Clin Invest. 1976; 57:818-825. [PubMed: 947954]

247. James PF, Grupp IL, Grupp G, Woo AL, Askew GR, Croyle ML, Walsh RA, Lingrel JB. Identification of a specific role for the $\mathrm{Na}, \mathrm{K}-\mathrm{ATPase}$ alpha 2 isoform as a regulator of calcium in the heart. Mol Cell. 1999; 3:555-563. [PubMed: 10360172]

248. Jamison RL. Micropuncture study of superficial and juxtamedullary nephrons in the rat. Am J Physiol. 1970; 218:46-55. [PubMed: 5409892]

249. Jamison RL. Intrarenal heterogeneity. The case for two functionally dissimilar populations of nephrons in the mammalian kidney. Am J Med. 1973; 54:281-289. [PubMed: 4571744]

250. Johnston CI, Fabris B, Jandeleit K. Intrarenal renin-angiotensin system in renal physiology and pathophysiology. Kidney Int Suppl. 1993; 42:S59-S63. [PubMed: 8361131]

251. Jorgensen PL. Isolation and characterization of the components of the sodium pump. Q Rev Biophys. 1974; 7:239-274. [PubMed: 4281090]

252. Jorgensen PL. Sodium and potassium ion pump in kidney tubules. Physiol Rev. 1980; 60:864917. [PubMed: 6248909]

253. Jose PA, Eisner GM, Felder RA. Role of dopamine receptors in the kidney in the regulation of blood pressure. Curr Opin Nephrol Hypertens. 2002; 11:87-92. [PubMed: 11753092]

254. Jose PA, Soares-da-Silva P, Eisner GM, Felder RA. Dopamine and G protein-coupled receptor kinase 4 in the kidney: role in blood pressure regulation. Biochim Biophys Acta. 2010; 1802:1259-1267. [PubMed: 20153824]

255. Jourdain M, Amiel C, Friedlander G. Modulation of Na-H exchange activity by angiotensin II in opossum kidney cells. Am J Physiol. 1992; 263:C1141-C1146. [PubMed: 1335686]

256. Jung JS, Bhat RV, Preston GM, Guggino WB, Baraban JM, Agre P. Molecular characterization of an aquaporin cDNA from brain: candidate osmoreceptor and regulator of water balance. Proc Natl Acad Sci U S A. 1994; 91:13052-13056. [PubMed: 7528931] 
257. Kaelin WG Jr. Molecular biology. Use and abuse of RNAi to study mammalian gene function. Science. 2012; 337:421-422. [PubMed: 22837515]

258. Kallskog O, Wolgast M. Driving forces over the peritubular capillary membrane in the rat kidney during antidiuresis and saline expansion. Acta Physiol Scand. 1973; 89:116-125. [PubMed: 4761515]

259. Kanai Y, Lee WS, You G, Brown D, Hediger MA. The human kidney low affinity Na+/glucose cotransporter SGLT2. Delineation of the major renal reabsorptive mechanism for D-glucose. J Clin Invest. 1994; 93:397-404. [PubMed: 8282810]

260. Kaplan JH. Biochemistry of Na,K-ATPase. Annu Rev Biochem. 2002; 71:511-535. [PubMed: 12045105]

261. Karim Z, Defontaine N, Paillard M, Poggioli J. Protein kinase C isoforms in rat kidney proximal tubule: acute effect of angiotensin II. Am J Physiol. 1995; 269:C134-C140. [PubMed: 7631740]

262. Karim ZG, Chambrey R, Chalumeau C, Defontaine N, Warnock DG, Paillard M, Poggioli J. Regulation by $\mathrm{PKC}$ isoforms of $\mathrm{Na}(+) / \mathrm{H}(+)$ exchanger in luminal membrane vesicles isolated from cortical tubules. Am J Physiol. 1999; 277:F773-F778. [PubMed: 10564242]

263. Kashgarian M, Biemesderfer D, Caplan M, Forbush B III. Monoclonal antibody to Na,K-ATPase: immunocytochemical localization along nephron segments. Kidney Int. 1985; 28:899-913. [PubMed: 3003443]

264. Katz AI, Doucet A, Morel F. Na-K-ATPase activity along the rabbit, rat, mouse nephron. Am J Physiol. 1979; 237:F114-F120. [PubMed: 223456]

265. Kaunisto K, Parkkila S, Rajaniemi H, Waheed A, Grubb J, Sly WS. Carbonic anhydrase XIV: luminal expression suggests key role in renal acidification. Kidney Int. 2002; 61:2111-2118. [PubMed: 12028451]

266. Kawakami K, Nojima H, Ohta T, Nagano K. Molecular cloning and sequence analysis of human Na,K-ATPase beta-subunit. Nucleic Acids Res. 1986; 14:2833-2844. [PubMed: 3008098]

267. Kawakami K, Ohta T, Nojima H, Nagano K. Primary structure of the alpha-subunit of human Na,K-ATPase deduced from cDNA sequence. J Biochem. 1986; 100:389-397. [PubMed: 2430951]

268. Kemp BA, Bell JF, Rottkamp DM, Howell NL, Shao W, Navar LG, Padia SH, Carey RM. Intrarenal angiotensin III is the predominant agonist for proximal tubule angiotensin type 2 receptors. Hypertension. 2012; 60(2):387-395. [PubMed: 22689743]

269. Kessler SP, Hashimoto S, Senanayake PS, Gaughan C, Sen GC, Schnermann J. Nephron function in transgenic mice with selective vascular or tubular expression of Angiotensin-converting enzyme. J Am Soc Nephrol. 2005; 16:3535-3542. [PubMed: 16221869]

270. Kiil F. Mechanism of glomerulotubular balance: the whole kidney approach. Ren Physiol. 1982; 5:209-221. [PubMed: 6753068]

271. Kirchner KA. Lithium as a marker for proximal tubular delivery during low salt intake and diuretic infusion. Am J Physiol. 1987; 253:F188-F196. [PubMed: 3605348]

272. Kitamura K, Shiraishi N, Singer WD, Handlogten ME, Tomita K, Miller RT. Endothelin-B receptors activate Galpha13. Am J Physiol. 1999; 276:C930-C937. [PubMed: 10199825]

273. Kittelson JA. The postnatal growth of the kidney of the albino rat, with observations on an adult human kidney. Anat Rec. 1917; 13:385-408.

274. Knox FG, Cuche J-L, Ott CE, Diaz-Buxo JA, Marchand G. Regulation of glomerular filtration and proximal tubule reabsorption. Circ Res. 1975; 36:107-118. [PubMed: 805670]

275. Kobori H, Harrison-Bernard LM, Navar LG. Enhancement of angiotensinogen expression in angiotensin II-dependent hypertension. Hypertension. 2001; 37:1329-1335. [PubMed: 11358949]

276. Kobori H, Nangaku M, Navar LG, Nishiyama A. The intrarenal renin-angiotensin system: from physiology to the pathobiology of hypertension and kidney disease. Pharmacol Rev. 2007; 59:251-287. [PubMed: 17878513]

277. Kohan DE. Endothelin synthesis by rabbit renal tubule cells. Am J Physiol. 1991; 261:F221F226. [PubMed: 1877647]

278. Kohan DE. Endothelins: renal tubule synthesis and actions. Clin Exp Pharmacol Physiol. 1996; 23:337-344. [PubMed: 8717071] 
279. Kohan DE. Endothelin, hypertension and chronic kidney disease: new insights. Curr Opin Nephrol Hypertens. 2010; 19:134-139. [PubMed: 20051851]

280. Kohan DE, Rossi NF, Inscho EW, Pollock DM. Regulation of blood pressure and salt homeostasis by endothelin. Physiol Rev. 2011; 91:1-77. [PubMed: 21248162]

281. Kohzuki M, Johnston CI, Abe K, Chai SY, Casley DJ, Yasujima M, Yoshinaga K, Mendelsohn FA. In vitro autoradiographic endothelin-1 binding sites and sarafotoxin S6B binding sites in rat tissues. Clin Exp Pharmacol Physiol. 1991; 18:509-515. [PubMed: 1655320]

282. Kohzuki M, Johnston CI, Chai SY, Casley DJ, Mendelsohn FA. Localization of endothelin receptors in rat kidney. Eur J Pharmacol. 1989; 160:193-194. [PubMed: 2540991]

283. Kokko JP, Burg MB, Orloff J. Characteristics of $\mathrm{NaCl}$ and water transport in the renal proximal tubule. J Clin Invest. 1971; 50:69-76. [PubMed: 5543883]

284. Kokko JP, Rector FC. Flow dependence of transtubular potential difference in isolated perfused segments of rabbit proximal convoluted tubule. J Clin Invest. 1971; 50:2745-2750. [PubMed: 5129322]

285. Kolb RJ, Woost PG, Hopfer U. Membrane trafficking of angiotensin receptor type-1 and mechanochemical signal transduction in proximal tubule cells. Hypertension. 2004; 44:352-359. [PubMed: 15262908]

286. Komuro I, Wenninger KE, Philipson KD, Izumo S. Molecular cloning and characterization of the human cardiac Na+/Ca2+ exchanger cDNA. Proc Natl Acad Sci U S A. 1992; 89:4769-4773. [PubMed: 1374913]

287. Kondo Y, Imai M, Kangawa K, Matsuo H. Lack of direct action of alpha-human atrial natriuretic polypeptide on the in vitro perfused segments of Henle's loop isolated from rabbit kidney. Pflugers Arch. 1986; 406:273-278. [PubMed: 2938076]

288. Koomans HA, Boer WH, Dorhout Mees EJ. Evaluation of lithium clearance as a marker of proximal tubule sodium handling. Kidney Int. 1989; 36:2-12. [PubMed: 2681925]

289. Krapf R, Solioz M. Na/H antiporter mRNA expression in single nephron segments of rat kidney cortex. J Clin Invest. 1991; 88:783-788. [PubMed: 1653275]

290. Kriz W, Bankir L. A standard nomenclature for structures of the kidney. The Renal Commission of the International Union of Physiological Sciences (IUPS). Kidney Int. 1988; 33:1-7. [PubMed: 3352156]

291. Kriz, W.; Kaissling, B. Structural and functional organization of the kidney. In: Alpern, RJ.; Hebert, SC., editors. Seldin and Giebisch's The Kidney: Physiology and Pathophysiology. London: Academic Press; 2008.

292. Laghmani K, Preisig PA, Alpern RJ. The role of endothelin in proximal tubule proton secretion and the adaptation to a chronic metabolic acidosis. J Nephrol. 2002; 15(Suppl 5):S75-S87. [PubMed: 12027224]

293. Laghmani K, Preisig PA, Moe OW, Yanagisawa M, Alpern RJ. Endothelin-1/endothelin-B receptor-mediated increases in NHE3 activity in chronic metabolic acidosis. J Clin Invest. 2001; 107:1563-1569. [PubMed: 11413164]

294. Lameire NH, Lifschitz MD, Stein JH. Heterogeneity of nephron function. Annu Rev Physiol. 1977; 39:159-184. [PubMed: 322596]

295. Lang, F. Cell volume control. In: Alpern, RJ.; Hebert, SC., editors. The Kidney: Physiology and Pathophysiology. Burlington, San Diego, \& London: Academic Press; 2008.

296. Lang F, Messner G, Rehwald W. Electrophysiology of sodium-coupled transport in proximal renal tubules. Am J Physiol. 1986; 250:F953-F962. [PubMed: 3521326]

297. Larsen EH, Mobjerg N. Na+ recirculation and isosmotic transport. J Membr Biol. 2006; 212:115. [PubMed: 17206513]

298. Larsen EH, Willumsen NJ, Mobjerg N, Sorensen JN. The lateral intercellular space as osmotic coupling compartment in isotonic transport. Acta Physiol (Oxf). 2009; 195:171-186. [PubMed: 18983444]

299. Le TH, Oliverio MI, Kim HS, Salzler H, Dash RC, Howell DN, Smithies O, Bronson S, Coffman TM. A gammaGT-AT1A receptor transgene protects renal cortical structure in AT1 receptordeficient mice. Physiol Genomics. 2004; 18:290-298. [PubMed: 15306694] 
300. Ledoussal C, Lorenz JN, Nieman ML, Soleimani M, Schultheis PJ, Shull GE. Renal salt wasting in mice lacking NHE3 Na+/H+ exchanger but not in mice lacking NHE2. Am J Physiol Renal Physiol. 2001; 281:F718-F727. [PubMed: 11553519]

301. Lee YJ, Lee YJ, Han HJ. Regulatory mechanisms of $\mathrm{Na}(+)$ /glucose cotransporters in renal proximal tubule cells. Kidney Int Suppl. 2007:S27-S35. [PubMed: 17653207]

302. Leong PK, Yang LE, Holstein-Rathlou NH, McDonough AA. Angiotensin II clamp prevents the second step in renal apical NHE3 internalization during acute hypertension. Am J Physiol Renal Physiol. 2002; 283:F1142-F1150. [PubMed: 12372791]

303. Lewis SE, Erickson RP, Barnett LB, Venta PJ, Tashian RE. N-ethyl-N-nitrosourea-induced null mutation at the mouse Car-2 locus: an animal model for human carbonic anhydrase II deficiency syndrome. Proc Natl Acad Sci U S A. 1988; 85:1962-1966. [PubMed: 3126501]

304. Lewy JE, Windhager EE. Peritubular control of proximal tubular fluid reabsorption in the rat kidney. Am J Physiol. 1968; 214:943-954. [PubMed: 5647198]

305. Leyssac PP. Dependence of glomerular filtration rate on proximal tubular reabsorption of salt. Acta Physiol Scand. 1963; 58:236-242. [PubMed: 13930368]

306. Leyssac PP. The in vivo effect of angiotensin on the proximal tubular reabsorption of salt in rat kidneys. Acta Physiol Scand. 1964; 62:436-448. [PubMed: 14252578]

307. Li H, Weatherford ET, Davis DR, Keen HL, Grobe JL, Daugherty A, Cassis LA, Allen AM, Sigmund CD. Renal proximal tubule angiotensin AT1A receptors regulate blood pressure. Am J Physiol Regul Integr Comp Physiol. 2011; 301(4):R1067-R1077. [PubMed: 21753145]

308. Li XC, Campbell DJ, Ohishi M, Yuan S, Zhuo JL. AT1 receptor-activated signaling mediates angiotensin IV-induced renal cortical vasoconstriction in rats. Am J Physiol Renal Physiol. 2006; 290:F1024-F1033. [PubMed: 16380463]

309. Li XC, Carretero OA, Navar LG, Zhuo JL. AT1 receptor-mediated accumulation of extracellular angiotensin II in proximal tubule cells: role of cytoskeleton microtubules and tyrosine phosphatases. Am J Physiol Renal Physiol. 2006; 291:F375-F383. [PubMed: 16478976]

310. Li XC, Cook JL, Rubera I, Tauc M, Zhang F, Zhuo JL. Intrarenal transfer of an intracellular cyan fluorescent fusion of angiotensin II selectively in proximal tubules increases blood pressure in rats and mice. Am J Physiol Renal Physiol. 2011; 300:F1076-F1088. [PubMed: 21307128]

311. Li XC, Hopfer U, Zhuo JL. AT1 receptor-mediated uptake of angiotensin II and NHE-3 expression in proximal tubule cells through the microtubule-dependent endocytic pathway. Am J Physiol Renal Physiol. 2009; 297:F1342-F1352. [PubMed: 19726542]

312. Li XC, Zhuo JL. Selective knockdown of AT1 receptors by RNA interference inhibits Val5-Ang II endocytosis and NHE-3 expression in immortalized rabbit proximal tubule cells. Am J Physiol Cell Physiol. 2007; 293:C367-C378. [PubMed: 17428839]

313. Li XC, Zhuo JL. Phosphoproteomic analysis of AT(1) receptor-mediated signaling responses in proximal tubules of angiotensin II-induced hypertensive rats. Kidney Int. 2011; 80:620-632. [PubMed: 21697807]

314. Licht C, Laghmani K, Yanagisawa M, Preisig PA, Alpern RJ. An autocrine role for endothelin-1 in the regulation of proximal tubule NHE3. Kidney Int. 2004; 65:1320-1326. [PubMed: 15086471]

315. Lin HY, Kaji EH, Winkel GK, Ives HE, Lodish HF. Cloning and functional expression of a vascular smooth muscle endothelin 1 receptor. Proc Natl Acad Sci U S A. 1991; 88:3185-3189. [PubMed: 1849646]

316. Litchfield JB, Bott PA. Micropuncture study of renal excretion of water, $\mathrm{K}, \mathrm{Na}$, and $\mathrm{Cl}$ in the rat. Am J Physiol. 1962; 203:667-670. [PubMed: 13930952]

317. Liu FY, Cogan MG. Angiotensin II stimulation of hydrogen ion secretion in the rat early proximal tubule. Modes of action, mechanism, and kinetics. J Clin Invest. 1988; 82:601-607. [PubMed: 2841357]

318. Liu FY, Cogan MG. Atrial natriuretic factor does not inhibit basal or angiotensin II-stimulated proximal transport. Am J Physiol. 1988; 255:F434-F437. [PubMed: 2970798]

319. Liu FY, Cogan MG. Role of angiotensin II in glomerulotubular balance. Am J Physiol. 1990; 259:F72-F79. [PubMed: 2165360] 
320. Liu FY, Cogan MG. Role of protein kinase $\mathrm{C}$ in proximal bicarbonate absorption and angiotensin signaling. Am J Physiol. 1990; 258:F927-F933. [PubMed: 2330986]

321. Liu FY, Cogan MG, Rector FC Jr. Axial heterogeneity in the rat proximal convoluted tubule. II. Osmolality and osmotic water permeability. Am J Physiol. 1984; 247:F822-F826. [PubMed: 6496748]

322. Liu J, Kesiry R, Periyasamy SM, Malhotra D, Xie Z, Shapiro JI. Ouabain induces endocytosis of plasmalemmal Na/K-ATPase in LLC-PK1 cells by a clathrin-dependent mechanism. Kidney Int. 2004; 66:227-241. [PubMed: 15200429]

323. Liu J, Liang M, Liu L, Malhotra D, Xie Z, Shapiro JI. Ouabain-induced endocytosis of the plasmalemmal Na/K-ATPase in LLC-PK1 cells requires caveolin-1. Kidney Int. 2005; 67:18441854. [PubMed: 15840032]

324. Liu J, Yan Y, Liu L, Xie Z, Malhotra D, Joe B, Shapiro JI. Impairment of Na/K-ATPase Signaling in Renal Proximal Tubule Contributes to Dahl Salt-sensitive Hypertension. J Biol Chem. 2011; 286:22806-22813. [PubMed: 21555512]

325. Lorenz JN, Schultheis PJ, Traynor T, Shull GE, Schnermann J. Micropuncture analysis of singlenephron function in NHE3-deficient mice. Am J Physiol. 1999; 277:F447-F453. [PubMed: 10484528]

326. Lorenzen M, Lee CO, Windhager EE. Cytosolic $\mathrm{Ca} 2+$ and $\mathrm{Na}+$ activities in perfused proximal tubules of Necturus kidney. Am J Physiol. 1984; 247:F93-F102. [PubMed: 6331203]

327. Luft FC. Renalase, a catecholamine-metabolizing hormone from the kidney. Cell Metab. 2005; 1:358-360. [PubMed: 16054084]

328. Luyckx VA, Brenner BM. Low birth weight, nephron number, and kidney disease. Kidney Int Suppl. 2005:S68-S77. [PubMed: 16014104]

329. Ly JP, Onay T, Sison K, Sivaskandarajah G, Sabbisetti V, Li L, Bonventre JV, Flenniken A, Paragas N, Barasch JM, Adamson SL, Osborne L, Rossant J, Schnermann J, Quaggin SE. The Sweet Pee model for Sglt2 mutation. J Am Soc Nephrol. 2011; 22:113-123. [PubMed: 21209254]

330. Lytton J. Na+/Ca2+ exchangers: three mammalian gene families control $\mathrm{Ca} 2+$ transport. Biochem J. 2007; 406:365-382. [PubMed: 17716241]

331. Ma T, Yang B, Gillespie A, Carlson EJ, Epstein CJ, Verkman AS. Severely impaired urinary concentrating ability in transgenic mice lacking aquaporin-1 water channels. J Biol Chem. 1998; 273:4296-4299. [PubMed: 9468475]

332. Maack T, Camargo MJ, Kleinert HD, Laragh JH, Atlas SA. Atrial natriuretic factor: structure and functional properties. Kidney Int. 1985; 27:607-615. [PubMed: 2989607]

333. Maddox DA, Gennari FJ. The early proximal tubule: a high-capacity delivery-responsive reabsorptive site. Am J Physiol. 1987; 252:F573-F584. [PubMed: 3551629]

334. Madhun ZT, Goldthwait DA, McKay D, Hopfer U, Douglas JG. An epoxygenase metabolite of arachidonic acid mediates angiotensin II-induced rises in cytosolic calcium in rabbit proximal tubule epithelial cells. J Clin Invest. 1991; 88:456-461. [PubMed: 1650793]

335. Madjdpour C, Bacic D, Kaissling B, Murer H, Biber J. Segment-specific expression of sodiumphosphate cotransporters NaPi-IIa and -IIc and interacting proteins in mouse renal proximal tubules. Pflugers Arch. 2004; 448:402-410. [PubMed: 15007650]

336. Madsen, KM.; Nielsen, S.; Tisher, CC. Anatomy of the kidney. In: Brenner, BM., editor. Brenner and Rector's The Kidney. Saunders, An Imprint of Elsevier; 2007.

337. Maduwegedera D, Kett MM, Flower RL, Lambert GW, Bertram JF, Wintour EM, Denton KM. Sex differences in postnatal growth and renal development in offspring of rabbit mothers with chronic secondary hypertension. Am J Physiol Regul Integr Comp Physiol. 2007; 292:R706R714. [PubMed: 17082352]

338. Manhiani MM, Cormican MT, Brands MW. Chronic sodium-retaining action of insulin in diabetic dogs. Am J Physiol Renal Physiol. 2011; 300:F957-F965. [PubMed: 21228110]

339. Marsenic O. Glucose control by the kidney: an emerging target in diabetes. Am J Kidney Dis. 2009; 53:875-883. [PubMed: 19324482] 
340. Mathisen O, Monclair T, Holdaas H, Kiil F. Bicarbonate as mediator of proximal tubular $\mathrm{NaCl}$ reabsorption and glomerulotubular balance. Scand J Clin Lab Invest. 1978; 38:7-17. [PubMed: 415348]

341. Matsusaka T, Niimura F, Shimizu A, Pastan I, Saito A, Kobori H, Nishiyama A, Ichikawa I. Liver angiotensinogen is the primary source of renal angiotensin II. J Am Soc Nephrol. 2012; 23:11811189. [PubMed: 22518004]

342. Maunsbach AB, Boulpaep EL. Hydrostatic pressure changes related to paracellular shunt ultrastructure in proximal tubule. Kidney Int. 1980; 17:732-748. [PubMed: 7191026]

343. McDonough AA. Mechanisms of proximal tubule sodium transport regulation that link extracellular fluid volume and blood pressure. Am J Physiol Regul Integr Comp Physiol. 2010; 298:R851-R861. [PubMed: 20106993]

344. McDonough AA, Leong PK, Yang LE. Mechanisms of pressure natriuresis: how blood pressure regulates renal sodium transport. Ann N Y Acad Sci. 2003; 986:669-677. [PubMed: 12763917]

345. Mendelsohn FA. Evidence for the local occurrence of angiotensin II in rat kidney and its modulation by dietary sodium intake and converting enzyme blockade. Clin Sci (Lond). 1979; 57:173-179. [PubMed: 477254]

346. Mendelsohn FA. Angiotensin II: evidence for its role as an intrarenal hormone. Kidney Int Suppl. 1982; 12:S78-S81. [PubMed: 6182339]

347. Mendelsohn FA, Allen AM, Chai SY, Sexton PM, Figdor R. Overlapping distributions of receptors for atrial natriuretic peptide and angiotensin II visualized by in vitro autoradiography: morphological basis of physiological antagonism. Can J Physiol Pharmacol. 1987; 65:15171521. [PubMed: 2825937]

348. Menini S, Ricci C, Iacobini C, Bianchi G, Pugliese G, Pesce C. Glomerular number and size in Milan hypertensive and normotensive rats: their relationship to susceptibility and resistance to hypertension and renal disease. J Hypertens. 2004; 22:2185-2192. [PubMed: 15480104]

349. Mercer RW, Biemesderfer D, Bliss DP Jr, Collins JH, Forbush B III. Molecular cloning and immunological characterization of the gamma polypeptide, a small protein associated with the Na,K-ATPase. J Cell Biol. 1993; 121:579-586. [PubMed: 8387529]

350. Mimran A, Casellas D. The renin-angiotensin system and nephron function heterogeneity. Kidney Int Suppl. 1987; 20:S57-S63. [PubMed: 3298804]

351. Miyazaki E, Sakaguchi M, Wakabayashi S, Shigekawa M, Mihara K. NHE6 protein possesses a signal peptide destined for endoplasmic reticulum membrane and localizes in secretory organelles of the cell. J Biol Chem. 2001; 276:49221-49227. [PubMed: 11641397]

352. Moe OW. Acute regulation of proximal tubule apical membrane $\mathrm{Na} / \mathrm{H}$ exchanger NHE-3: role of phosphorylation, protein trafficking, and regulatory factors. J Am Soc Nephrol. 1999; 10:24122425. [PubMed: 10541303]

353. Molitoris BA, Dahl R, Geerdes A. Cytoskeleton disruption and apical redistribution of proximal tubule $\mathrm{Na}(+)-\mathrm{K}(+)-A T P a s e$ during ischemia. Am J Physiol. 1992; 263:F488-F495. [PubMed: 1329535]

354. Moran A, Handler JS, Turner RJ. Na+-dependent hexose transport in vesicles from cultured renal epithelial cell line. Am J Physiol. 1982; 243:C293-C298. [PubMed: 7137338]

355. Morgan T, Berliner RW. In vivo perfusion of proximal tubules of the rat: glomerulotubular balance. Am J Physiol. 1969; 217:992-997. [PubMed: 4309978]

356. Mori K, Ogawa Y, Ebihara K, Tamura N, Tashiro K, Kuwahara T, Mukoyama M, Sugawara A, Ozaki S, Tanaka I, Nakao K. Isolation and characterization of CA XIV, a novel membrane-bound carbonic anhydrase from mouse kidney. J Biol Chem. 1999; 274:15701-15705. [PubMed: 10336468]

357. Moseley AE, Lieske SP, Wetzel RK, James PF, He S, Shelly DA, Paul RJ, Boivin GP, Witte DP, Ramirez JM, Sweadner KJ, Lingrel JB. The Na,K-ATPase alpha 2 isoform is expressed in neurons, and its absence disrupts neuronal activity in newborn mice. J Biol Chem. 2003; 278:5317-5324. [PubMed: 12458206]

358. Mount, DB.; Yu, ASL. Brenner: Brenner and Rector's The Kidney. St Louis: Saunders; 2007. Transport of inorganic solutes: sodium, chloride, potassium, magnesium, calcium and phosphate. 
359. Mullins LJ. Steady-state calcium fluxes: membrane versus mitochondrial control of ionized calcium in axoplasm. Fed Proc. 1976; 35:2583-2588. [PubMed: 992110]

360. Murawski IJ, Maina RW, Gupta IR. The relationship between nephron number, kidney size and body weight in two inbred mouse strains. Organogenesis. 2010; 6:189-194. [PubMed: 21197222]

361. Murer H, Hopfer U, Kinne R. Sodium/proton antiport in brush-border-membrane vesicles isolated from rat small intestine and kidney. Biochem J. 1976; 154:597-604. [PubMed: 942389]

362. Murray RD, Itoh S, Inagami T, Misono K, Seto S, Scicli AG, Carretero OA. Effects of synthetic atrial natriuretic factor in the isolated perfused rat kidney. Am J Physiol. 1985; 249:F603-F609. [PubMed: 2931997]

363. Murtazina R, Kovbasnjuk O, Zachos NC, Li X, Chen Y, Hubbard A, Hogema BM, Steplock D, Seidler U, Hoque KM, Tse CM, De Jonge HR, Weinman EJ, Donowitz M. Tissue-specific regulation of sodium/proton exchanger isoform 3 activity in $\mathrm{Na}(+) / \mathrm{H}(+)$ exchanger regulatory factor 1 (NHERF1) null mice. cAMP inhibition is differentially dependent on NHERF1 and exchange protein directly activated by cAMP in ileum versus proximal tubule. J Biol Chem. 2007; 282:25141-25151. [PubMed: 17580307]

364. Myers BD, Deen WM, Brenner BM. Effects of norepinephrine and angiotensin II on the determinants of glomerular ultrafiltration and proximal tubule fluid reabsorption in the rat. Circ Res. 1975; 37:101-110. [PubMed: 1149180]

365. Nair S, Wilding JP. Sodium glucose cotransporter 2 inhibitors as a new treatment for diabetes mellitus. J Clin Endocrinol Metab. 2010; 95:34-42. [PubMed: 19892839]

366. Nakamura N, Tanaka S, Teko Y, Mitsui K, Kanazawa H. Four Na+/H+ exchanger isoforms are distributed to Golgi and post-Golgi compartments and are involved in organelle $\mathrm{pH}$ regulation. $\mathrm{J}$ Biol Chem. 2005; 280:1561-1572. [PubMed: 15522866]

367. Nakamuta M, Takayanagi R, Sakai Y, Sakamoto S, Hagiwara H, Mizuno T, Saito Y, Hirose S, Yamamoto M, Nawata H. Cloning and sequence analysis of a cDNA encoding human nonselective type of endothelin receptor. Biochem Biophys Res Commun. 1991; 177:34-39. [PubMed: 1710450]

368. Navar LG, Carmines PK, Huang WC, Mitchell KD. The tubular effects of angiotensin II. Kidney Int Suppl. 1987; 20:S81-S88. [PubMed: 3298806]

369. Navar LG, Imig JD, Zou L, Wang CT. Intrarenal production of angiotensin II. Semin Nephrol. 1997; 17:412-422. [PubMed: 9316209]

370. Navar LG, Inscho EW, Majid SA, Imig JD, Harrison-Bernard LM, Mitchell KD. Paracrine regulation of the renal microcirculation. Physiol Rev. 1996; 76:425-536. [PubMed: 8618962]

371. Navar LG, Kobori H, Prieto-Carrasquero M. Intrarenal Angiotensin II and Hypertension. Curr Hypertens Rep. 2003; 5:135-143. [PubMed: 12642013]

372. Navar LG, Lewis L, Hymel A, Braam B, Mitchell KD. Tubular fluid concentrations and kidney contents of angiotensins I and II in anesthetized rats. J Am Soc Nephrol. 1994; 5:1153-1158. [PubMed: 7849257]

373. Navar LG, Satou R, Gonzalez-Villalobos RA. The increasing complexity of the intratubular Renin-Angiotensin system. J Am Soc Nephrol. 2012; 23:1130-1132. [PubMed: 22677556]

374. Navar LG, Schafer JA. Comment on "Lithium clearance: a new research area. News Physiol Sci. $1987 ; 2: 34-35$.

375. Navar LG, Zou L, Von Thun A, Tarng WC, Imig JD, Mitchell KD. Unraveling the Mystery of Goldblatt Hypertension. News Physiol Sci. 1998; 13:170-176. [PubMed: 11390784]

376. Needleman P, Adams SP, Cole BR, Currie MG, Geller DM, Michener ML, Saper CB, Schwartz D, Standaert DG. Atriopeptins as cardiac hormones. Hypertension. 1985; 7:469-482. [PubMed: 2989170]

377. Neumann KH, Rector FC Jr. Mechanism of $\mathrm{NaCl}$ and water reabsorption in the proximal convoluted tubule of rat kidney. J Clin Invest. 1976; 58:1110-1118. [PubMed: 993334]

378. Nicoll DA, Longoni S, Philipson KD. Molecular cloning and functional expression of the cardiac sarcolemmal $\mathrm{Na}(+)-\mathrm{Ca}$ + exchanger. Science. 1990; 250:562-565. [PubMed: 1700476]

379. Nonoguchi H, Sands JM, Knepper MA. ANF inhibits $\mathrm{NaCl}$ and fluid absorption in cortical collecting duct of rat kidney. Am J Physiol. 1989; 256:F179-F186. [PubMed: 2521430] 
380. Noonan WT, Woo AL, Nieman ML, Prasad V, Schultheis PJ, Shull GE, Lorenz JN. Blood pressure maintenance in NHE3-deficient mice with transgenic expression of NHE3 in small intestine. Am J Physiol Regul Integr Comp Physiol. 2005; 288:R685-R691. [PubMed: 15550620]

381. Nurnberger A, Rabiger M, Mack A, Diaz J, Sokoloff P, Muhlbauer B, Luippold G. Subapical localization of the dopamine D3 receptor in proximal tubules of the rat kidney. J Histochem Cytochem. 2004; 52:1647-1655. [PubMed: 15557219]

382. O'Connell DP, Botkin SJ, Ramos SI, Sibley DR, Ariano MA, Felder RA, Carey RM. Localization of dopamine D1A receptor protein in rat kidneys. Am J Physiol. 1995; 268:F1185-F1197. [PubMed: 7611459]

383. O'Connell DP, Vaughan CJ, Aherne AM, Botkin SJ, Wang ZQ, Felder RA, Carey RM. Expression of the dopamine D3 receptor protein in the rat kidney. Hypertension. 1998; 32:886895. [PubMed: 9822449]

384. Ogawa Y, Nakao K, Arai H, Nakagawa O, Hosoda K, Suga S, Nakanishi S, Imura H. Molecular cloning of a non-isopeptide-selective human endothelin receptor. Biochem Biophys Res Commun. 1991; 178:248-255. [PubMed: 1648908]

385. Oliver J, Macdowell M. The structural and functional aspects of the handling of glucose by the nephrons and the kidney and their correlation by means of structural-functional equivalents. $\mathbf{J}$ Clin Invest. 1961; 40:1093-1112. [PubMed: 13730807]

386. Olsen NV, Aachmann-Andersen NJ, Oturai P, Munch-Andersen T, Borno A, Hulston C, Holstein-Rathlou NH, Robach P, Lundby C. Erythropoietin down-regulates proximal renal tubular reabsorption and causes a fall in glomerular filtration rate in humans. J Physiol. 2011; 589:1273-1281. [PubMed: 20724370]

387. Ong AC, Jowett TP, Moorhead JF, Owen JS. Human high density lipoproteins stimulate endothelin-1 release by cultured human renal proximal tubular cells. Kidney Int. 1994; 46:13151321. [PubMed: 7853789]

388. Orlowski J. Heterologous expression and functional properties of amiloride high affinity (NHE-1) and low affinity (NHE-3) isoforms of the rat Na/H exchanger. J Biol Chem. 1993; 268:1636916377. [PubMed: 8393860]

389. Orlowski J, Kandasamy RA, Shull GE. Molecular cloning of putative members of the Na/H exchanger gene family. cDNA cloning, deduced amino acid sequence, and mRNA tissue expression of the rat $\mathrm{Na} / \mathrm{H}$ exchanger NHE-1 and two structurally related proteins. J Biol Chem. 1992; 267:9331-9339. [PubMed: 1577762]

390. Ozono R, O'Connell DP, Wang ZQ, Moore AF, Sanada H, Felder RA, Carey RM. Localization of the dopamine D1 receptor protein in the human heart and kidney. Hypertension. 1997; 30:725729. [PubMed: 9323013]

391. Ozono R, Wang ZQ, Moore AF, Inagami T, Siragy HM, Carey RM. Expression of the subtype 2 angiotensin (AT2) receptor protein in rat kidney. Hypertension. 1997; 30:1238-1246. [PubMed: 9369282]

392. Padia SH, Howell NL, Siragy HM, Carey RM. Renal angiotensin type 2 receptors mediate natriuresis via angiotensin III in the angiotensin II type 1 receptor-blocked rat. Hypertension. 2006; 47:537-544. [PubMed: 16380540]

393. Padia SH, Kemp BA, Howell NL, Gildea JJ, Keller SR, Carey RM. Intrarenal angiotensin III infusion induces natriuresis and angiotensin type 2 receptor translocation in Wistar-Kyoto but not in spontaneously hypertensive rats. Hypertension. 2009; 53:338-343. [PubMed: 19075092]

394. Padia SH, Kemp BA, Howell NL, Keller SR, Gildea JJ, Carey RM. Mechanisms of dopamine $\mathrm{D}(1)$ and angiotensin type 2 receptor interaction in natriuresis. Hypertension. 2012; 59:437-445. [PubMed: 22203736]

395. Padia SH, Kemp BA, Howell NL, Siragy HM, Fournie-Zaluski MC, Roques BP, Carey RM. Intrarenal aminopeptidase $\mathrm{N}$ inhibition augments natriuretic responses to angiotensin III in angiotensin type 1 receptor-blocked rats. Hypertension. 2007; 49:625-630. [PubMed: 17190872]

396. Palmer, LG.; Alpern, RJ.; Seldin, DW. Physiology and pathophysiology of sodium retention and wastage. In: Alpern, RJ.; Hebert, SC., editors. The Kidney: Physiology and Pathophysiology. Burlington, San Diego, and London: Academic Press; 2008. 
397. Pandey KN. Biology of natriuretic peptides and their receptors. Peptides. 2005; 26:901-932. [PubMed: 15911062]

398. Pandey KN. Emerging Roles of Natriuretic Peptides and their Receptors in Pathophysiology of Hypertension and Cardiovascular Regulation. J Am Soc Hypertens. 2008; 2:210-226. [PubMed: 19746200]

399. Panico C, Luo Z, Damiano S, Artigiano F, Gill P, Welch WJ. Renal proximal tubular reabsorption is reduced in adult spontaneously hypertensive rats: roles of superoxide and $\mathrm{Na}+\mathrm{H}+$ exchanger 3. Hypertension. 2009; 54:1291-1297. [PubMed: 19805644]

400. Pao AC, Bhargava A, Di SF, Quigley R, Shao X, Wang J, Thomas S, Zhang J, Shi M, Funder JW, Moe OW, Pearce D. Expression and role of serum and glucocorticoid-regulated kinase 2 in the regulation of $\mathrm{Na}+\mathrm{H}+$ exchanger 3 in the mammalian kidney. Am J Physiol Renal Physiol. 2010; 299:F1496-F1506. [PubMed: 20926631]

401. Parker, MD.; Boron, WF. Sodium-coupled bicarbonate transporters. In: Alpern, RJ.; Hebert, SC., editors. Seldin and Giebisch's The Kidney: Physiology and Pathophysiology. London: Academic Press; 2008.

402. Pelayo JC, Fildes RD, Eisner GM, Jose PA. Effects of dopamine blockade on renal sodium excretion. Am J Physiol. 1983; 245:F247-F253. [PubMed: 6881340]

403. Peng Y, Amemiya M, Yang X, Fan L, Moe OW, Yin H, Preisig PA, Yanagisawa M, Alpern RJ. ET(B) receptor activation causes exocytic insertion of NHE3 in OKP cells. Am J Physiol Renal Physiol. 2001; 280:F34-F42. [PubMed: 11133512]

404. Peng Y, Moe OW, Chu T, Preisig PA, Yanagisawa M, Alpern RJ. ETB receptor activation leads to activation and phosphorylation of NHE3. Am J Physiol. 1999; 276:C938-C945. [PubMed: 10199826]

405. Perico N, Cornejo RP, Benigni A, Malanchini B, Ladny JR, Remuzzi G. Endothelin induces diuresis and natriuresis in the rat by acting on proximal tubular cells through a mechanism mediated by lipoxygenase products. J Am Soc Nephrol. 1991; 2:57-69. [PubMed: 1655094]

406. Periyasamy SM, Liu J, Tanta F, Kabak B, Wakefield B, Malhotra D, Kennedy DJ, Nadoor A, Fedorova OV, Gunning W, Xie Z, Bagrov AY, Shapiro JI. Salt loading induces redistribution of the plasmalemmal Na/K-ATPase in proximal tubule cells. Kidney Int. 2005; 67:1868-1877. [PubMed: 15840034]

407. Pesce C. Glomerular number and size: facts and artefacts. Anat Rec. 1998; 251:66-71. [PubMed: 9605222]

408. Peterson LN, de RC, Sonnenberg H, Levine DZ. Thick ascending limb response to dDAVP and atrial natriuretic factor in vivo. Am J Physiol. 1987; 252:F374-F381. [PubMed: 2950772]

409. Philipson KD, Nicoll DA, Ottolia M, Quednau BD, Reuter H, John S, Qiu Z. The Na+/Ca2+ exchange molecule: an overview. Ann N Y Acad Sci. 2002; 976:1-10. [PubMed: 12502528]

410. Pinho MJ, Serrao MP, Gomes P, Hopfer U, Jose PA, Soares-da-Silva P. Over-expression of renal LAT1 and LAT2 and enhanced L-DOPA uptake in SHR immortalized renal proximal tubular cells. Kidney Int. 2004; 66:216-226. [PubMed: 15200428]

411. Pittner J, Wolgast M, Casellas D, Persson AE. Increased shear stress-released NO and decreased endothelial calcium in rat isolated perfused juxtamedullary nephrons. Kidney Int. 2005; 67:227236. [PubMed: 15610246]

412. Pollock DM. Dissecting the complex physiology of endothelin: new lessons from genetic models. Hypertension. 2010; 56:31-33. [PubMed: 20516396]

413. Pritchard, JB.; Miller, DS. Proximal tubular transport of organic anions and cations. In: Seldin, DW.; Giebisch, G., editors. The Kidney: Physiology and Pathophysiology. New York: Raven Press; 1992.

414. Pruijm M, Wuerzner G, Maillard M, Bovet P, Renaud C, Bochud M, Burnier M. Glomerular hyperfiltration and increased proximal sodium reabsorption in subjects with type 2 diabetes or impaired fasting glucose in a population of the African region. Nephrol Dial Transplant. 2010; 25:2225-2231. [PubMed: 20124214]

415. Puelles VG, Hoy WE, Hughson MD, Diouf B, Douglas-Denton RN, Bertram JF. Glomerular number and size variability and risk for kidney disease. Curr Opin Nephrol Hypertens. 2011; 20:7-15. [PubMed: 21099687] 
416. Purkerson JM, Kittelberger AM, Schwartz GJ. Basolateral carbonic anhydrase IV in the proximal tubule is a glycosylphosphatidylinositol-anchored protein. Kidney Int. 2007; 71:407-416. [PubMed: 17228367]

417. Purkerson JM, Schwartz GJ. The role of carbonic anhydrases in renal physiology. Kidney Int. 2007; 71:103-115. [PubMed: 17164835]

418. Quamme GA, Dirks JH. Micropuncture techniques. Kidney Int. 1986; 30:152-165. [PubMed: 3531672]

419. Quinn MD, Marsh DJ. Peritubular capillary control of proximal tubule reabsorption in the rat. Am J Physiol. 1979; 236:F478-F487. [PubMed: 375749]

420. Rakugi H, Ogihara T, Nakamaru M, Saito H, Shima J, Sakaguchi K, Kumahara Y. Renal interaction of atrial natriuretic peptide with angiotensin II: glomerular and tubular effects. Clin Exp Pharmacol Physiol. 1989; 16:97-107. [PubMed: 2523767]

421. Rakugi H, Ogihara T, Nakamaru M, Saito H, Shima J, Sakaguchi K, Kumahara Y. Role of angiotensin II in the renal response to atrial natriuretic peptide in normal subjects. J Cardiovasc Pharmacol. 1989; 13(Suppl 6):S55-S58. [PubMed: 2473352]

422. Rector FC Jr. Sodium, bicarbonate, and chloride absorption by the proximal tubule. Am J Physiol. 1983; 244:F461-F471. [PubMed: 6303131]

423. Rector FC Jr. Sodium, bicarbonate, and chloride absorption by the proximal tubule. Am J Physiol. 1983; 244:F461-F471. [PubMed: 6303131]

424. Rector FC Jr, Brunner FP, Seldin DW. Mechanism of glomerulotubular balance. I. Effect of aortic constriction and elevated ureteropelvic pressure on glomerular filtration rate, fractional reabsorption, transit time, and tubular size in the proximal tubule of the rat. J Clin Invest. 1966; 45:590-602. [PubMed: 5937030]

425. Reilly AM, Harris PJ, Williams DA. Biphasic effect of angiotensin II on intracellular sodium concentration in rat proximal tubules. Am J Physiol. 1995; 269:F374-F380. [PubMed: 7573486]

426. Reilly RF, Shugrue CA. cDNA cloning of a renal Na(+)-Ca2+ exchanger. Am J Physiol. 1992; 262:F1105-F1109. [PubMed: 1621815]

427. Reilly RF, Shugrue CA, Lattanzi D, Biemesderfer D. Immunolocalization of the Na+/Ca2+ exchanger in rabbit kidney. Am J Physiol. 1993; 265:F327-F332. [PubMed: 8368343]

428. Riquier-Brison AD, Leong PK, Pihakaski-Maunsbach K, McDonough AA. Angiotensin II stimulates trafficking of NHE3, NaPi2, and associated proteins into the proximal tubule microvilli. Am J Physiol Renal Physiol. 2010; 298:F177-F186. [PubMed: 19864301]

429. Rodicio J, Herrera-Acosta J, Sellman JC, Rector FC Jr, Seldin DW. Studies on glomerulotubular balance during aortic constriction, ureteral obstruction and venous occlusion in hydropenic and saline-loaded rats. Nephron. 1969; 6:437-456. [PubMed: 5791286]

430. Roman RJ. Pressure diuresis mechanism in the control of renal function and arterial pressure. Fed Proc. 1986; 45:2878-2884. [PubMed: 3536584]

431. Roman RJ. Pressure-diuresis in volume-expanded rats. Tubular reabsorption in superficial and deep nephrons. Hypertension. 1988; 12:177-183. [PubMed: 3410526]

432. Romano G, Giagu P, Favret G, Bartoli E. Effect of endothelin 1 on proximal reabsorption and tubuloglomerular feedback. Kidney Blood Press Res. 2000; 23:360-365. [PubMed: 11070415]

433. Romero MF. Molecular pathophysiology of SLC4 bicarbonate transporters. Curr Opin Nephrol Hypertens. 2005; 14:495-501. [PubMed: 16046910]

434. Rostgaard J, Moller O. Localization of Na+, K+ -ATPase to the inside of the basolateral cell membranes of epithelial cells of proximal and distal tubules in rabbit kidney. Cell Tissue Res. 1980; 212:17-28. [PubMed: 6254659]

435. Sackin, H.; Palmer, LG. Electrophysiological analysis of transepithelial transport. In: Alpern, RJ.; Hebert, SC., editors. Seldin and Giebisch's The Kidney: Physiology and Pathophysiology. London: Academic Press; 2008.

436. Sakamoto A, Yanagisawa M, Sakurai T, Takuwa Y, Yanagisawa H, Masaki T. Cloning and functional expression of human cDNA for the ETB endothelin receptor. Biochem Biophys Res Commun. 1991; 178:656-663. [PubMed: 1713452] 
437. Sakurai T, Yanagisawa M, Takuwa Y, Miyazaki H, Kimura S, Goto K, Masaki T. Cloning of a cDNA encoding a non-isopeptide-selective subtype of the endothelin receptor. Nature. 1990; 348:732-735. [PubMed: 2175397]

438. Salazar FJ, Granger JP, Fiksen-Olsen MJ, Bentley MD, Romero JC. Possible modulatory role of angiotensin II on atrial peptide-induced natriuresis. Am J Physiol. 1987; 253:F880-F883. [PubMed: 2961275]

439. Samuel T, Hoy WE, Douglas-Denton R, Hughson MD, Bertram JF. Determinants of glomerular volume in different cortical zones of the human kidney. J Am Soc Nephrol. 2005; 16:3102-3109. [PubMed: 16107583]

440. Sardet C, Franchi A, Pouyssegur J. Molecular cloning, primary structure, and expression of the human growth factor-activatable $\mathrm{Na}+\mathrm{H}+$ antiporter. Cell. 1989; 56:271-280. [PubMed: 2536298]

441. Schafer JA, Robert F. Pitts Memorial Lecture. Mechanisms coupling the absorption of solutes and water in the proximal nephron. Kidney Int. 1984; 25:708-716. [PubMed: 6482175]

442. Schafer JA, Andreoli TE. Rheogenic and passive Na+ absorption by the proximal nephron. Annu Rev Physiol. 1979; 41:211-227. [PubMed: 373589]

443. Schafer JA, Troutman SL, Andreoli TE. Volume reabsorption, transepithelial potential differences, and ionic permeability properties in mammalian superficial proximal straight tubules. J Gen Physiol. 1974; 64:582-607. [PubMed: 4443793]

444. Scherzer P, Popovtzer MM. Segmental localization of mRNAs encoding $\mathrm{Na}(+)-\mathrm{K}(+)$-ATPase alpha(1)- and beta(1)-subunits in diabetic rat kidneys using RT-PCR. Am J Physiol Renal Physiol. 2002; 282:F492-F500. [PubMed: 11832431]

445. Schneider MP, Boesen EI, Pollock DM. Contrasting actions of endothelin ET(A) and ET(B) receptors in cardiovascular disease. Annu Rev Pharmacol Toxicol. 2007; 47:731-759. 731-759. [PubMed: 17002597]

446. Schnermann J. Sodium transport deficiency and sodium balance in gene-targeted mice. Acta Physiol Scand. 2001; 173:59-66. [PubMed: 11678727]

447. Schnermann J, Chou CL, Ma T, Traynor T, Knepper MA, Verkman AS. Defective proximal tubular fluid reabsorption in transgenic aquaporin-1 null mice. Proc Natl Acad Sci U S A. 1998; 95:9660-9664. [PubMed: 9689137]

448. Schnermann J, Wahl M, Liebau G, Fischbach H. Balance between tubular flow rate and net fluid reabsorption in the proximal convolution of the rat kidney. I. Dependency of reabsorptive net fluid flux upon proximal tubular surface area at spontaneous variations of filtration rate. Pflugers Arch. 1968; 304:90-103. [PubMed: 5748572]

449. Schou M, Thomsen K, Vestergaard P. The renal lithium clearance and its correlations with other biological variables: observations in a large group of physically healthy persons. Clin Nephrol. 1986; 25:207-211. [PubMed: 3698353]

450. Schreuder MF, Nauta J. Prenatal programming of nephron number and blood pressure. Kidney Int. 2007; 72:265-268. [PubMed: 17495859]

451. Schultheis PJ, Clarke LL, Meneton P, Miller ML, Soleimani M, Gawenis LR, Riddle TM, Duffy JJ, Doetschman T, Wang T, Giebisch G, Aronson PS, Lorenz JN, Shull GE. Renal and intestinal absorptive defects in mice lacking the NHE3 Na+/H+ exchanger. Nat Genet. 1998; 19:282-285. [PubMed: 9662405]

452. Schulz A, Hansch J, Kuhn K, Schlesener M, Kossmehl P, Nyengaard JR, Wendt N, Huber M, Kreutz R. Nephron deficit is not required for progressive proteinuria development in the Munich Wistar Fromter rat. Physiol Genomics. 2008; 35:30-35. [PubMed: 18647879]

453. Schuster VL, Kokko JP, Jacobson HR. Angiotensin II directly stimulates sodium transport in rabbit proximal convoluted tubules. J Clin Invest. 1984; 73:507-515. [PubMed: 6699174]

454. Schuster, VL.; Seldin, DW. Renal clearance. In: Seldin, DW.; Giebisch, G., editors. The Kidney: Physiology and Pathophysiology. New York: Raven Press; 1985.

455. Schwartz GJ, Kittelberger AM, Barnhart DA, Vijayakumar S. Carbonic anhydrase IV is expressed in $\mathrm{H}(+)$-secreting cells of rabbit kidney. Am J Physiol Renal Physiol. 2000; 278:F894F904. [PubMed: 10836977] 
456. Seri I. Dopamine and natriuresis. Mechanism of action and developmental aspects. Am J Hypertens. 1990; 3:82S-86S. [PubMed: 2200437]

457. Serneri GG, Modesti PA, Cecioni I, Biagini D, Migliorini A, Costoli A, Colella A, Naldoni A, Paoletti P. Plasma endothelin and renal endothelin are two distinct systems involved in volume homeostasis. Am J Physiol. 1995; 268:H1829-H1837. [PubMed: 7771534]

458. Sexton PM, Zhuo J, Mendelsohn FA. Localization and regulation of renal receptors for angiotensin II and atrial natriuretic peptide. Tohoku J Exp Med. 1992; 166:41-56. [PubMed: 1412446]

459. Shamraj OI, Lingrel JB. A putative fourth $\mathrm{Na}+\mathrm{K}(+)$-ATPase alpha-subunit gene is expressed in testis. Proc Natl Acad Sci U S A. 1994; \%20(91):12952-12956. [PubMed: 7809153]

460. Sheng, S.; Johnson, JP.; Kleyman, TR. Epithelial Na+ channels. In: Alpern, RJ.; Hebert, SC., editors. Seldin and Giebisch' The Kidney: Physiology and Pathophysiology. London: Academic Press; 2008.

461. Shenolikar S, Voltz JW, Minkoff CM, Wade JB, Weinman EJ. Targeted disruption of the mouse NHERF-1 gene promotes internalization of proximal tubule sodium-phosphate cotransporter type IIa and renal phosphate wasting. Proc Natl Acad Sci U S A. 2002; \%20(99):11470-11475. [PubMed: 12169661]

462. Shichiri M, Hirata Y, Ando K, Emori T, Ohta K, Kimoto S, Ogura M, Inoue A, Marumo F. Plasma endothelin levels in hypertension and chronic renal failure. Hypertension. 1990; 15:493496. [PubMed: 2185151]

463. Shirley DG, Walter SJ, Thomsen K. A comparison of micropuncture and lithium clearance methods in the assessment of renal tubular function in rats with diabetes insipidus. Pflugers Arch. 1983; 399:266-270. [PubMed: 6664829]

464. Shull GE, Greeb J, Lingrel JB. Molecular cloning of three distinct forms of the $\mathrm{Na}+\mathrm{K}+-\mathrm{ATPase}$ alpha-subunit from rat brain. Biochemistry. 1986; 25:8125-8132. [PubMed: 3028470]

465. Shull GE, Lane LK, Lingrel JB. Amino-acid sequence of the beta-subunit of the $(\mathrm{Na}++\mathrm{K}$ +)ATPase deduced from a cDNA. Nature. 1986; 321:429-431. [PubMed: 3012356]

466. Shull GE, Lingrel JB. Molecular cloning of the rat stomach (H++ K+)-ATPase. J Biol Chem. 1986; 261:16788-16791. [PubMed: 3023364]

467. Shull GE, Schwartz A, Lingrel JB. Amino-acid sequence of the catalytic subunit of the (Na+ + K +)ATPase deduced from a complementary DNA. Nature. 1985; 316:691-695. [PubMed: 2993903]

468. Silverman, M. Glucose reabsorption in the kidney:glucouria: molecular mechanism of $\mathrm{Na}+$ / glucose cotransport. In: Alpern, RJ.; Hebert, SC., editors. Seldin and Giebisch's The Kidney: Physiology and Pathophysiology. London: Academic Press; 2008.

469. Sindic A, Chang MH, Mount DB, Romero MF. Renal physiology of SLC26 anion exchangers. Curr Opin Nephrol Hypertens. 2007; 16:484-490. [PubMed: 17693766]

470. Skou JC. The influence of some cations on an adenosine triphosphatase from peripheral nerves. Biochim Biophys Acta. 1957; 23:394-401. [PubMed: 13412736]

471. Sly WS, Hewett-Emmett D, Whyte MP, Yu YS, Tashian RE. Carbonic anhydrase II deficiency identified as the primary defect in the autosomal recessive syndrome of osteopetrosis with renal tubular acidosis and cerebral calcification. Proc Natl Acad Sci U S A. 1983; 80:2752-2756. [PubMed: 6405388]

472. Sly WS, Hu PY. Human carbonic anhydrases and carbonic anhydrase deficiencies. Annu Rev Biochem. 1995; 64:375-401. 375-401. [PubMed: 7574487]

473. Sly WS, Whyte MP, Sundaram V, Tashian RE, Hewett-Emmett D, Guibaud P, Vainsel M, Baluarte HJ, Gruskin A, Al-Mosawi M. Carbonic anhydrase II deficiency in 12 families with the autosomal recessive syndrome of osteopetrosis with renal tubular acidosis and cerebral calcification. N Engl J Med. 1985; 313:139-145. [PubMed: 3925334]

474. Smith, HW. The Kidney: Structure and Function in Health and Disease. New York: Oxford University Press; 1951. p. 460-495.

475. Soleimani M, Singh G, Bizal GL, Gullans SR, McAteer JA. Na+/H+ exchanger isoforms NHE-2 and NHE-1 in inner medullary collecting duct cells. Expression, functional localization, and differential regulation. J Biol Chem. 1994; 269:27973-27978. [PubMed: 7961730] 
476. Solomon LR, Atherton JC, Bobinski H, Cottam SL, Gray C, Green R, Watts HJ. Effect of a meal containing protein on lithium clearance and plasma immunoreactive atrial natriuretic peptide in man. Clin Sci (Lond). 1988; 75:151-157. [PubMed: 2970361]

477. Sonnenberg H, Chong CK, Veress AT. Cardiac atrial factor--an endogenous diuretic? Can J Physiol Pharmacol. 1981; 59:1278-1279. [PubMed: 7337882]

478. Sonnenberg H, Cupples WA, de Bold AJ, Veress AT. Intrarenal localization of the natriuretic effect of cardiac atrial extract. Can J Physiol Pharmacol. 1982; 60:1149-1152. [PubMed: 7151010]

479. Sonnenberg H, Honrath U, Chong CK, Wilson DR. Atrial natriuretic factor inhibits sodium transport in medullary collecting duct. Am J Physiol. 1986; 250:F963-F966. [PubMed: 2940876]

480. Sorensen SS, Madsen JK, Pedersen EB. Systemic and renal effect of intravenous infusion of endothelin-1 in healthy human volunteers. Am J Physiol. 1994; 266:F411-F418. [PubMed: 8160789]

481. Souster LP, Emery JL. The sizes of renal glomeruli in fetuses and infants. J Anat. 1980; 130:595602. [PubMed: 7410201]

482. Staudacher T, Pech B, Tappe M, Gross G, Muhlbauer B, Luippold G. Arterial blood pressure and renal sodium excretion in dopamine D3 receptor knockout mice. Hypertens Res. 2007; 30:93101. [PubMed: 17460376]

483. Steele TH, Manuel MA, Newton M, Boner G. Renal lithium reabsorption in man: physiologic and pharmacologic determinants. Am J Med Sci. 1975; 269:349-363. [PubMed: 1171618]

484. Stein JH, Reineck JH, Osgood RW, Ferris TF. Effect of acetylcholine on proximal tubular sodium reabsorption in the dog. Am J Physiol. 1971; 220:227-232. [PubMed: 5538656]

485. Sterio DC. The unbiased estimation of number and sizes of arbitrary particles using the disector. J Microsc. 1984; 134:127-136. [PubMed: 6737468]

486. Su Z, Zimpelmann J, Burns KD. Angiotensin-(1-7) inhibits angiotensin II-stimulated phosphorylation of MAP kinases in proximal tubular cells. Kidney Int. 2006; 69:2212-2218. [PubMed: 16672906]

487. Sun D, Wilborn TW, Schafer JA. Dopamine D4 receptor isoform mRNA and protein are expressed in the rat cortical collecting duct. Am J Physiol. 1998; 275:F742-F751. [PubMed: 9815131]

488. Szabo AJ, Muller V, Chen GF, Samsell LJ, Erdely A, Baylis C. Nephron number determines susceptibility to renal mass reduction-induced CKD in Lewis and Fisher 344 rats: implications for development of experimentally induced chronic allograft nephropathy. Nephrol Dial Transplant. 2008; 23:2492-2495. [PubMed: 18332065]

489. Takada T, Yamamoto A, Omori K, Tashiro Y. Quantitative immunogold localization of Na, KATPase along rat nephron. Histochemistry. 1992; 98:183-197. [PubMed: 1333463]

490. Takemoto F, Uchida S, Ogata E, Kurokawa K. Endothelin-1 and endothelin-3 binding to rat nephrons. Am J Physiol. 1993; 264:F827-F832. [PubMed: 8498535]

491. Tang SS, Jung F, Diamant D, Brown D, Bachinsky D, Hellman P, Ingelfinger JR. Temperaturesensitive SV40 immortalized rat proximal tubule cell line has functional renin-angiotensin system. Am J Physiol. 1995; 268:F435-F446. [PubMed: 7900843]

492. Taylor A, Windhager EE. Possible role of cytosolic calcium and Na-Ca exchange in regulation of transepithelial sodium transport. Am J Physiol. 1979; 236:F505-F512. [PubMed: 375753]

493. Tendron A, Decramer S, Justrabo E, Gouyon JB, Semama DS, Gilbert T. Cyclosporin A administration during pregnancy induces a permanent nephron deficit in young rabbits. J Am Soc Nephrol. 2003; 14:3188-3196. [PubMed: 14638917]

494. Thomsen K. Lithium clearance: a new method for determining proximal and distal tubular reabsorption of sodium and water. Nephron. 1984; 37:217-223. [PubMed: 6379482]

495. Thomsen K, Holstein-Rathlou NH, Leyssac PP. Comparison of three measures of proximal tubular reabsorption: lithium clearance, occlusion time, and micropuncture. Am J Physiol. 1981; 241:F348-F355. [PubMed: 7315960]

496. Thomsen K, Olesen OV. Renal lithium clearance as a measure of the delivery of water and sodium from the proximal tubule in humans. Am J Med Sci. 1984; 288:158-161. [PubMed: 6496561] 
497. Thomson SC, Blantz RC. Glomerulotubular balance, tubuloglomerular feedback, and salt homeostasis. J Am Soc Nephrol. 2008; 19:2272-2275. [PubMed: 18322161]

498. Thomson SC, Deng A, Wead L, Richter K, Blantz RC, Vallon V. An unexpected role for angiotensin II in the link between dietary salt and proximal reabsorption. J Clin Invest. 2006; 116:1110-1116. [PubMed: 16557296]

499. Torielli L, Tivodar S, Montella RC, Iacone R, Padoani G, Tarsini P, Russo O, Sarnataro D, Strazzullo P, Ferrari P, Bianchi G, Zurzolo C. alpha-Adducin mutations increase Na/K pump activity in renal cells by affecting constitutive endocytosis: implications for tubular $\mathrm{Na}$ reabsorption. Am J Physiol Renal Physiol. 2008; 295:F478-F487. [PubMed: 18524856]

500. Tse CM, Brant SR, Walker MS, Pouyssegur J, Donowitz M. Cloning and sequencing of a rabbit cDNA encoding an intestinal and kidney-specific Na+/H+ exchanger isoform (NHE-3). J Biol Chem. 1992; 267:9340-9346. [PubMed: 1374392]

501. Tse CM, Levine SA, Yun CH, Brant SR, Pouyssegur J, Montrose MH, Donowitz M. Functional characteristics of a cloned epithelial $\mathrm{Na}+\mathrm{H}+$ exchanger (NHE3): resistance to amiloride and inhibition by protein kinase C. Proc Natl Acad Sci U S A. 1993; 90:9110-9114. [PubMed: 8415663]

502. Tse CM, Levine SA, Yun CH, Montrose MH, Little PJ, Pouyssegur J, Donowitz M. Cloning and expression of a rabbit cDNA encoding a serum-activated ethylisopropylamiloride-resistant epithelial Na+/H+ exchanger isoform (NHE-2). J Biol Chem. 1993; 268:11917-11924. [PubMed: 7685025]

503. Tse CM, Ma AI, Yang VW, Watson AJ, Levine S, Montrose MH, Potter J, Sardet C, Pouyssegur J, Donowitz M. Molecular cloning and expression of a cDNA encoding the rabbit ileal villus cell basolateral membrane Na+/H+ exchanger. EMBO J. 1991; 10:1957-1967. [PubMed: 1712287]

504. Tsuruoka S, Kittelberger AM, Schwartz GJ. Carbonic anhydrase II and IV mRNA in rabbit nephron segments: stimulation during metabolic acidosis. Am J Physiol. 1998; 274:F259-F267. [PubMed: 9486220]

505. Tucker BJ, Blantz RC. Determinants of proximal tubular reabsorption as mechanisms of glomerulotubular balance. Am J Physiol. 1978; 235:F142-F150. [PubMed: 686177]

506. Turner RJ, Moran A. Heterogeneity of sodium-dependent D-glucose transport sites along the proximal tubule: evidence from vesicle studies. Am J Physiol. 1982; 242:F406-F414. [PubMed: 6278960]

507. Uchida S, Takemoto F, Ogata E, Kurokawa K. Detection of endothelin-1 mRNA by RT-PCR in isolated rat renal tubules. Biochem Biophys Res Commun. 1992; 188:108-113. [PubMed: 1384475]

508. Uchida S, Takemoto F, Ogata E, Kurokawa K. Endothelin-1 and-3 binding to ETB receptors in rat renal tubules. J Cardiovasc Pharmacol. 1993; 22(Suppl 8):S177-S180. [PubMed: 7509937]

509. Ujiie K, Terada Y, Nonoguchi H, Shinohara M, Tomita K, Marumo F. Messenger RNA expression and synthesis of endothelin-1 along rat nephron segments. J Clin Invest. 1992; 90:1043-1048. [PubMed: 1522212]

510. Ullrich, KJ.; Greger, R. Approaches to the study of tubular transport functions. In: Seldin, DW.; Giebisch, G., editors. The Kidney: Physiology and Pathophysiology. New York: Raven Press; 1985.

511. Ullrich KJ, Rumrich G, Kloss S. Specificity and sodium dependence of the active sugar transport in the proximal convolution of the rat kidney. Pflugers Arch. 1974; 351:35-48. [PubMed: 4472834]

512. Ussing HH, Eskesen K. Mechanism of isotonic water transport in glands. Acta Physiol Scand. 1989; 136:443-454. [PubMed: 2473601]

513. Ussing HH, Lind F, Larsen EH. Ion secretion and isotonic transport in frog skin glands. J Membr Biol. 1996; 152:101-110. [PubMed: 9139121]

514. Vallon V. Micropuncturing the nephron. Pflugers Arch. 2009; 458:189-201. [PubMed: 18752000]

515. Vallon V. The proximal tubule in the pathophysiology of the diabetic kidney. Am J Physiol Regul Integr Comp Physiol. 2011; 300:R1009-R1022. [PubMed: 21228342] 
516. Vallon V, Platt KA, Cunard R, Schroth J, Whaley J, Thomson SC, Koepsell H, Rieg T. SGLT2 mediates glucose reabsorption in the early proximal tubule. J Am Soc Nephrol. 2011; 22:104112. [PubMed: 20616166]

517. Vallon V, Verkman AS, Schnermann J. Luminal hypotonicity in proximal tubules of aquaporin-1knockout mice. Am J Physiol Renal Physiol. 2000; 278:F1030-F1033. [PubMed: 10836992]

518. van Kats JP, Schalekamp MA, Verdouw PD, Duncker DJ, Danser AH. Intrarenal angiotensin II: interstitial and cellular levels and site of production. Kidney Int. 2001; 60:2311-2317. [PubMed: 11737604]

519. Vives D, Farage S, Motta R, Lopes AG, Caruso-Neves C. Atrial natriuretic peptides and urodilatin modulate proximal tubule $\mathrm{Na}(+)$-ATPase activity through activation of the NPR-A/ cGMP/PKG pathway. Peptides. 2010; 31:903-908. [PubMed: 20206222]

520. Wade JB, Liu J, Coleman RA, Cunningham R, Steplock DA, Lee-Kwon W, Pallone TL, Shenolikar S, Weinman EJ. Localization and interaction of NHERF isoforms in the renal proximal tubule of the mouse. Am J Physiol Cell Physiol. 2003; 285:C1494-C1503. [PubMed: 12917102]

521. Wagner, CA.; Geibel, JP. Expression, function, and the regulation of Na+.K+-ATPase in the kidney. In: Alpern, RJ.; Hebert, SC., editors. Seldin and Giebisch's The Kidney: Physiology and Pathophysiology. London: Academic Press; 2008.

522. Wakabayashi S, Shigekawa M, Pouyssegur J. Molecular physiology of vertebrate Na+/H+ exchangers. Physiol Rev. 1997; 77:51-74. [PubMed: 9016300]

523. Walker AM, Bott PA, Oliver J, MacDowell MC. The collection and analysis of fluid from single nephrons of the mammalian kidney. Am J Physiol. 1941; 134:580-595.

524. Walker AM, Oliver J. Methods for the collection of fluid from single glomeruli and tubules of the mammalian kidney. Am J Physiol. 1941; 134:562-579.

525. Walter R, Helmle-Kolb C, Forgo J, Binswanger U, Murer H. Stimulation of Na+/H+ exchange activity by endothelin in opossum kidney cells. Pflugers Arch. 1995; 430:137-144. [PubMed: 7545278]

526. Wang D, Zhang H, Lang F, Yun CC. Acute activation of NHE3 by dexamethasone correlates with activation of SGK1 and requires a functional glucocorticoid receptor. Am J Physiol Cell Physiol. 2007; 292:C396-C404. [PubMed: 16971495]

527. Wang T. Flow-activated transport events along the nephron. Curr Opin Nephrol Hypertens. 2006; 15:530-536. [PubMed: 16914967]

528. Wang T, Chan YL. Mechanism of angiotensin II action on proximal tubular transport. J Pharmacol Exp Ther. 1990; 252:689-695. [PubMed: 2313594]

529. Wang T, Chan YL. The role of phosphoinositide turnover in mediating the biphasic effect of angiotensin II on renal tubular transport. J Pharmacol Exp Ther. 1991; 256:309-317. [PubMed: 1846421]

530. Wang T, Yang CL, Abbiati T, Schultheis PJ, Shull GE, Giebisch G, Aronson PS. Mechanism of proximal tubule bicarbonate absorption in NHE3 null mice. Am J Physiol. 1999; 277:F298F302. [PubMed: 10444585]

531. Wang X, Armando I, Upadhyay K, Pascua A, Jose PA. The regulation of proximal tubular salt transport in hypertension: an update. Curr Opin Nephrol Hypertens. 2009; 18:412-420. [PubMed: 19654544]

532. Wang Z, Orlowski J, Shull GE. Primary structure and functional expression of a novel gastrointestinal isoform of the rat $\mathrm{Na} / \mathrm{H}$ exchanger. J Biol Chem. 1993; 268:11925-11928. [PubMed: 7685026]

533. Wang ZQ, Felder RA, Carey RM. Selective inhibition of the renal dopamine subtype D1A receptor induces antinatriuresis in conscious rats. Hypertension. 1999; 33:504-510. [PubMed: 9931156]

534. Weinman EJ, Cunningham R, Shenolikar S. NHERF and regulation of the renal sodium-hydrogen exchanger NHE3. Pflugers Arch. 2005; 450:137-144. [PubMed: 15742180]

535. Weinman EJ, Cunningham R, Wade JB, Shenolikar S. The role of NHERF-1 in the regulation of renal proximal tubule sodium-hydrogen exchanger 3 and sodium-dependent phosphate cotransporter 2a. J Physiol. 2005; 567:27-32. [PubMed: 15932893] 
536. Weinman EJ, Shenolikar S. Regulation of the renal brush border membrane $\mathrm{Na}(+)-\mathrm{H}+$ exchanger. Annu Rev Physiol. 1993; 55:289-304. [PubMed: 8385434]

537. Weinstein, AM. Sodium and chloride transport: proximal nephron. In: Alpern, RJ.; Hebert, SC., editors. Seldin and Giebisch's The Kidney: Physiology and Pathophysiology. London: Academic Press; 2008.

538. Wendel M, Knels L, Kummer W, Koch T. Distribution of endothelin receptor subtypes ETA and ETB in the rat kidney. J Histochem Cytochem. 2006; 54:1193-1203. [PubMed: 16835394]

539. Wesson LG. Glomerulotubular balance: history of a name. Kidney Int. 1973; 4:236-238. [PubMed: 4750914]

540. Wesson LG Jr, ANSLOW WP Jr, Smith HW. The excretion of strong electrolytes. Bull N Y Acad Med. 1948; 24:586-606. [PubMed: 18879167]

541. Wesson LG, Anslow WP, Smith HW. The excretion of strong electrolytes. Bull NY Acad Med. 1948; 24:586-606.

542. Wesson LG, Anslow WP Jr, Smith HW. The renal excretion of strong electrolytes. Fed Proc. 1948; 7:132. [PubMed: 18934659]

543. Wetzel RK, Sweadner KJ. Immunocytochemical localization of Na-K-ATPase alpha- and gamma-subunits in rat kidney. Am J Physiol Renal Physiol. 2001; 281:F531-F545. [PubMed: 11502602]

544. Whittembury G, Windhager EE. Electrical potential difference measurements in perfused single proximal tubules of Necturus kidney. J Gen Physiol. 1961; 44:679-687. [PubMed: 13784944]

545. Wiederholt M, Hierholzer K, Windhager EE, Giebisch G. Microperfusion study of fluid reabsorption in proximal tubules of rat kidneys. Am J Physiol. 1967; 213:809-818. [PubMed: 6036804]

546. Wilcox, CS.; Baylis, C.; Wingo, CS. Glomerular-tubular balance and proximal regulation. In: Seldin, DW.; Giebisch, G., editors. The Kidney: Physiology and Pathophysiology. New York: Raven Press; 1992.

547. Wilcox CS, Welch WJ, Schreiner GF, Belardinelli L. Natriuretic and diuretic actions of a highly selective adenosine A1 receptor antagonist. J Am Soc Nephrol. 1999; 10:714-720. [PubMed: 10203354]

548. Wilkes BM, Susin M, Mento PF, Macica CM, Girardi EP, Boss E, Nord EP. Localization of endothelin-like immunoreactivity in rat kidneys. Am J Physiol. 1991; 260:F913-F920. [PubMed: 2058711]

549. Winghager EE. Glomerulo-tubular balance of sale and water. Physiologist. 1968; 11:103-114. [PubMed: 5655971]

550. Woo AL, Noonan WT, Schultheis PJ, Neumann JC, Manning PA, Lorenz JN, Shull GE. Renal function in NHE3-deficient mice with transgenic rescue of small intestinal absorptive defect. Am J Physiol Renal Physiol. 2003; 284:F1190-F1198. [PubMed: 12582007]

551. Woodhall PB, Tisher CC, Simonton CA, Robinson RR. Relationship between paraaminohippurate secretion and cellular morphology in rabbit proximal tubules. J Clin Invest. 1978; 61:1320-1329. [PubMed: 659594]

552. Wright EM. Renal Na(+)-glucose cotransporters. Am J Physiol Renal Physiol. 2001; 280:F10_ F18. [PubMed: 11133510]

553. Wright EM, Loo DD, Hirayama BA. Biology of human sodium glucose transporters. Physiol Rev. 2011; 91:733-794. [PubMed: 21527736]

554. Wu MS, Biemesderfer D, Giebisch G, Aronson PS. Role of NHE3 in mediating renal brush border Na+-H+ exchange. Adaptation to metabolic acidosis. J Biol Chem. 1996; 271:32749_ 32752. [PubMed: 8955109]

555. Xu H, Chen R, Ghishan FK. Subcloning, localization, and expression of the rat intestinal sodiumhydrogen exchanger isoform 8. Am J Physiol Gastrointest Liver Physiol. 2005; 289:G36-G41. [PubMed: 15731506]

556. Xu J, Li G, Wang P, Velazquez H, Yao X, Li Y, Wu Y, Peixoto A, Crowley S, Desir GV. Renalase is a novel, soluble monoamine oxidase that regulates cardiac function and blood pressure. J Clin Invest. 2005; 115:1275-1280. [PubMed: 15841207] 
557. Yamaguchi I, Jose PA, Mouradian MM, Canessa LM, Monsma FJ Jr, Sibley DR, Takeyasu K, Felder RA. Expression of dopamine D1A receptor gene in proximal tubule of rat kidneys. Am J Physiol. 1993; 264:F280-F285. [PubMed: 8447437]

558. Yamamoto T, Suzuki H, Kubo Y, Matsumoto A, Uemura H. Endothelin A receptor-like immunoreactivity on the basal infoldings of rat renal tubules and collecting ducts. Arch Histol Cytol. 2008; 71:77-87. [PubMed: 18974600]

559. Yamamoto T, Uemura H. Distribution of endothelin-B receptor-like immunoreactivity in rat brain, kidney, and pancreas. J Cardiovasc Pharmacol. 1998; 31(Suppl 1):S207-S211. [PubMed: 9595439]

560. Yanagisawa M, Kurihara H, Kimura S, Tomobe Y, Kobayashi M, Mitsui Y, Yazaki Y, Goto K, Masaki T. A novel potent vasoconstrictor peptide produced by vascular endothelial cells. Nature. 1988; 332:411-415. [PubMed: 2451132]

561. Yingst DR, Araghi A, Doci TM, Mattingly R, Beierwaltes WH. Decreased renal perfusion rapidly increases plasma membrane Na-K-ATPase in rat cortex by an angiotensin II-dependent mechanism. Am J Physiol Renal Physiol. 2009; 297:F1324-F1329. [PubMed: 19726543]

562. Yingst DR, Massey KJ, Rossi NF, Mohanty MJ, Mattingly RR. Angiotensin II directly stimulates activity and alters the phosphorylation of Na-K-ATPase in rat proximal tubule with a rapid time course. Am J Physiol Renal Physiol. 2004; 287:F713-F721. [PubMed: 15161602]

563. Yingst DR, Polasek PM. Sensitivity and reversibility of Ca-dependent inhibition of the (Na++ K + )-ATPase of human red blood cells. Biochim Biophys Acta. 1985; 813:282-286. [PubMed: 2982403]

564. You G, Lee WS, Barros EJ, Kanai Y, Huo TL, Khawaja S, Wells RG, Nigam SK, Hediger MA. Molecular characteristics of $\mathrm{Na}(+)$-coupled glucose transporters in adult and embryonic rat kidney. J Biol Chem. 1995; 270:29365-29371. [PubMed: 7493971]

565. Yu C, Yang Z, Ren H, Zhang Y, Han Y, He D, Lu Q, Wang X, Wang X, Yang C, Asico LD, Hopfer U, Eisner GM, Jose PA, Zeng C. D3 dopamine receptor regulation of ETB receptors in renal proximal tubule cells from WKY and SHRs. Am J Hypertens. 2009; 22:877-883. [PubMed: 19390510]

566. Yu P, Asico LD, Luo Y, Andrews P, Eisner GM, Hopfer U, Felder RA, Jose PA. D1 dopamine receptor hyperphosphorylation in renal proximal tubules in hypertension. Kidney Int. 2006; 70:1072-1079. [PubMed: 16850019]

567. Yun CH, Tse CM, Nath SK, Levine SA, Brant SR, Donowitz M. Mammalian Na+/H+ exchanger gene family: structure and function studies. Am J Physiol. 1995; 269:G1-G11. [PubMed: 7631785]

568. Zeidel ML, Seifter JL, Lear S, Brenner BM, Silva P. Atrial peptides inhibit oxygen consumption in kidney medullary collecting duct cells. Am J Physiol. 1986; 251:F379-F383. [PubMed: 3017127]

569. Zeng C, Asico LD, Wang X, Hopfer U, Eisner GM, Felder RA, Jose PA. Angiotensin II regulation of AT1 and D3 dopamine receptors in renal proximal tubule cells of SHR. Hypertension. 2003; 41:724-729. [PubMed: 12623987]

570. Zeng C, Jose PA. Dopamine receptors: important antihypertensive counterbalance against hypertensive factors. Hypertension. 2011; 57:11-17. [PubMed: 21098313]

571. Zeng C, Liu Y, Wang Z, He D, Huang L, Yu P, Zheng S, Jones JE, Asico LD, Hopfer U, Eisner GM, Felder RA, Jose PA. Activation of D3 dopamine receptor decreases angiotensin II type 1 receptor expression in rat renal proximal tubule cells. Circ Res. 2006; 99:494-500. [PubMed: 16902178]

572. Zeng C, Zhang M, Asico LD, Eisner GM, Jose PA. The dopaminergic system in hypertension. Clin Sci (Lond). 2007; 112:583-597. [PubMed: 17492945]

573. Zhang J, Ren C, Chen L, Navedo MF, Antos LK, Kinsey SP, Iwamoto T, Philipson KD, Kotlikoff MI, Santana LF, Wier WG, Matteson DR, Blaustein MP. Knockout of $\mathrm{Na}+\mathrm{Ca} 2+$ exchanger in smooth muscle attenuates vasoconstriction and L-type Ca2+ channel current and lowers blood pressure. Am J Physiol Heart Circ Physiol. 2010; 298:H1472-H1483. [PubMed: 20173044]

Compr Physiol. Author manuscript; available in PMC 2014 July 01. 
574. Zhao D, Zhang J, Blaustein MP, Navar LG. Attenuated renal vascular responses to acute angiotensin II infusion in smooth muscle specific $\mathrm{Na}+/ \mathrm{Ca} 2+$ exchanger knockout mice. Am J Physiol Renal Physiol. 2011; 301(3):F574-F579. [PubMed: 21697239]

575. Zhou Y, Bouyer P, Boron WF. Role of the AT1A receptor in the CO2-induced stimulation of HCO3- reabsorption by renal proximal tubules. Am J Physiol Renal Physiol. 2007; 293:F110 F120. [PubMed: 17356125]

576. Zhu Y, Wang DH. Segmental regulation of sodium and water excretion by TRPV1 activation in the kidney. J Cardiovasc Pharmacol. 2008; 51:437-442. [PubMed: 18398380]

577. Zhuo JL, Alcorn D, Harris PJ, Mendelsohn FA. Localization and properties of angiotensin II receptors in rat kidney. Kidney Int Suppl. 1993; 42:S40-S46. [PubMed: 8361127]

578. Zhuo, JL.; Allen, AM.; Alcorn, D.; MacGregor, D.; Aldred, GP.; Mendelsohn, FA. The distribution of angiotensin II receptors. In: Laragh, JH.; Brenner, BM., editors. Hypertension: Pathology, Diagnosis \& Management. 2nd Edition. Vol. 1. New York: Raven Press; 1995. p. 1739-1762.

579. Zhuo JL, Dean R, MacGregor D, Alcorn D, Mendelsohn FA. Presence of angiotensin II AT2 receptor binding sites in the adventitia of human kidney vasculature. Clin Exp Pharmacol Physiol Suppl. 1996; 3:S147-S154. [PubMed: 8993855]

580. Zhuo, JL.; Dean, R.; Maric, C.; Alcorn, D.; Harris, P.; Mendelsohn, FA. Localization and roles of angiotensin, endothelin and bradykinin receptors in interstitial cells of the renal medulla. In: Ulfendahl, H.; Aurell, M., editors. Wenner-Gren Foundation International Symposium: ReninAngiotensin; 1998. p. 221-235.

581. Zhuo JL, Dean R, Maric C, Aldred PG, Harris P, Alcorn D, Mendelsohn FA. Localization and interactions of vasoactive peptide receptors in renomedullary interstitial cells of the kidney. Kidney Int Suppl. 1998; 67:S22-S28. [PubMed: 9736248]

582. Zhuo JL, Harris PJ, Skinner SL. Modulation of proximal tubular reabsorption by angiotensin II. Clin Exp Pharmacol Physiol. 1986; 13:277-281. [PubMed: 3015459]

583. Zhuo, JL.; Mendelsohn, FA. Intrarenal Angiotensin II Receptors. In: Robertson, JIS.; Nicholls, MG., editors. The Renin-Angiotensin System: Biochemistry, Pathophysiology and Therapeutics. Vol. 1. London \& New York: Gower Medical Publishing; 1993. p. 25.1-25.14.

584. Zhuo J, Moeller I, Jenkins T, Chai SY, Allen AM, Ohishi M, Mendelsohn FA. Mapping tissue angiotensin-converting enzyme and angiotensin AT1, AT2 and AT4 receptors. J Hypertens. 1998; 16:2027-2037. [PubMed: 9886893]

585. Zhuo, JL.; Song, K.; Chai, SY.; Mendelsohn, FA. Anatomical localization of components of the renin-angiotensin system in different organs and tissues. In: MacGregor, GA.; Sever, PS., editors. Inhibition of the Renin-Angiotensin System: Recent Advances. Hong Kong: Gardiner-Calwell Communications (Pacific) Ltd.; 1993. p. 17-25.

586. Zhuo JL, Song K, Harris PJ, Mendelsohn FA. In vitro autoradiography reveals predominantly AT1 angiotensin II receptors in rat kidney. Ren Physiol Biochem. 1992; 15:231-239. [PubMed: 1279763]

587. Zhuo JL, Thomas D, Harris PJ, Skinner SL. The role of endogenous angiotensin II in the regulation of renal haemodynamics and proximal fluid reabsorption in the rat. J Physiol. 1992; 453:1-13. [PubMed: 1464825]

588. Zhuo JL. Renomedullary interstitial cells: a target for endocrine and paracrine actions of vasoactive peptides in the renal medulla. Clin Exp Pharmacol Physiol. 2000; 27:465-473. [PubMed: 10874500]

589. Zhuo JL, Harris PJ, Skinner SL. Atrial natriuretic factor modulates proximal glomerulotubular balance in anesthetized rats. Hypertension. 1989; 14:666-673. [PubMed: 2555304]

590. Zhuo JL, Li XC. Novel roles of intracrine angiotensin II and signalling mechanisms in kidney cells. J Renin Angiotensin Aldosterone Syst. 2007; 8:23-33. [PubMed: 17487823]

591. Zhuo JL, Li XC. New insights and perspectives on intrarenal renin-angiotensin system: Focus on intracrine/intracellular angiotensin II. Peptides. 2011; 32:1551-1565. [PubMed: 21699940]

592. Zhuo JL, Li XC, Garvin JL, Navar LG, Carretero OA. Intracellular angiotensin II induces cytosolic $\mathrm{Ca} 2+$ mobilization by stimulating intracellular AT1 receptors in proximal tubule cells. Am J Physiol Renal Physiol. 2006; 290:F1382-F1390. [PubMed: 16380461] 
593. Zimanyi MA, Hoy WE, Douglas-Denton RN, Hughson MD, Holden LM, Bertram JF. Nephron number and individual glomerular volumes in male Caucasian and African American subjects. Nephrol Dial Transplant. 2009; 24:2428-2433. [PubMed: 19297355]

594. Zimmerman RS, Schirger JA, Edwards BS, Schwab TR, Heublein DM, Burnett JC Jr. Cardiorenal-endocrine dynamics during stepwise infusion of physiologic and pharmacologic concentrations of atrial natriuretic factor in the dog. Circ Res. 1987; 61:63-69. [PubMed: 2955951] 


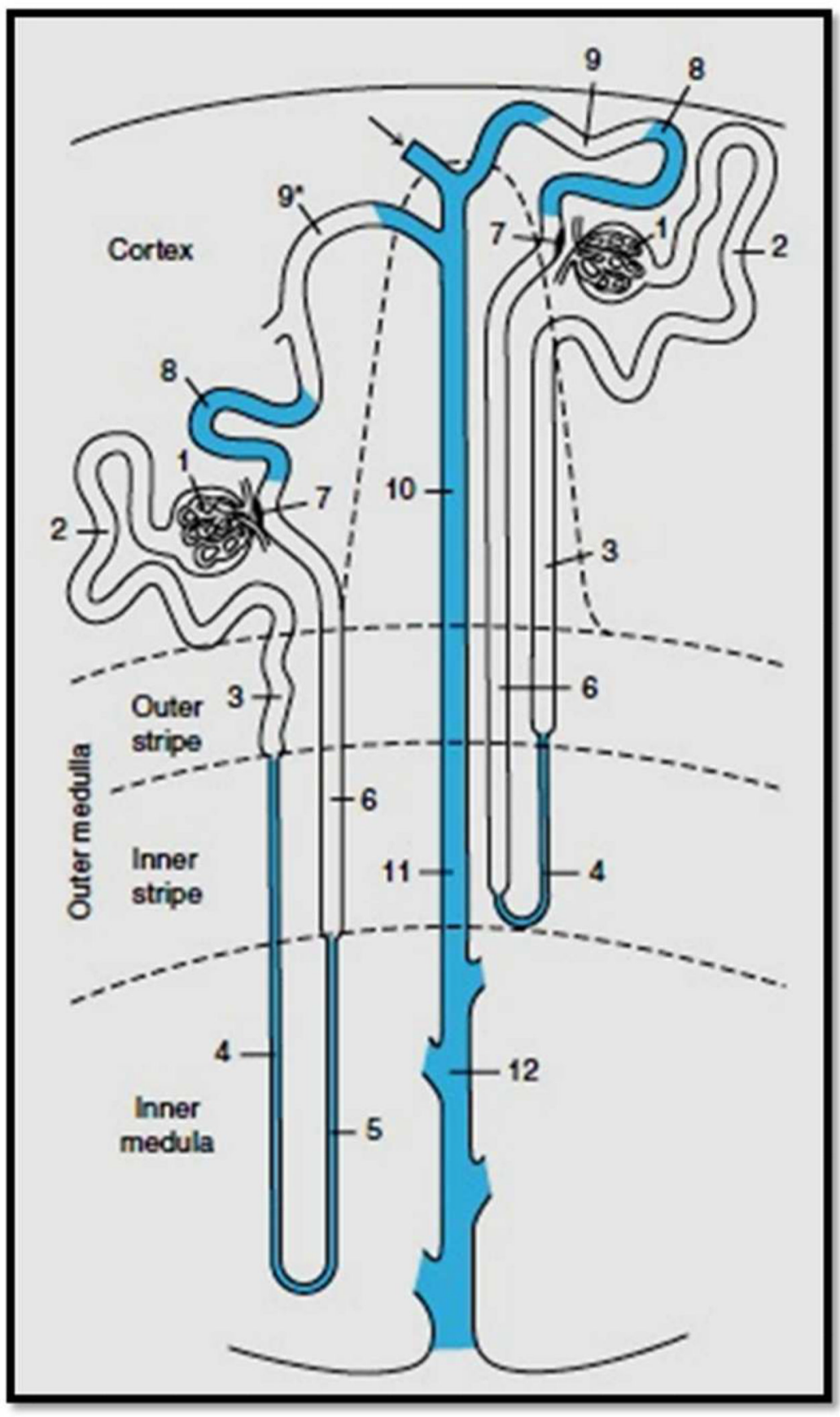

Figure 1.

Classification and localization of superficial (short-looped, upper) and juxtamedullary (longlooped, lower) nephrons, together with the collecting system. The cortical medullary ray is the part of the cortex that contains the straight proximal tubules, cortical thick ascending limbs, and cortical collecting ducts, delineated by a dashed line. 1, renal corpuscle (Bowman's capsule and the glomerulus); 2, proximal convoluted tubule; 3, proximal straight tubule; 4, descending thin limb; 5, ascending thin limb; 6, thick ascending limb; 7, macula densa (located within the final portion of the thick ascending limb); 8, distal convoluted tubule; 9 , connecting tubule; $9^{*}$, connecting tubule of a juxtamedullary nephron that arches upward to form a so-called arcade (there are only a few of these in the human kidney); 10 , 
cortical collecting duct; 11 , outer medullary collecting duct; 12 , inner medullary collecting duct. Reproduced with permission from Kriz W, Bankir L. (290). 


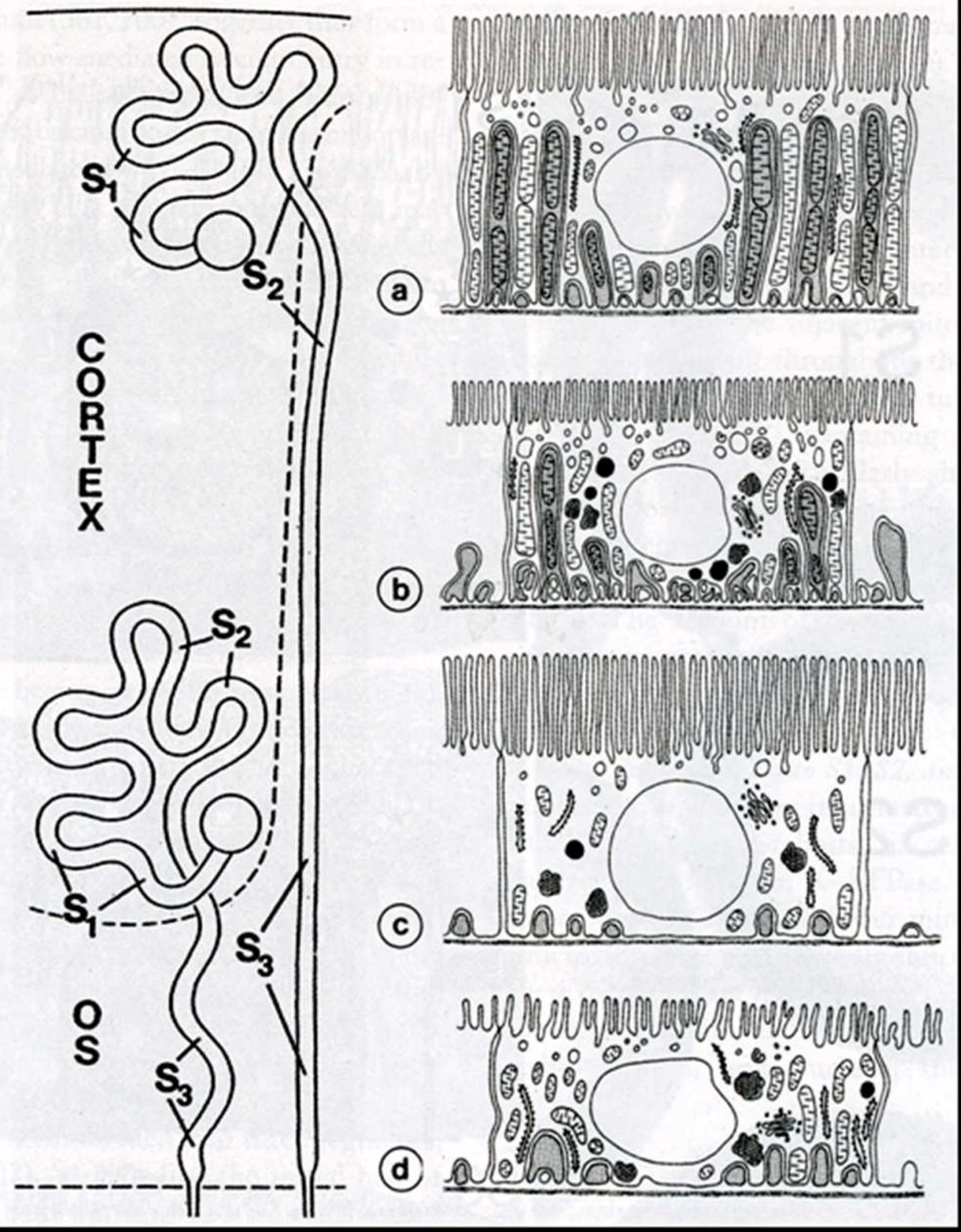

Figure 2.

Schematic location and ultrastructure of proximal tubular $S_{1}-S_{3}$ segments in superficial and juxtamedullary neprhons. For superficial nephrons, $S_{1}$ segments begin at the urinary pole of the renal corpuscle in the superficial cortex, transform gradually to $S_{2}$ segments within the labyrinth, and $S_{2}$ are transformed at different levels within the medullary rays. $S_{3}$ segments terminate at the border of the outer stripe (OS) to the inner stripe. For juxtamedullary nephrons, $S_{1}$ and $S_{2}$ segments start at the urinary pole of the renal corpuscle in the inner cortex, and S3 segments also terminate at the border of the outer stripe (OS) to the inner stripe. A): the S1 segment has the most extensive cellular interdigitation and dense brush border membranes. B): the vacuolar apparatus in the subapical cytoplasm, mitochondria, 
ER, Golgi apparatus, lysosomes, and peroxisomes in proximal tubule cells. C): the rabbit has tallest brush border microvilli in proximal tubule cells. D): many other species shows shortest microvilli in proximal tubule cells. Reproduced from Kriz and Kaissling with permission (291). 


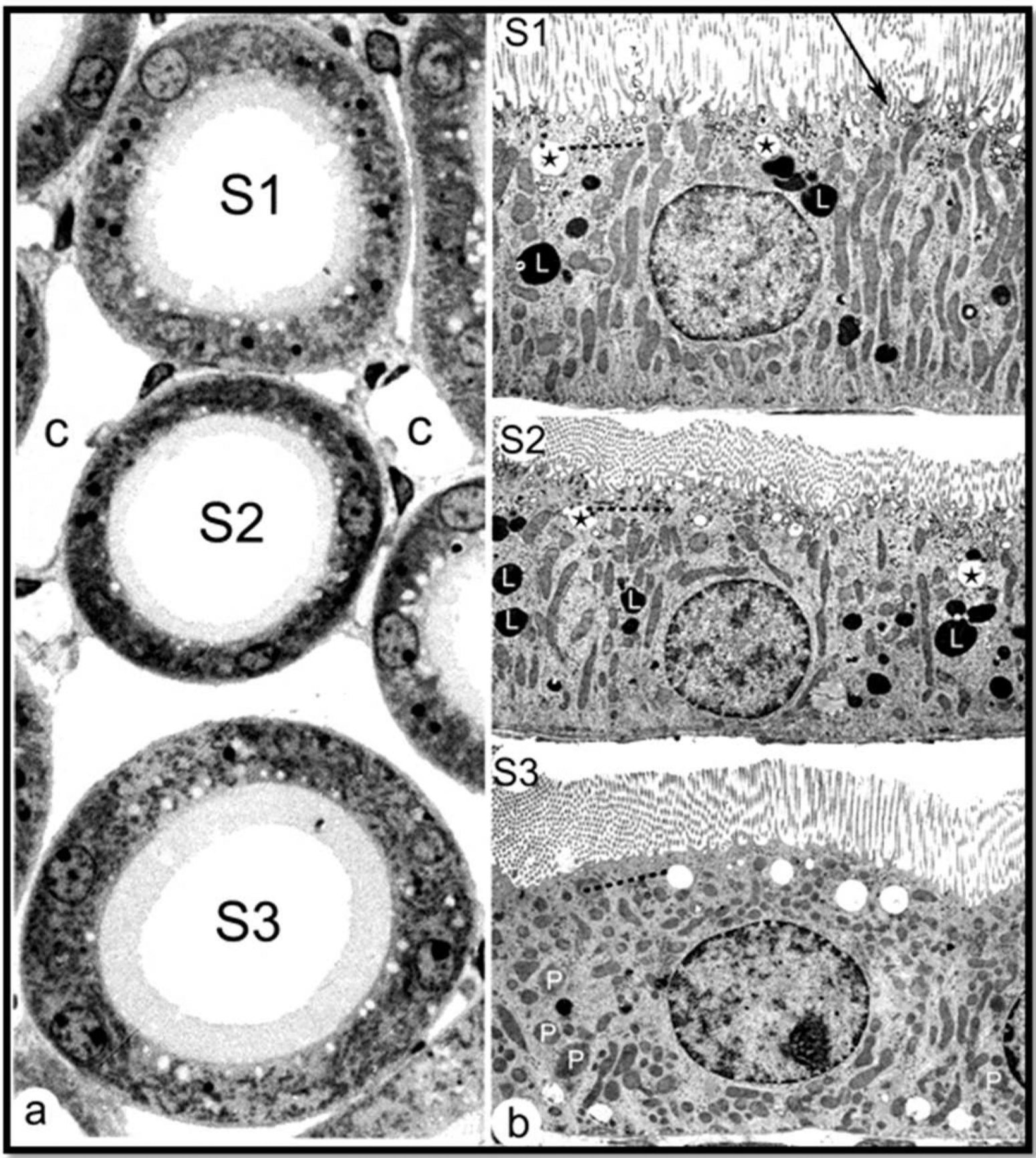

Figure 3.

Low resolution profiles and ultrastructures of proximal tubules in the rat kidney. A): profiles of S1, S2 and S3 segments of juxtamedullary proximal tubules with different brush border heights, cytoplasmic density, and outer diameters. Magnification: X 1000. B): ultrastructures of S1, S2 and S3 proximal tubular cells in the rat kidney. Note that the mitochondria in S1 and S2 are located in lateral cell processes, whereas in S3 they are mainly scattered throughout the cytoplasm. The endocytic apparatus is the subapical cytoplasm is most prominent in S1 and S2 segments (broken lines), whereas endosomes (stars) and lysosomes (L) are localized deeper in the cytoplasm. There are few vacuolar apparatus and lysosomes present in the $\mathrm{S} 3$ segment, but peroxisomes (P) are more frequent 
in this segment. C, capillaries. Magnification: $X \sim 5400$ from transmission electron microscopy. Reproduced from Kriz \& Kaissling with permission (290). 

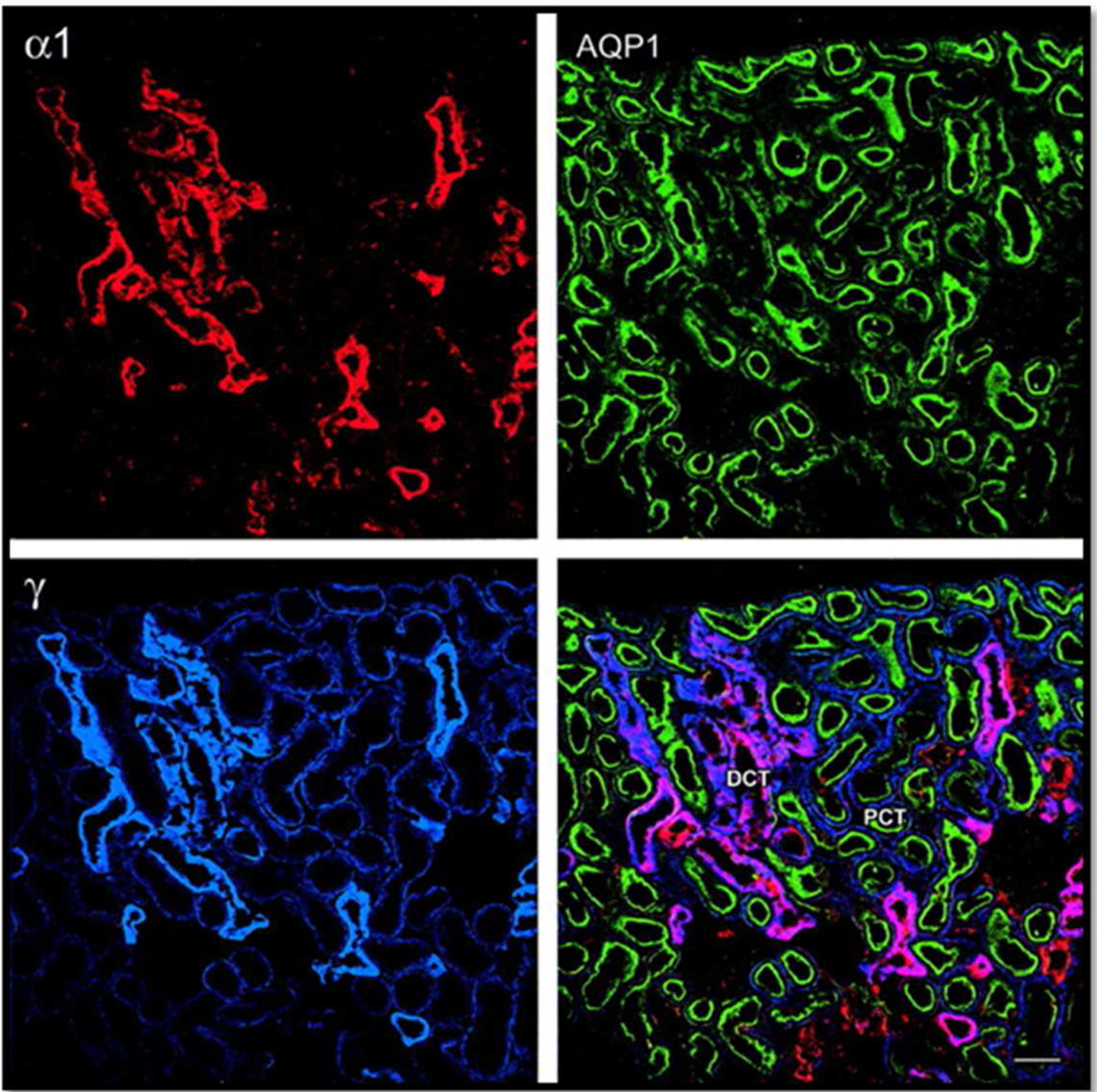

Figure 4.

Localization of $\mathrm{Na}^{+}-\mathrm{K}^{+}$-ATPase a 1- and $\gamma$-subunits and aquaporin-1 (AQP1) in the renal cortex. AQP1 was used as a marker of proximal tubule. Kidney cortex was triple labeled with a1- (red, TSA-Cy3), AQP1 (green, FITC), and $\gamma$-subunit (blue, Cy5) antibodies. Proximal segments containing AQP1 stain were lightly labeled with a 1- and $\gamma$-subunits (bottom right: merged image). Conversely, distal segments that were not labeled by the AQP1 antibody were brightly stained by a 1 - and $\gamma$-subunits (bottom right: merged image). Scale bar, $50 \mu \mathrm{m}$. Reproduced from Wetzel and Sweadner with permission (543). 


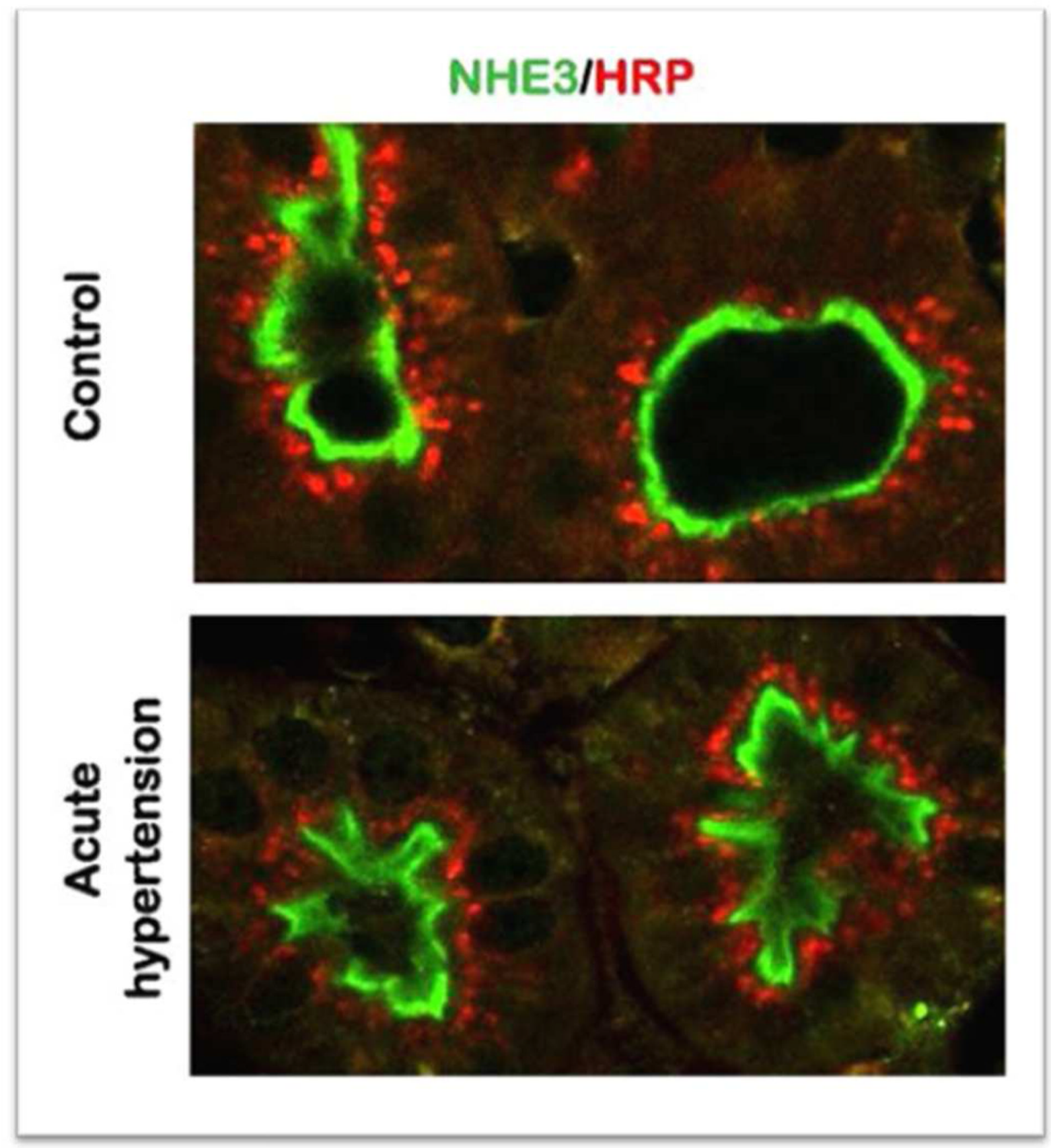

Figure 5.

Localization and redistribution of NHE3 during acute hypertension. The endocytic compartment of the proximal tubule was labeled by intravenous injection of horseradish peroxidase (HRP), and rats were sham operated (control), or blood pressure was increased for $20 \mathrm{~min}$ (acute hypertension). Kidneys were fixed in situ, sectioned, and double labeled with either polyclonal anti-NHE3 or monoclonal anti-HRP (red). NHE3 is retracted from the body to the base of the microvilli during acute hypertension, with no evidence that NHE3 moves into endocytic tracer HRP-labeled compartment. Reproduced from McDonough with permission (343). 

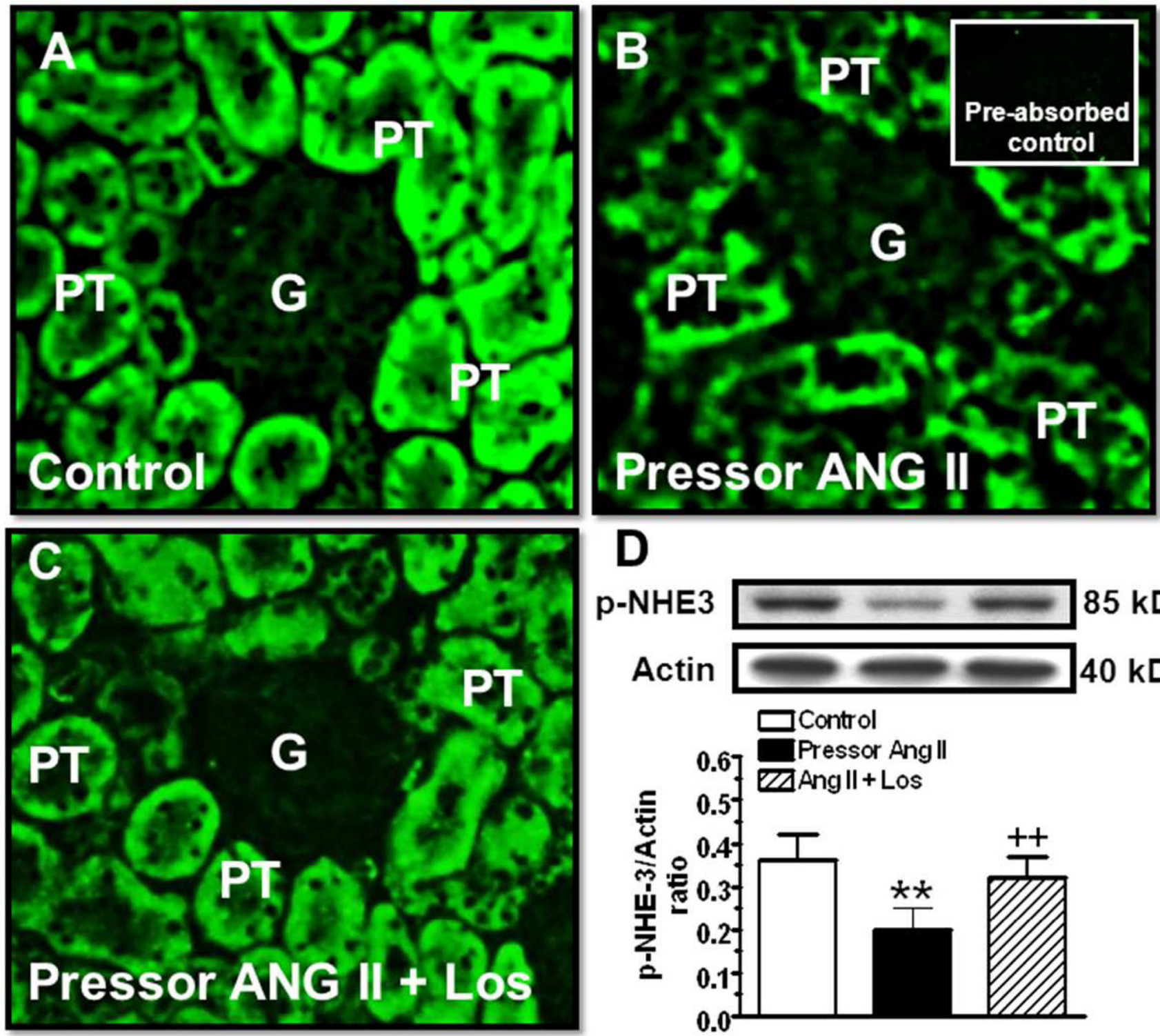

Figure 6.

Effects of 2 week infusion of a pressor dose of ANG II and concurrent losartan treatment on phosphorylated or activated NHE3 immunofluorescence staining (A-C, not quantitative) or phospho-NHE3 protein abundance in membrane fractions of proximal tubules of the rat kidney (semi-quantitative). $100 \mu \mathrm{g}$ proteins were loaded in each lane of western blot gels. $* p<0.05$ or $* * p<0.01$ vs. control; ${ }^{\dagger \dagger} p<0.01$ vs. ANG II-infused rats. Reproduced from Li and Zhuo (313). 

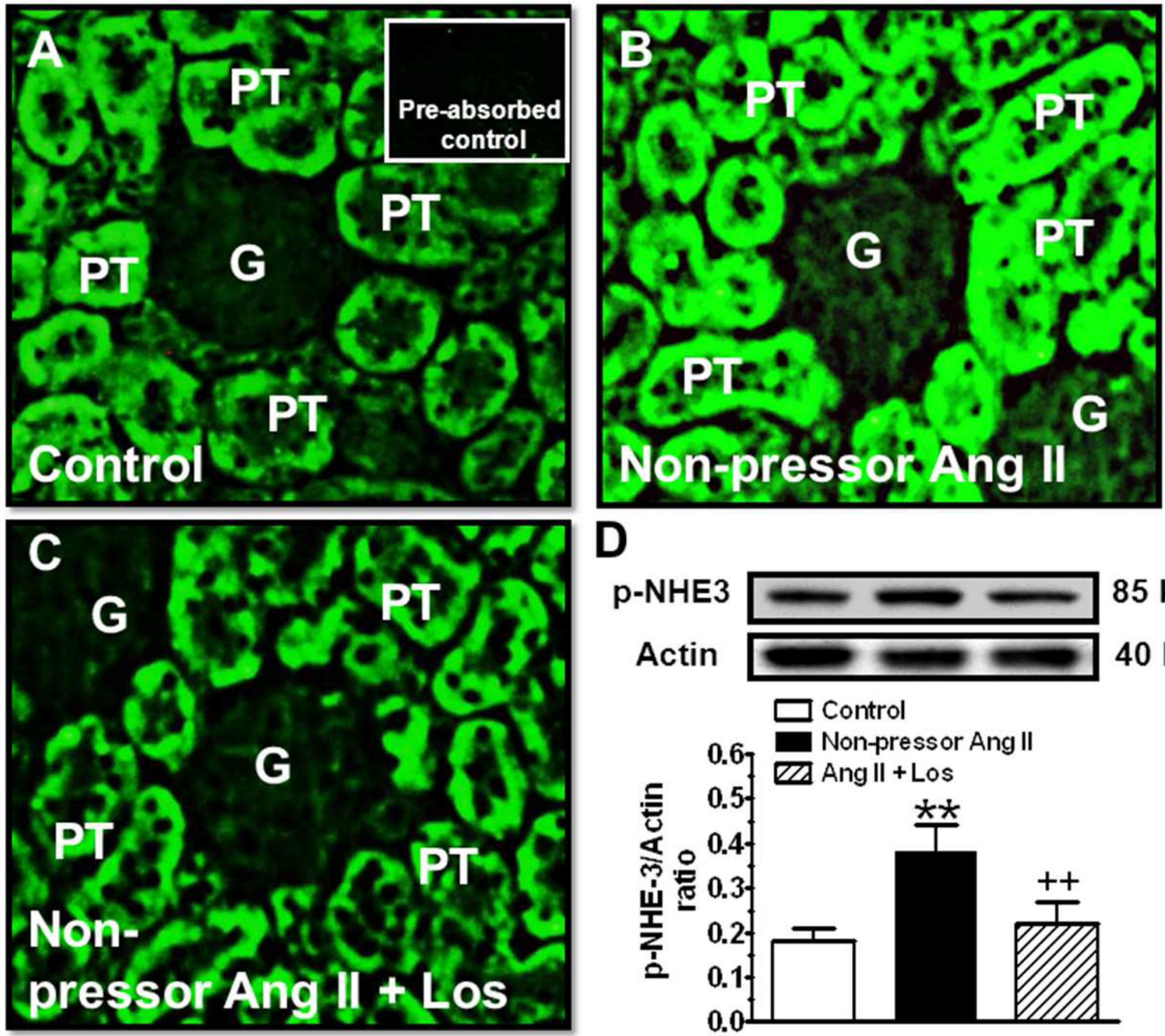

Figure 7.

Effects of 2 week infusion of the non-pressor dose of ANG II and concurrent losartan treatment on phosphorylated NHE3 immunofluorescence staining (A-C, not quantitative) or phospho-NHE3 protein abundance in membrane fractions of proximal tubules of the rat kidney (semi-quantitative). $100 \mu \mathrm{g}$ proteins were loaded in each lane.of western blot gels. $* p<0.05$ or $* * p<0.01$ vs. control; ${ }^{\dagger \dagger} p<0.01$ vs. ANG II-infused rats. Reproduced from Li and Zhuo (313). 
a

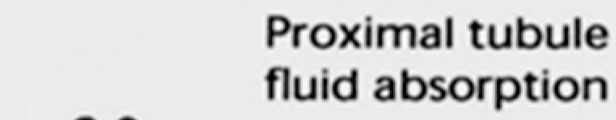

c

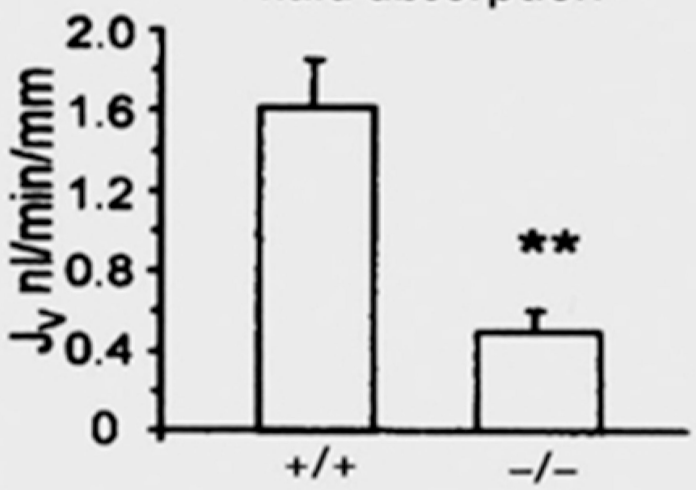

Tail-cuff pressure

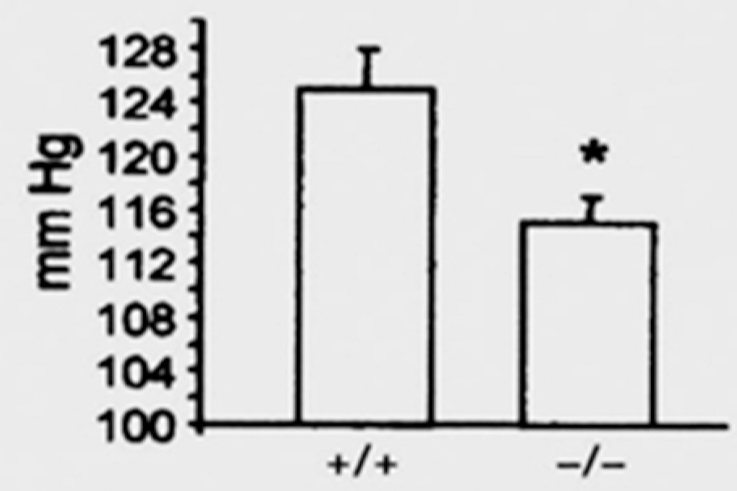

b

\section{Proximal tubule $\mathrm{HCO}_{3}{ }^{-}$absorption}

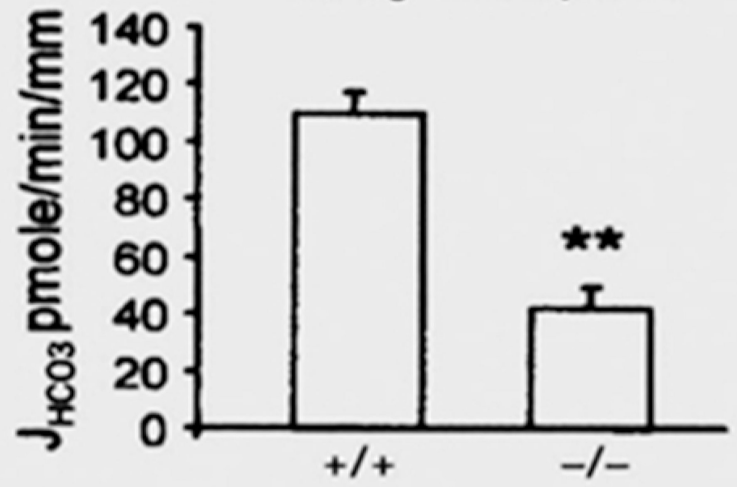

Intra-arterial

pressure

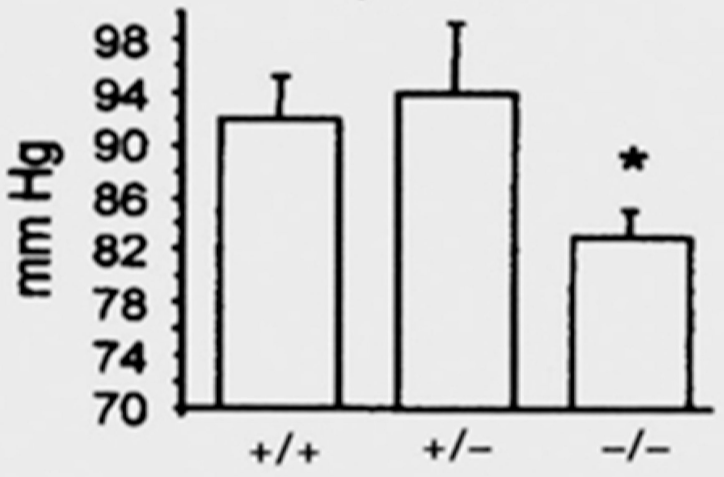

Figure 8.

Effects of global NHE3 gene knockout on proximal tubule fluid and bicarbonate absorption and blood pressure in adult $S l c 9_{a 3^{+/+}}(\mathrm{WT})$ and $S l c 9_{a} 3^{-/-}$(NHE-3 knockout) mice. $\boldsymbol{a}, \boldsymbol{b}$, In situ microperfusion of proximal convoluted tubules revealed that fluid (a) and $\mathrm{HCO}_{3}{ }^{-}$(b) absorption were sharply reduced in $S I c 9 a 3^{-/-}$tubules $(\mathrm{n}=14)$ relative to $S I c 9_{a 3^{+/+}}$tubules $(\mathrm{n}=12)$. ** $P<0.001 ; \mathrm{J}_{\mathrm{v}}$, fluid absorption; $\mathrm{J}_{\mathrm{HCO} 3}, \mathrm{HCO}_{3}{ }^{-}$absorption. $\boldsymbol{c}$, Blood-pressure measurements using the tail-cuff method showed that systolic pressure was significantly reduced in awake $S I c 9_{a 3^{-/-}}$mice $(* P<0.05, \mathrm{n}=4$ for each genotype). $\boldsymbol{d}$, Blood-pressure measurements using a femoral artery catheter showed that mean arterial pressure was reduced $(* P<0.05)$ in anaesthetized $S I c 9_{a 3^{-/-}}$mice $(\mathrm{n}=12)$ compared with both $S / c 9_{a 3^{+/-}}$ $(\mathrm{n}=7)$ and $S / c 9 a 3^{+/+}(\mathrm{n}=10)$ mice. Values for all analyses are mean s.e.m. Reproduced from Schultheis et al. (451). 


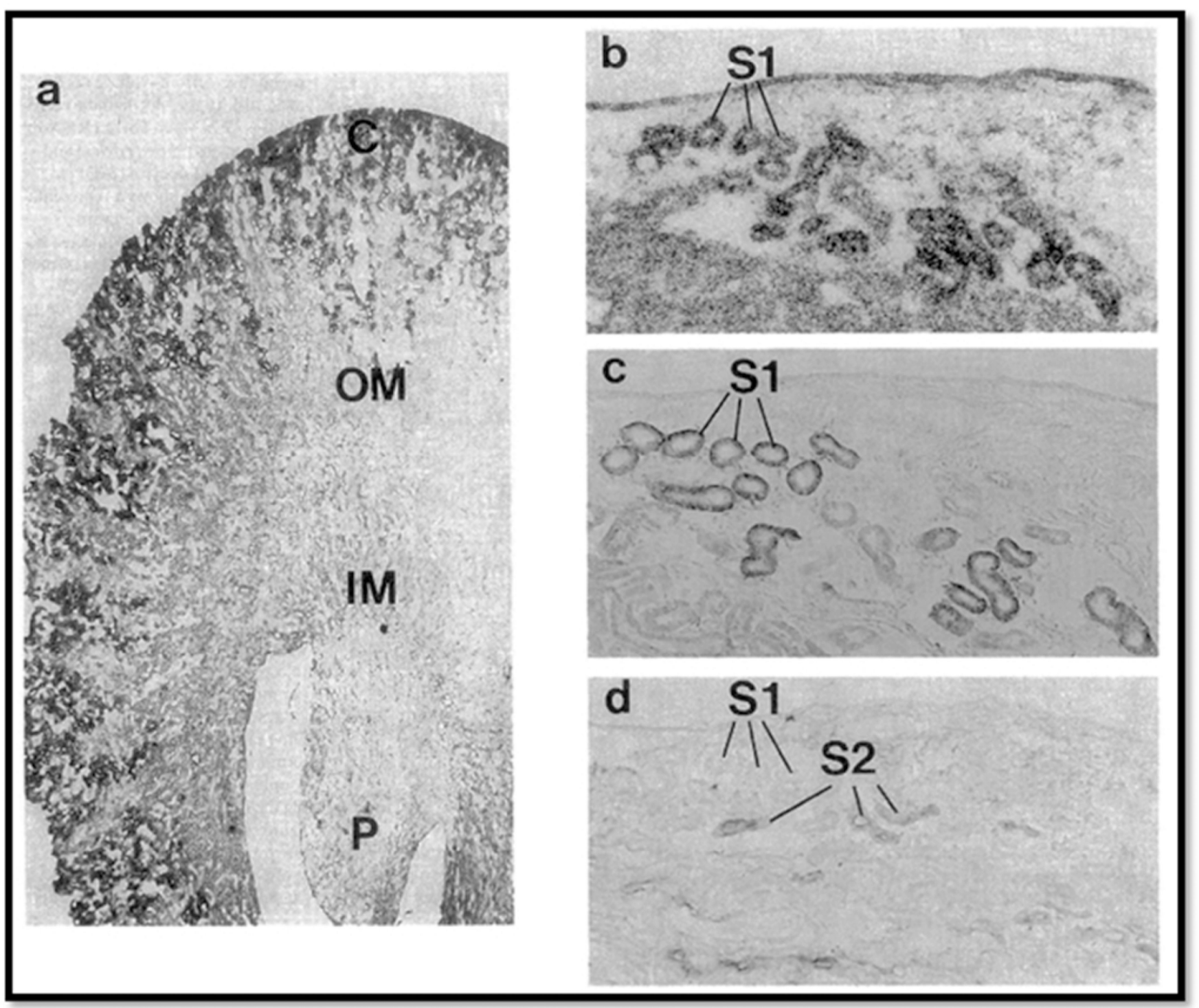

Figure 9.

Localization of the sodium and glucose cotransporter 2 (SGLT2) mRNAs in the kidney tubules by in situ hybridization. (a) Low power micrograph showing the pattern of hybridization of Hu 14 antisense cRNA probe (35S-labeled) to rat kidney cryosections. A strong hybridization is detected over tubules in the cortex $(\mathrm{C})$, whereas the signal is absent in outer medulla (OM), inner medulla (IM), and papilla (P). (b-d) Sequential $5 \mu \mathrm{m}$ sections of rat kidney cortex hybridized with Hu14 antisense cRNA probe (b) or stained with antibodies against the S1 segment specific marker GLUT2 (c) or carbonic anhydrase IV (d), which is specific for $\mathrm{S} 2$ segments of proximal tubules and the thick ascending limbs of Henle's loop. A strong hybridization signal is evident in $\mathrm{b}$ and is localized over tubules that show a basolateral staining for GLUT2 (indicated as SI in c). In contrast, carbonic anhydrase IV positive tubules (indicated as S2 in d) do not contain a Hu14 hybridization signal. The S3 segment-specific anti-ecto ATPase antibody did not stain tubules in the field corresponding to $b$ and ecto-ATPase-positive tubules detected in other areas of the kidney did not contain Hu14 hybridization signal (not shown). Bar, $0.4 \mathrm{~mm}$ (a) and $0.1 \mathrm{~mm}$ (b-d). Reproduced from Kenai et al. with permission (259). 


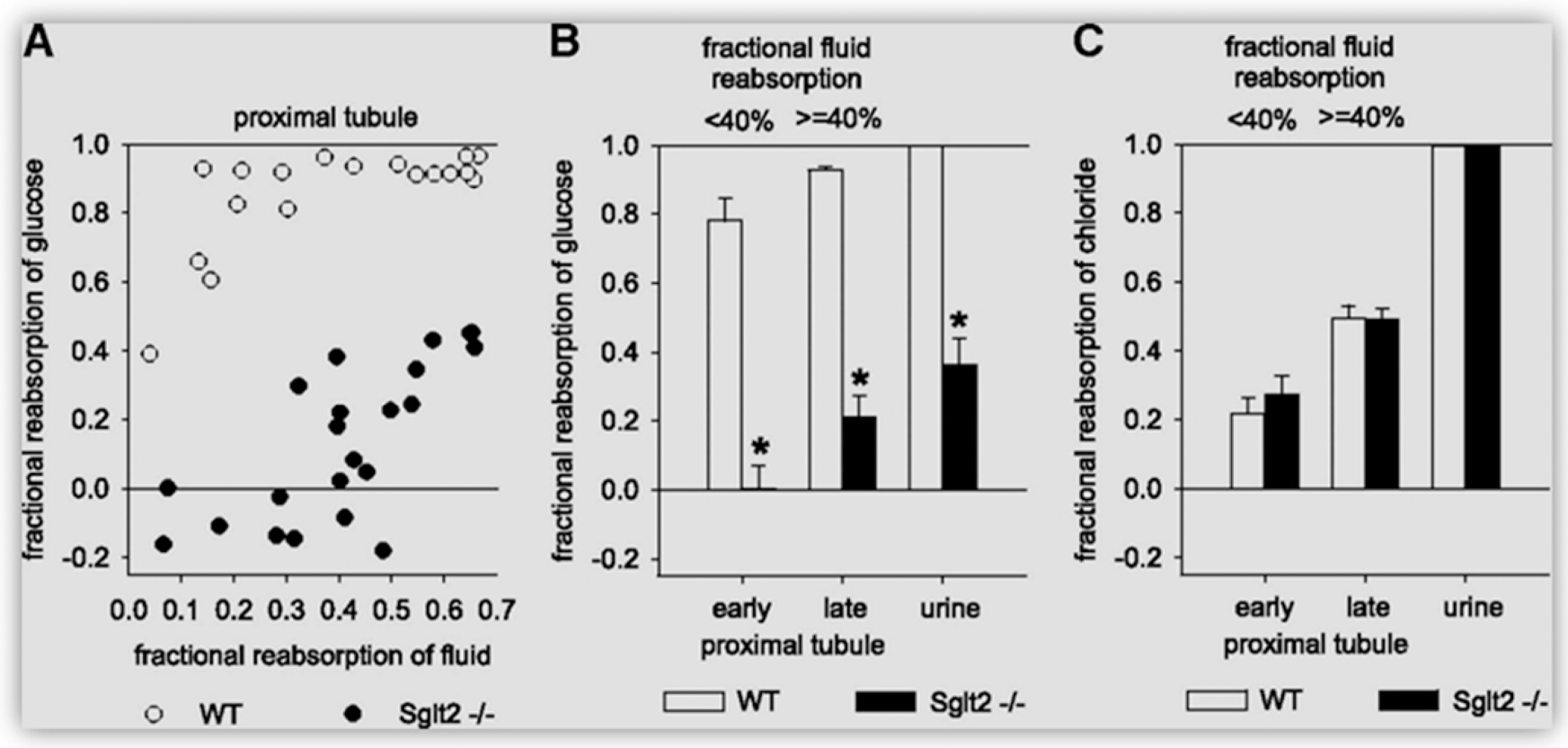

Figure 10.

Effects of SGLT2 knockout on glucose reabsorption in the early proximal tubule of SGLT $2^{-/-}$mice, as revealed by in vivo micropuncture studies under anesthesia. (A) Freeflow collections of tubular fluid are performed along accessible proximal tubules at the kidney surface to establish a profile for FR-glucose versus FR-fluid. (B and C) Mean FRglucose (B) and fractional reabsorption of chloride (C) for early (FR-fluid <40\%) and late (FR-fluid $\geq 40 \%$ ) proximal tubular collections and up to the urine ( $n=18$ to 23 nephrons in four to five mice). $* P<0.001$ versus WT mice. Reproduced from Vallon et al. with permission (516). 

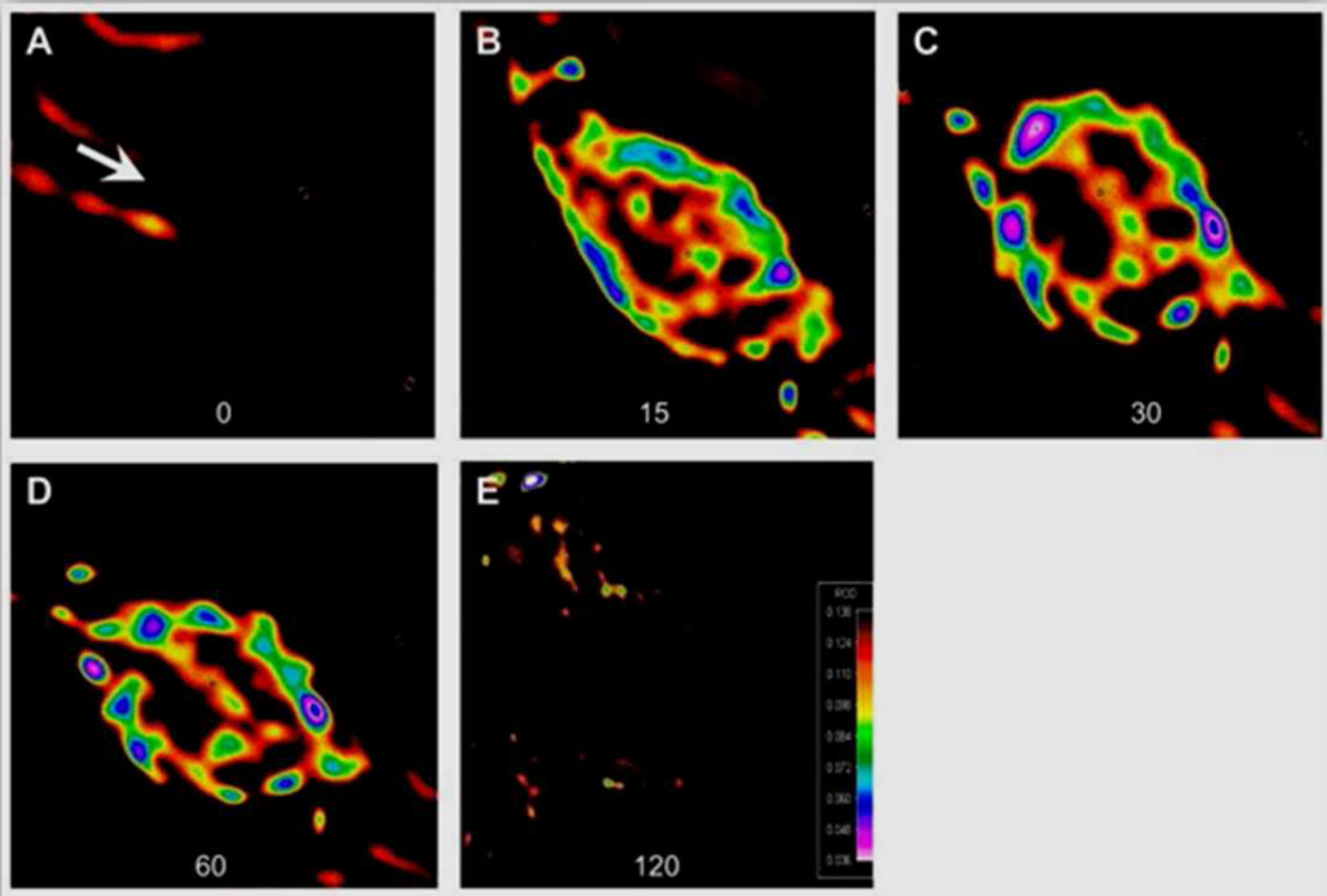

$\mathbf{F}$

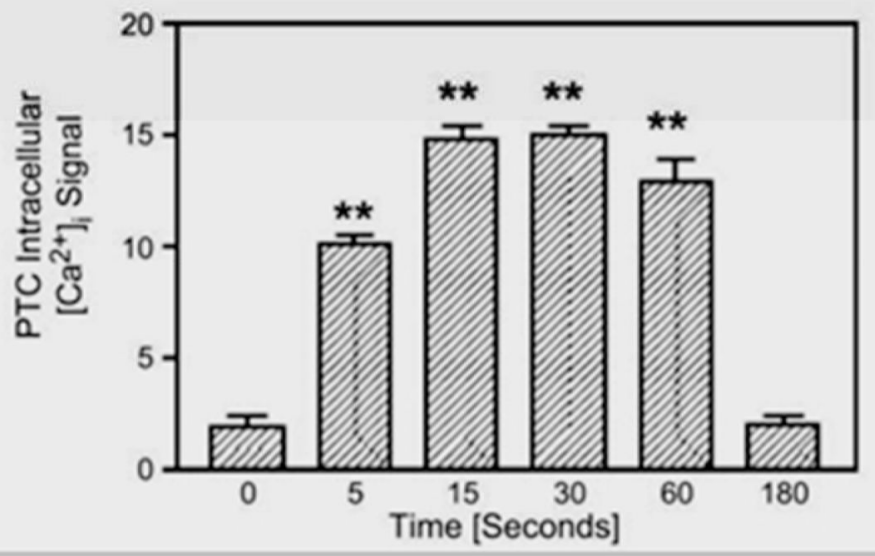

Figure 11.

$A-E$ : effect of intracellular microinjection of ANG II (1 nM, $\sim 70-100 \mathrm{fl})$ on $\left[\mathrm{Ca}^{2+}\right]_{\mathrm{i}}$ responses in single proximal tubule cells at baseline $(0 \mathrm{~s})$ and $15,30,60$, and $120 \mathrm{~s}$ after microinjection of Ang II in the cells. $F$ : relative levels of $\left[\mathrm{Ca}^{2+}\right]_{i}$ signaling before and after microinjection of Ang II. Red represents the highest level of $\left[\mathrm{Ca}^{2+}\right]_{i}$ responses, whereas black is the background. $* * P<0.01$ vs. basal. Reproduced from Zhuo et al. with permission (592). 


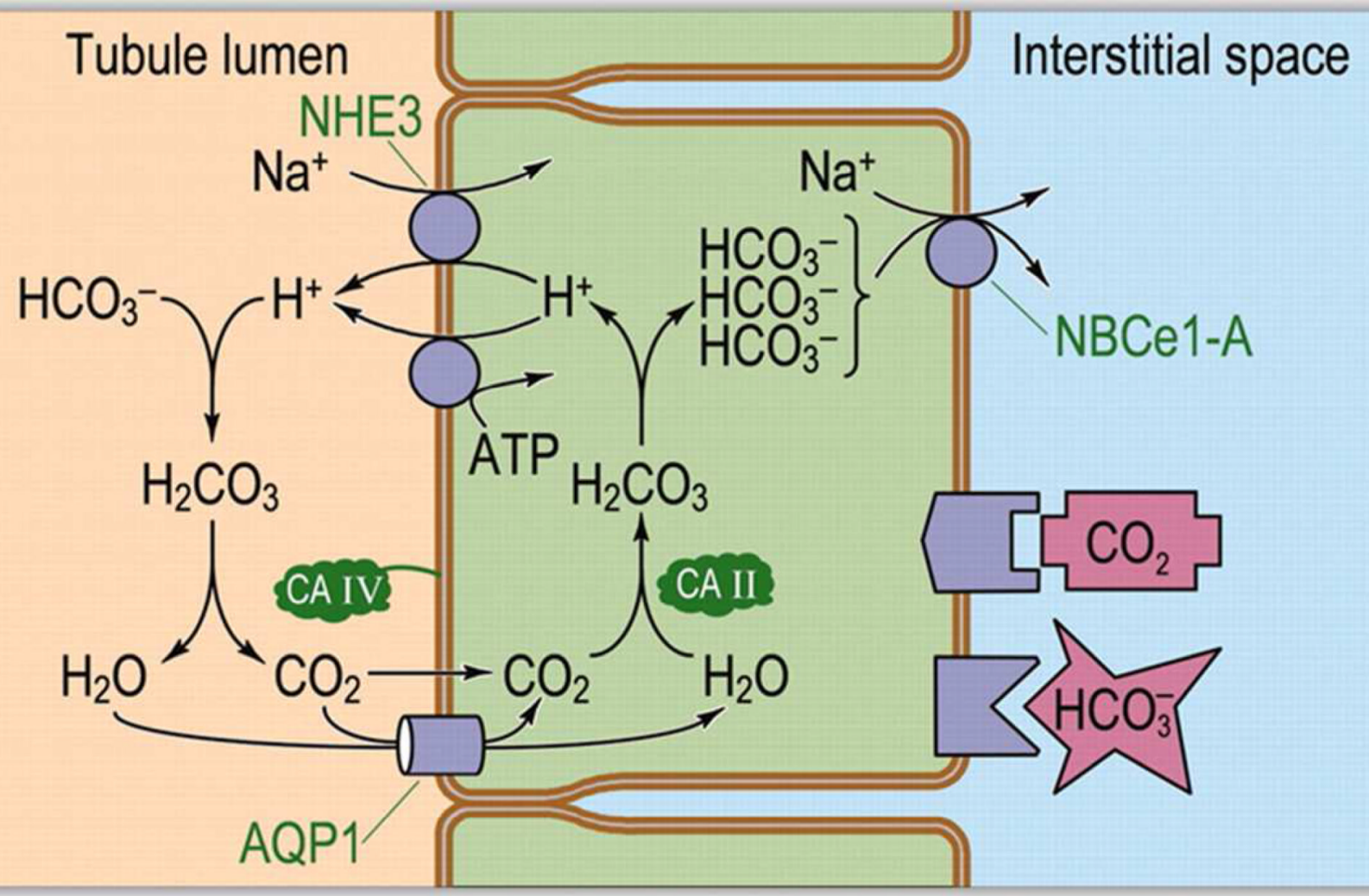

Figure 12.

Model of acid-base transport in the proximal tubule (PT). The PT reabsorbs $\mathrm{HCO}_{3}{ }^{-}$by using active-transport processes to secrete $\mathrm{H}^{+}$into the tubule lumen and titrating $\mathrm{HCO}_{3}{ }^{-}$to $\mathrm{CO}_{2}$ and $\mathrm{H}_{2} \mathrm{O}$. Thus, $\mathrm{HCO}_{3}{ }^{-}$reabsorption requires $\mathrm{CO}_{2}$ uptake across the apical membrane. Once inside the cell, $\mathrm{CO}_{2}$ and $\mathrm{H}_{2} \mathrm{O}$ recombine to regenerate $\mathrm{HCO}_{3}{ }^{-}$, which exits across the basolateral membrane. NHE3, Na-H exchanger 3; AQP1, aquaporin 1; CA II and CA IV, carbonic anhydrases II and IV; NBCe1-A, electrogenic $\mathrm{Na} / \mathrm{HCO}_{3}$ co-transporter 1 , splice variant A. Reproduced from Boron with permission (59). 


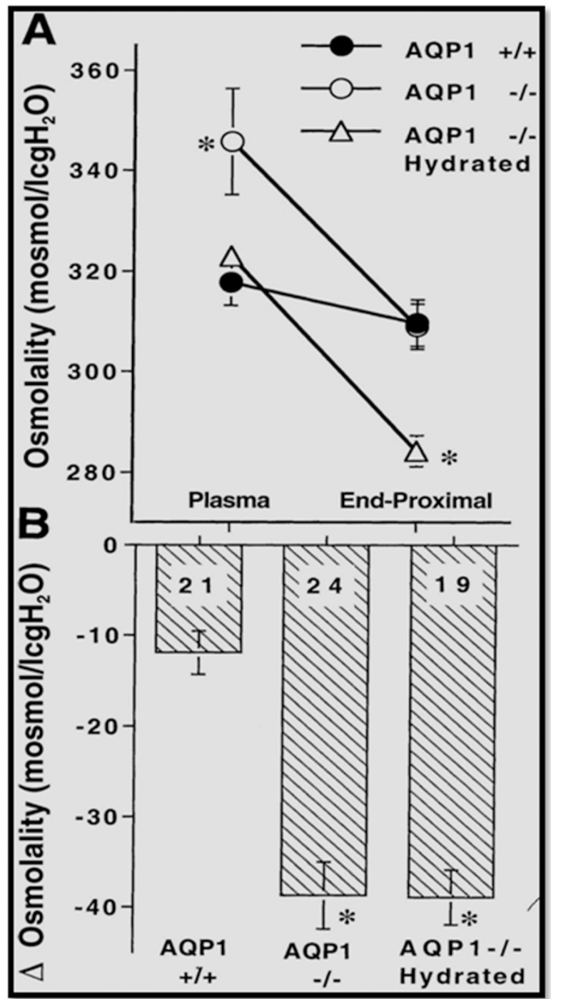

Figure 13.

Osmolality in plasma and late proximal tubular (LPT) fluid in aquaporin-1 (AQP1)knockout (-/-) and wild-type (+/+) mice. Values are means \pm SE and are shown for AQP1 $+/+(n=21$ nephrons in 4 mice $)$ AQP1 $-/-(n=24 / 5)$, and hydrated AQP1 -/- mice $(n=$ 19/3). $A$ : relationship between absolute values of osmolalities in plasma and late proximal tubule fluid (where SE bars cannot be seen, they are smaller than the symbol used). $B$ : transtubular osmotic gradients, i.e., the osmolality differences (e) between plasma and LPT. $* P<0.001$ compared with AQP1 +/+ mice. Reproduced from Vallon et al. with permission (517). 


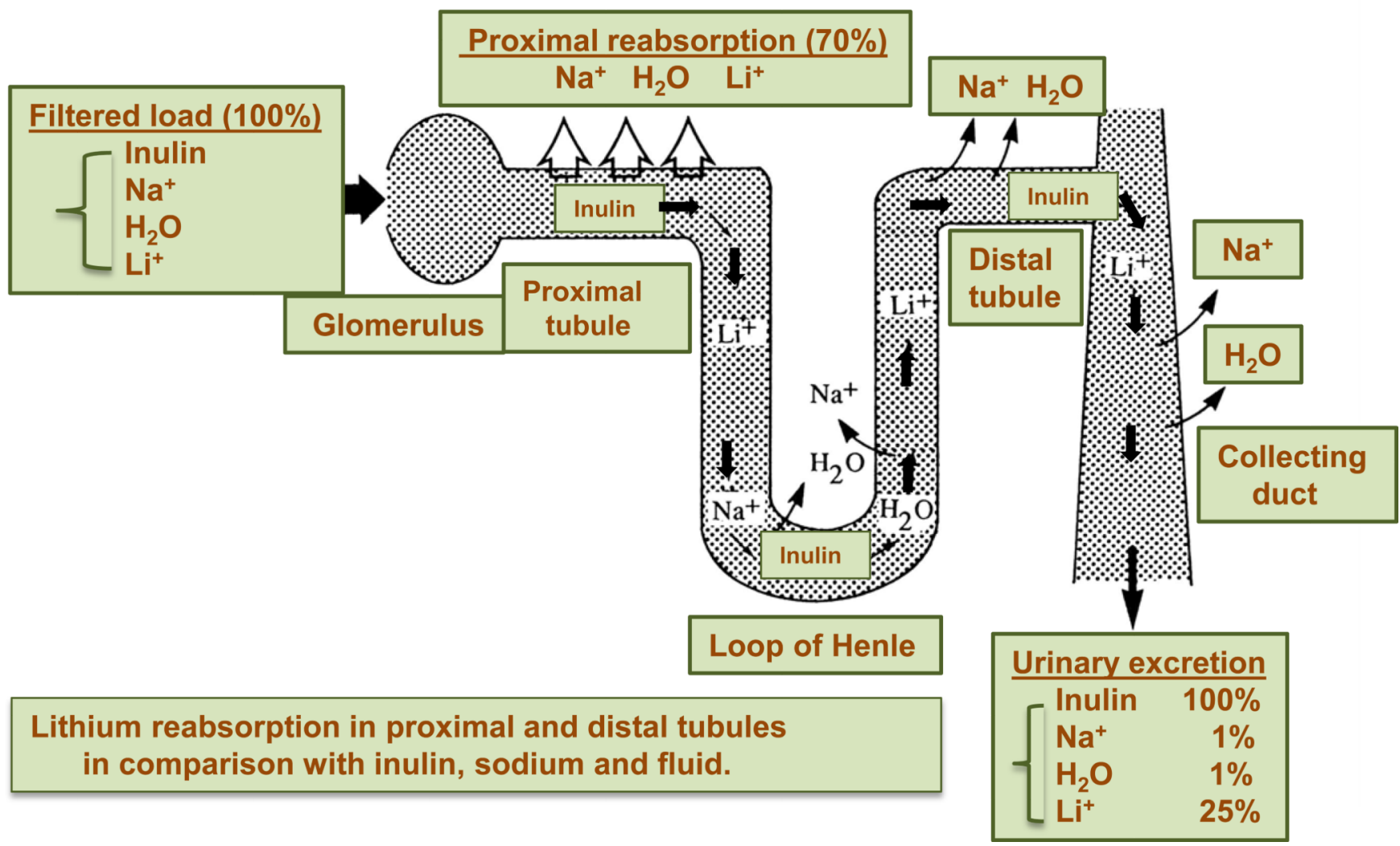

Figure 14.

Normal renal handling of lithium reabsorption in proximal tubules in comparison with those of inulin, sodium and water in rodents and humans with a normal sodium intake. Data are drawn from Refs. $(449 ; 463 ; 495 ; 496)$. 


\section{GFR}

\section{Determinants of GTB}

A. Physical factors: oncotic and hydrostatic pressure in peritubular capillaries and interstitium.

B. Intraluminal factors: filtered sodium, bicarbonate, glucose, amino acids, and unidentified glomerular-born factors.

C. Hormonal factors: angiotensin II and its active fragments, atrial natriuretic factor, glucagon, endothelin-1, catecholamines, and dopamine.

\section{End-proximal delivery}

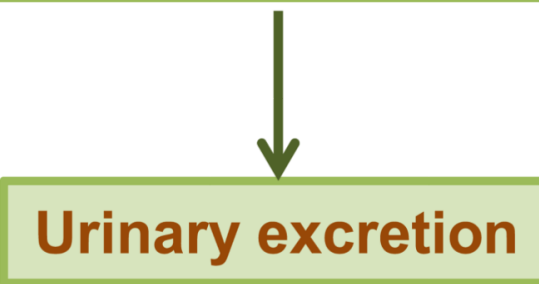

Figure 15.

A schematic diagram showing physical, intraluminal and humoral factors that regulate glomerulotubular balance (GTB). $\oplus$, increase. $\oslash$, decrease. 

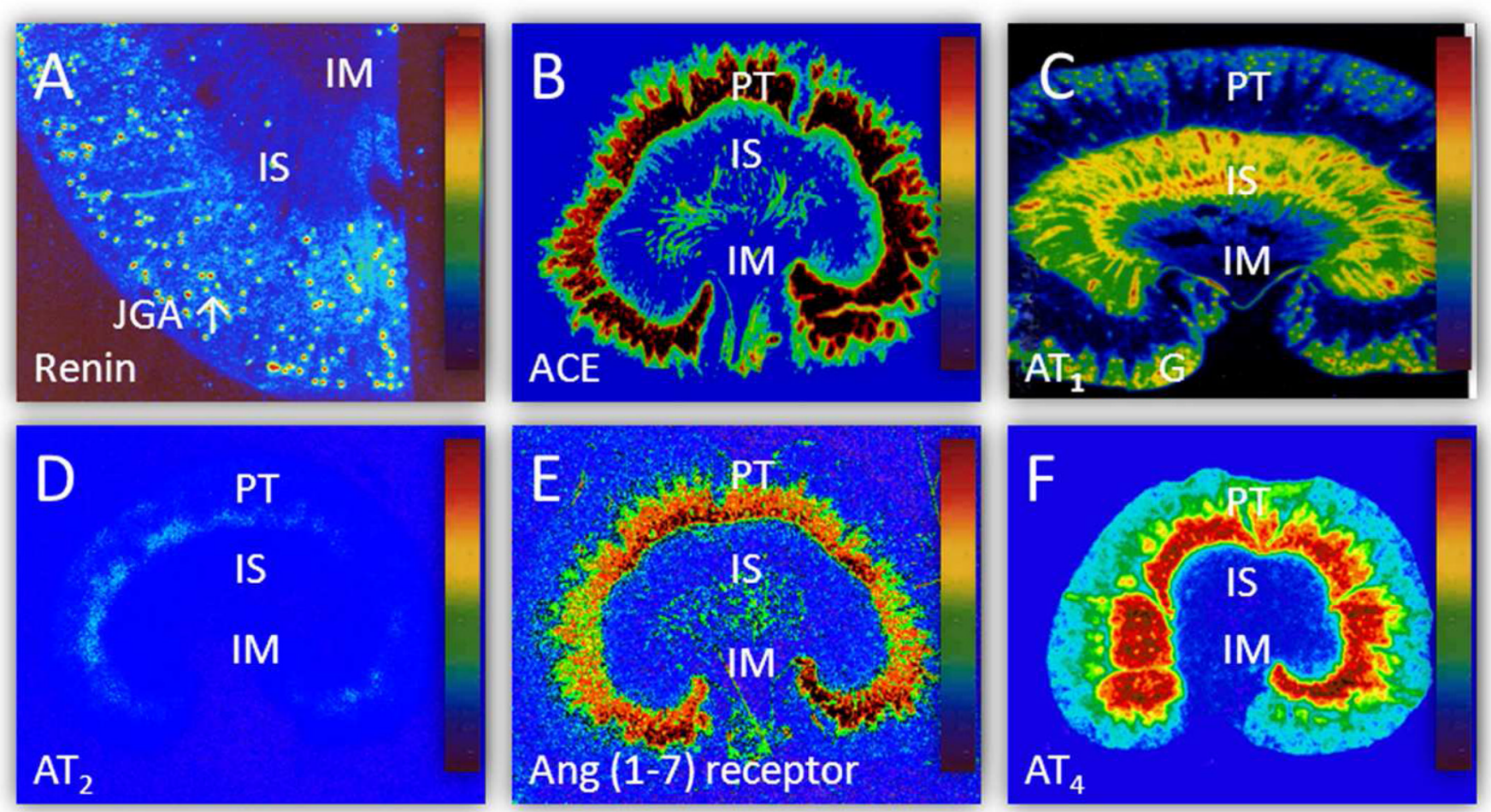

Figure 16.

In vitro autoradiographic mapping of: (A) active renin binding in justaglomerular apparatus in the dog kidney pretreated with sodium depletion using the radiolabeled renin inhibitor, ${ }^{125} \mathrm{I}-\mathrm{H} 77$, (B) angiotensin I-converting enzyme binding in proximal tubules of the rat kidney using ${ }^{125} \mathrm{I}-351 \mathrm{~A},(\mathrm{C}) \mathrm{AT}_{1}$ receptor in the presence of the $\mathrm{AT}_{2}$ receptor blocker $\mathrm{PD} 123319$ or (D) $\mathrm{AT}_{2}$ receptor binding in the presence of the $\mathrm{AT}_{1}$ receptor blocker losartan using ${ }^{125} \mathrm{I}$-[Sar ${ }^{1}$,Ile $\left.{ }^{8}\right]$-ANG II, (E) ANG (1-7) receptor binding in the rat kidney using ${ }^{125} \mathrm{I}$ ANG (1-7) as the radioligand, and (F) ANG IV receptor binding in the rat kidney using ${ }^{125}$ I-ANG (3-8). The levels of binding are indicated by color calibration bars with red representing the highest, whereas blue showing the lowest levels of enzyme or receptor binding. G: glomerulus. IM: inner medulla. IS: inner stripe of the outer medulla. JGA: juxtaglomerular apparatus. P: proximal tubule. Reproduced from Zhuo and Li with permission (591). 


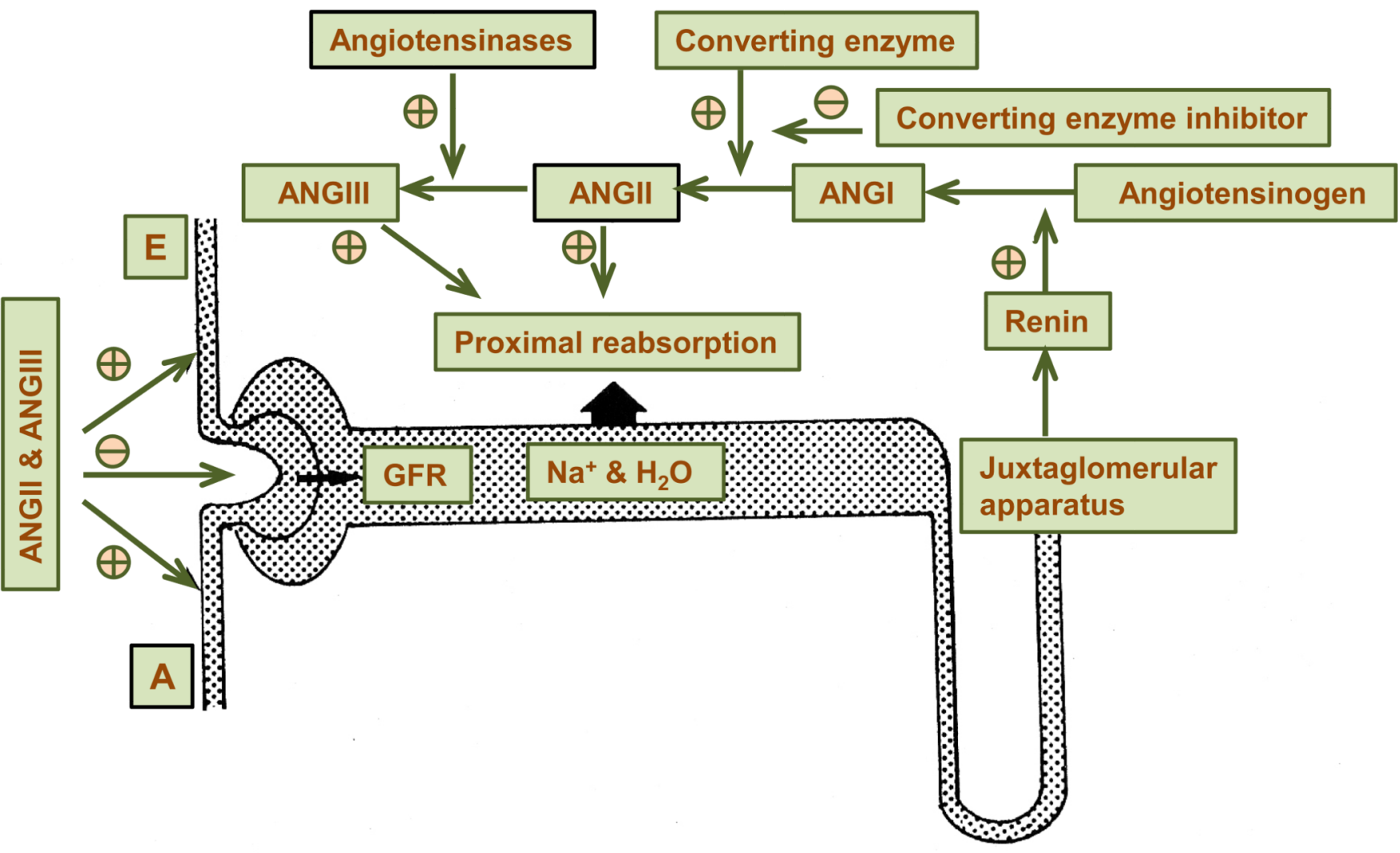

Figure 17.

A schematic representation of local generation of ANG II in proximal tubules of the kidney and its role in the regulation of proximal tubular reabsorption and glomerulotubular balance (GTB). $\oplus$, stimulation. $\oslash$, inhibition. 


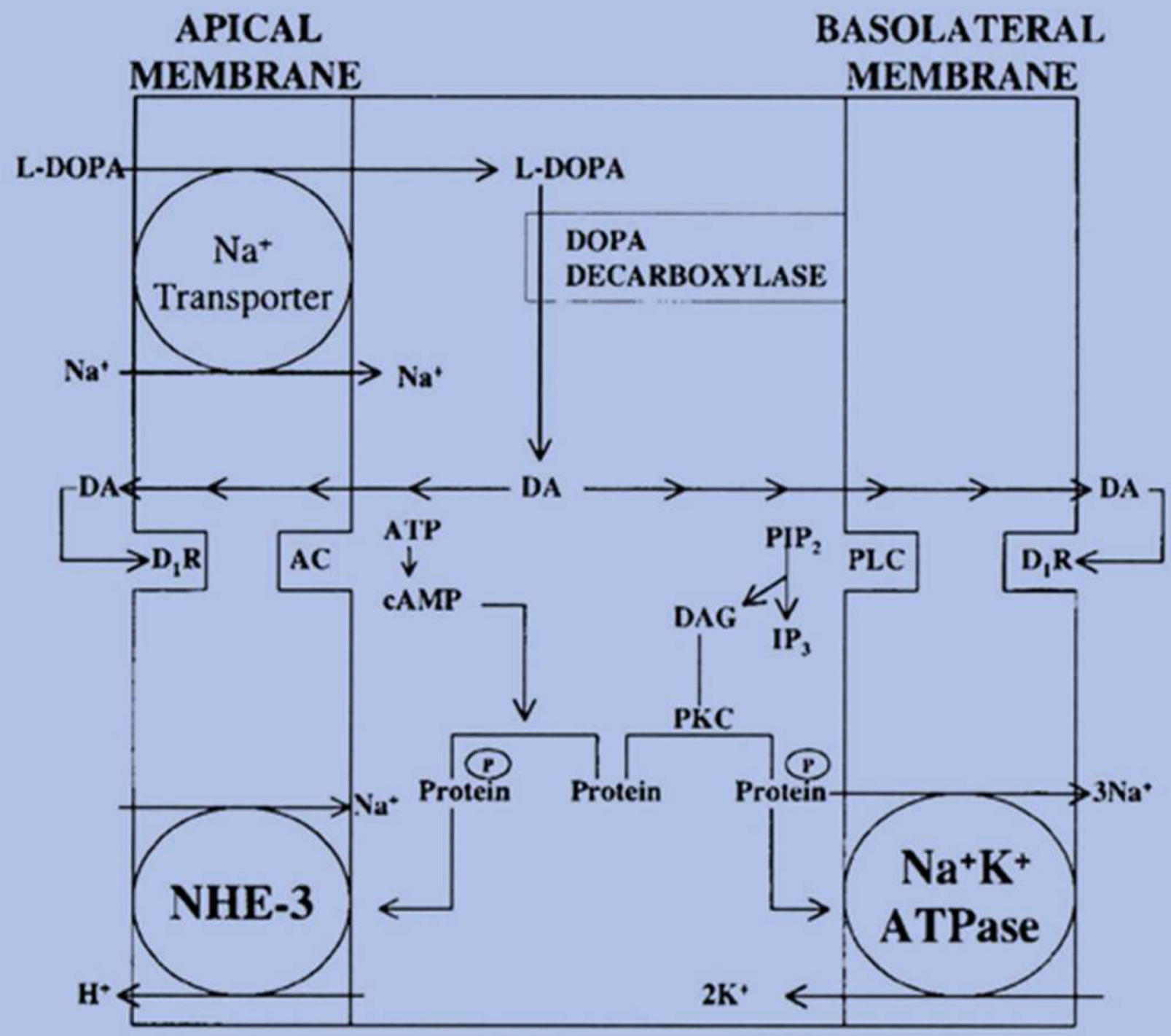

Figure 18.

Schematic depiction of dopamine formation and cell signaling mechanisms activating sodium transport across the proximal renal tubule cell. DA indicates dopamine; $\mathrm{D}_{1} \mathrm{R}$, dopamine D1 receptor; PLC, phospholipase C; DAG, diacylglycerol;and AC, adenylyl cyclase. Reproduced from Carey with permission (81). 


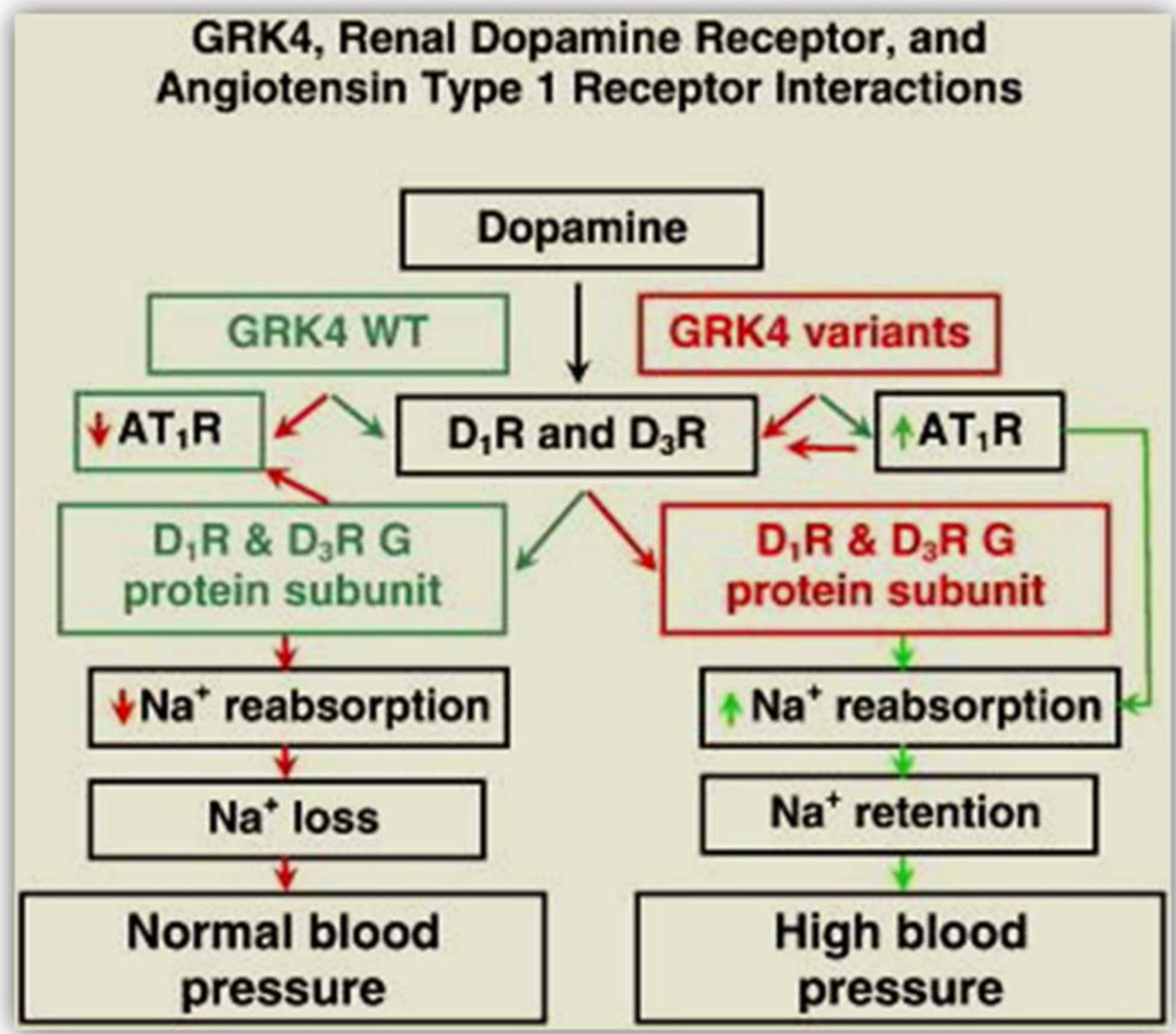

Figure 19.

A schematic diagram showing GRK4 and renal dopamine and ANG II type 1 receptor interactions to regulate renal tubular transport and blood pressure homeostasis. During conditions of moderately increased $\mathrm{NaCl}$ intake, the renal $\mathrm{D}_{1} \mathrm{R}$ is stimulated by dopamine produced in the kidney. The $\mathrm{D}_{1} \mathrm{R}$ or $\mathrm{D}_{3} \mathrm{R}$, whose coupling to $\mathrm{G}$ protein subunits is regulated by $\mathrm{G}$ protein-coupled receptor kinase type 4 (GRK4), inhibits sodium reabsorption in several nephron segments. This results in an increase in sodium excretion and maintenance of normal blood pressure. GRK4 wild-type (GRK4 WT) also negatively regulates $\mathrm{AT}_{1} \mathrm{R}$ transcription. The decrease in $\mathrm{AT}_{1} \mathrm{R}$ expression, caused by GRK4 WT, facilitates the inhibitory effect of $D_{1} R$ on renal sodium transport. In essential hypertension, constitutively active variants of GRK4 not only uncouple $D_{1} R$ and $D_{3} R$ from $G$ protein subunits, but also increase $\mathrm{AT}_{1} \mathrm{R}$ transcription in the kidney. These effects impair the ability of the kidney to excrete the excess sodium load, resulting in sodium retention, and ultimately hypertension. Green box $=$ normal coupling of $D_{1} R$ and $D_{3} R$ to $G$ protein subunits, Red box $=$ uncoupling 
of $D_{1} R$ and $D_{3} R$ from $G$ protein subunits. Green arrows $=$ stimulatory, Red arrows $=$ inhibitory. Reproduced from Jose with permission (254). 


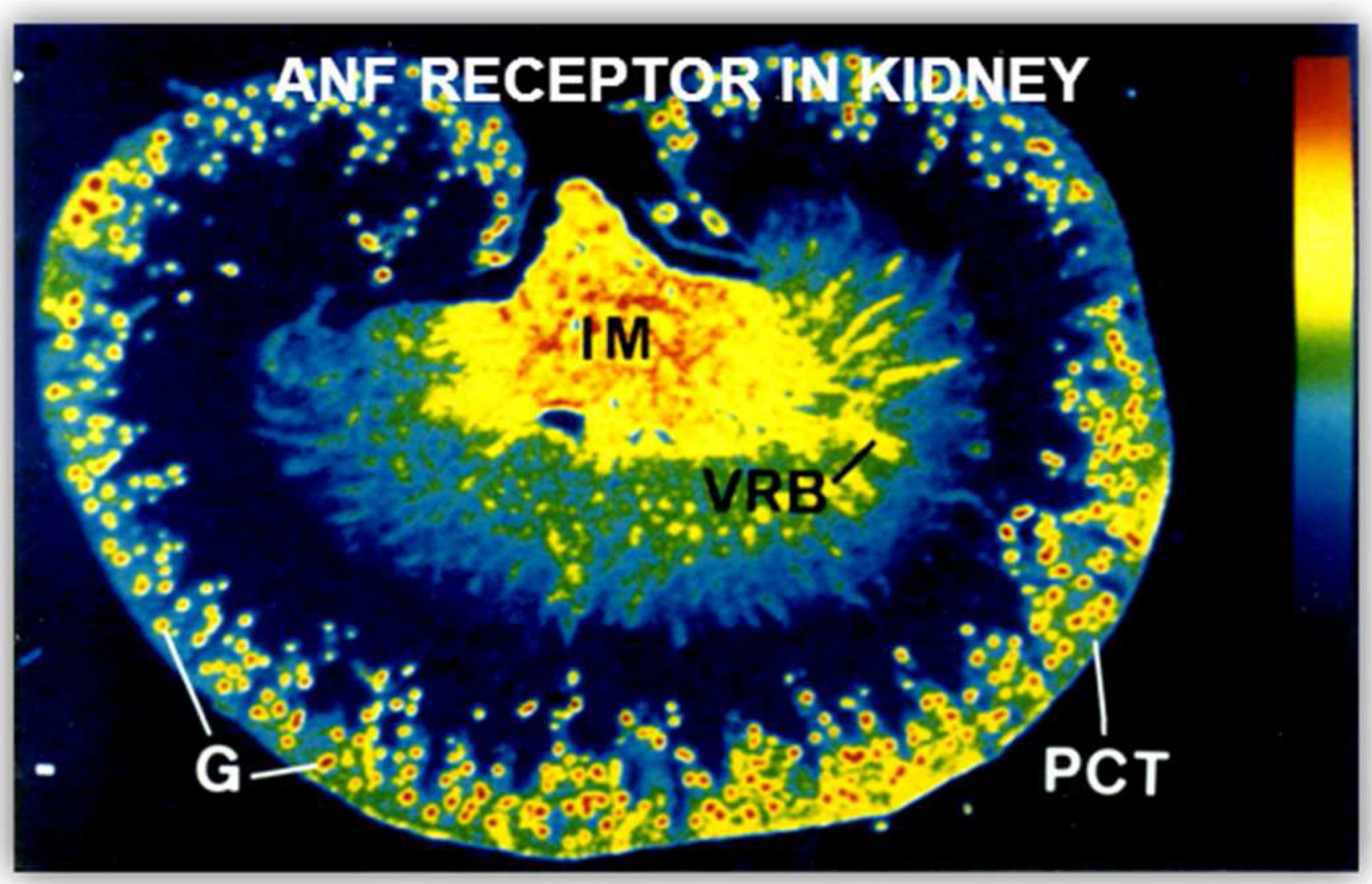

\section{Figure 20.}

The intrarenal distribution of ANF receptors in the rat kidney, as visualized by quantitative in vitro autoradiography using $\left[{ }^{125} \mathrm{I}\right]$-labeled ANF as the radioligand. High levels of ANF receptor binding occur in the glomeruli (G) and the inner medulla (IM), whereas moderate levels of ANF binding are seen in the proximal convoluted tubules (PCT) and inner stripe of the outer medulla (VRB). Red represents highest whereas black the lowest levels of ANF receptor binding. Reproduced from Zhuo and Mendelsohn with permission (583). 


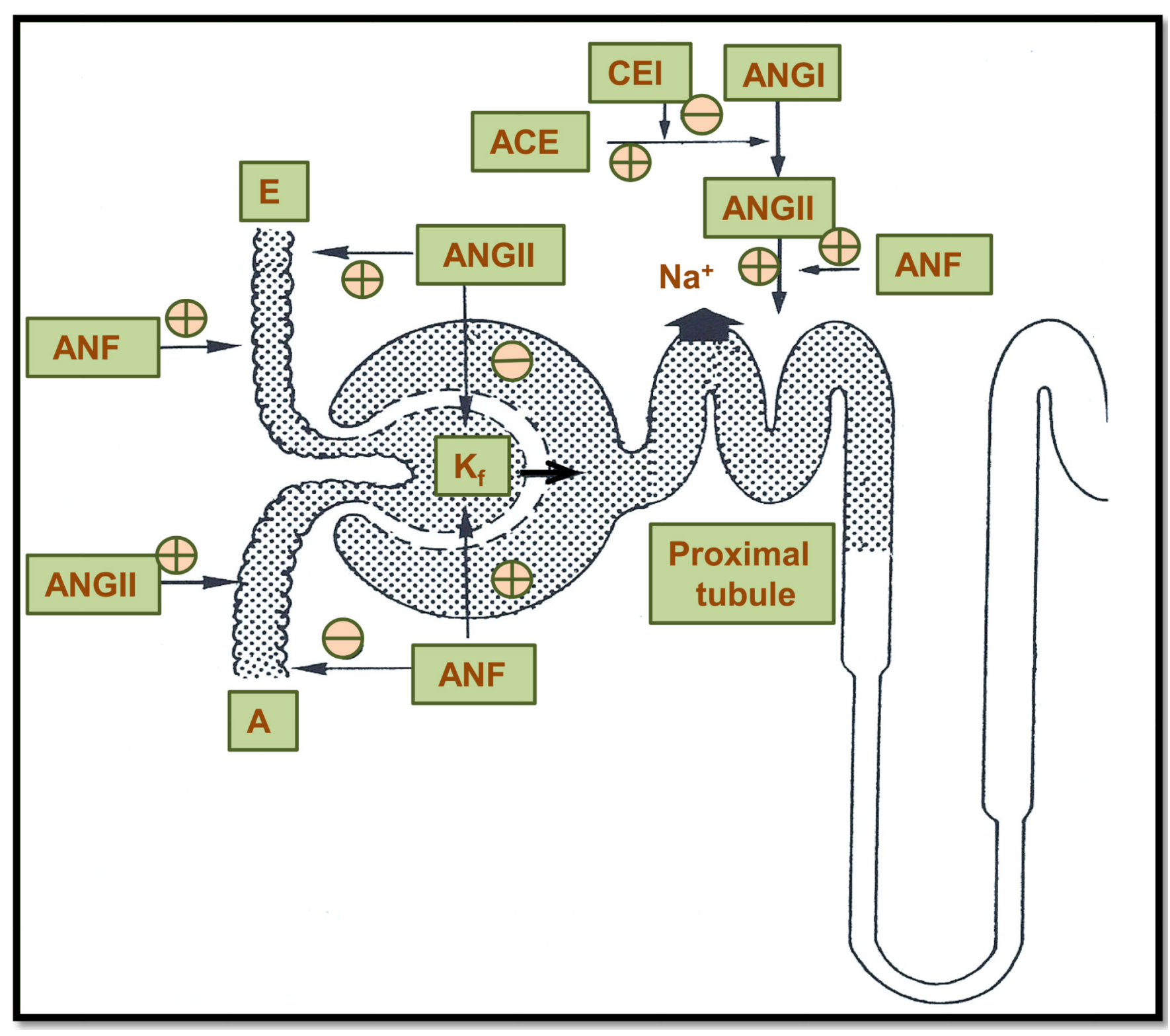

Figure 21.

Schematic representation of potential multi-level interactions between ANF and ANG II to regulate renal hemodynamics and proximal tubular transport of sodium and fluid in the kidney. A, afferent arteriole. E, efferent arteriole. AI, ANG I. AII, ANG II. CE, converting enzyme. CEI, converting enzyme inhibitor. $K_{f}$, ultrafiltration coefficient. $\oplus$, stimulation or increase. $\oslash$, inhibition or decrease. 


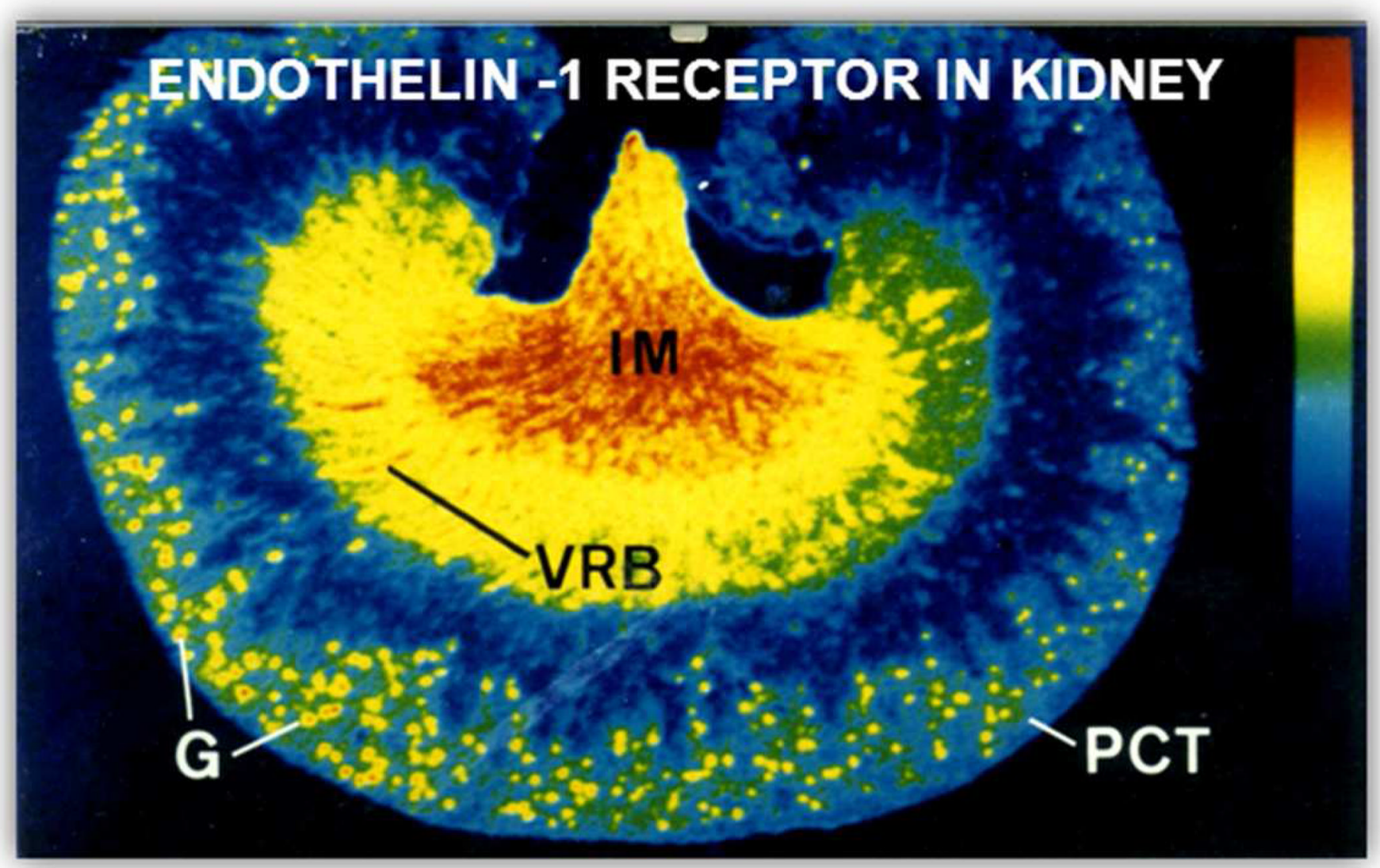

Figure 22.

The intrarenal distribution of endothelin 1 (ET-1) receptors in the rat kidney, as visualized by quantitative in vitro autoradiography using $\left[{ }^{125} \mathrm{I}\right]$-endothelin 1 as the radioligand. High levels of ET-1 receptor binding occur in the inner medulla (IM) and glomeruli (G), whereas moderate levels of ET-1 binding are seen in the proximal convoluted tubules (PCT) and inner stripe of the outer medulla (VRB). Red represents highest whereas black the lowest levels of ET-1 receptor binding. Reproduced from Zhuo and Mendelsohn with permission $(580 ; 583)$. 

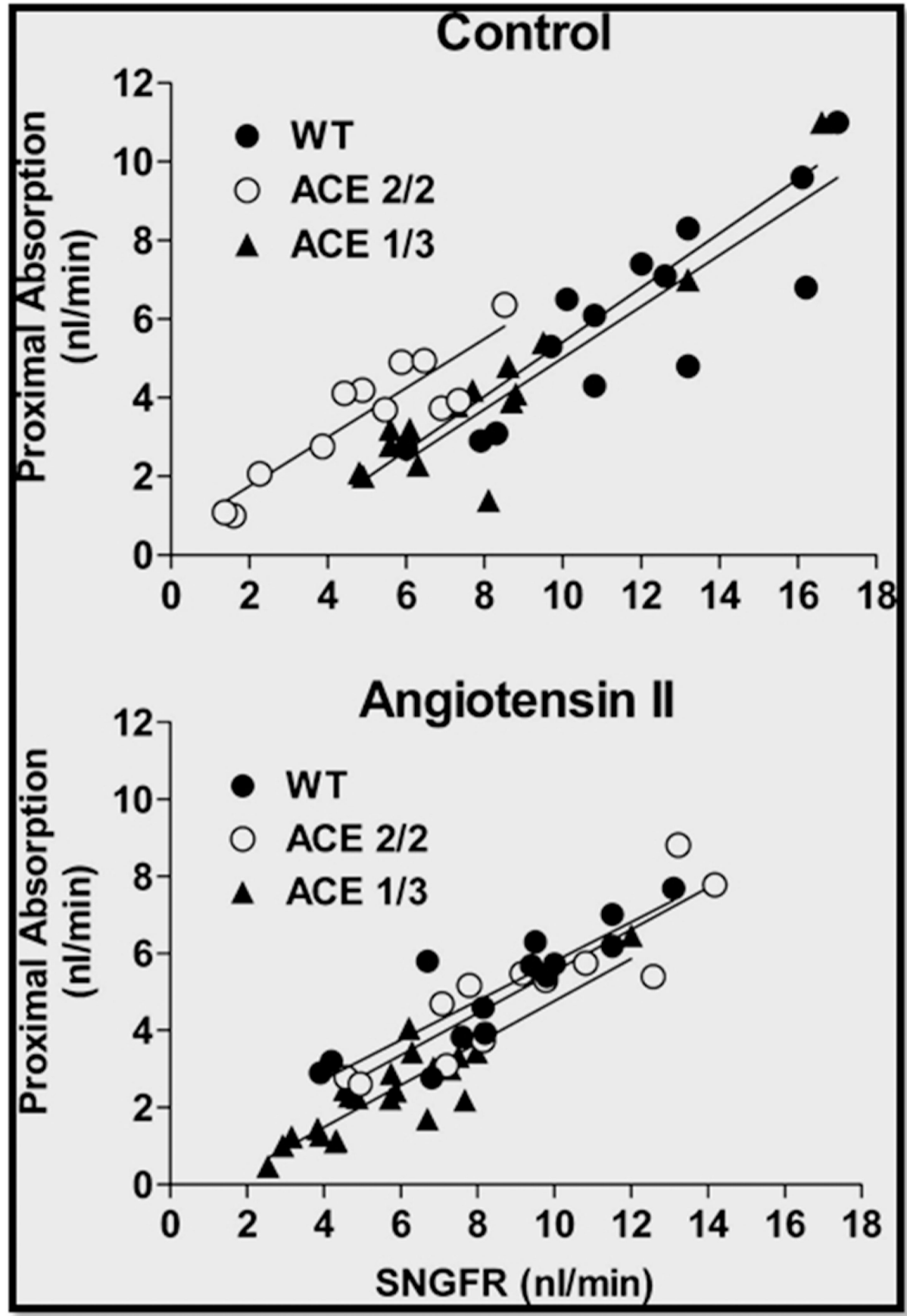

Figure 23.

Relationship between the rates of single nephron GFR (SNGFR) and proximal tubular fluid reabsorption of WT, ACE 2/2, and ACE 1/3 mice during control (top) and during angiotensin II infusion (bottom). Lines are linear regression lines calculated for the range of the data. Reproduced from Hashimoto et al. with permission (206). 


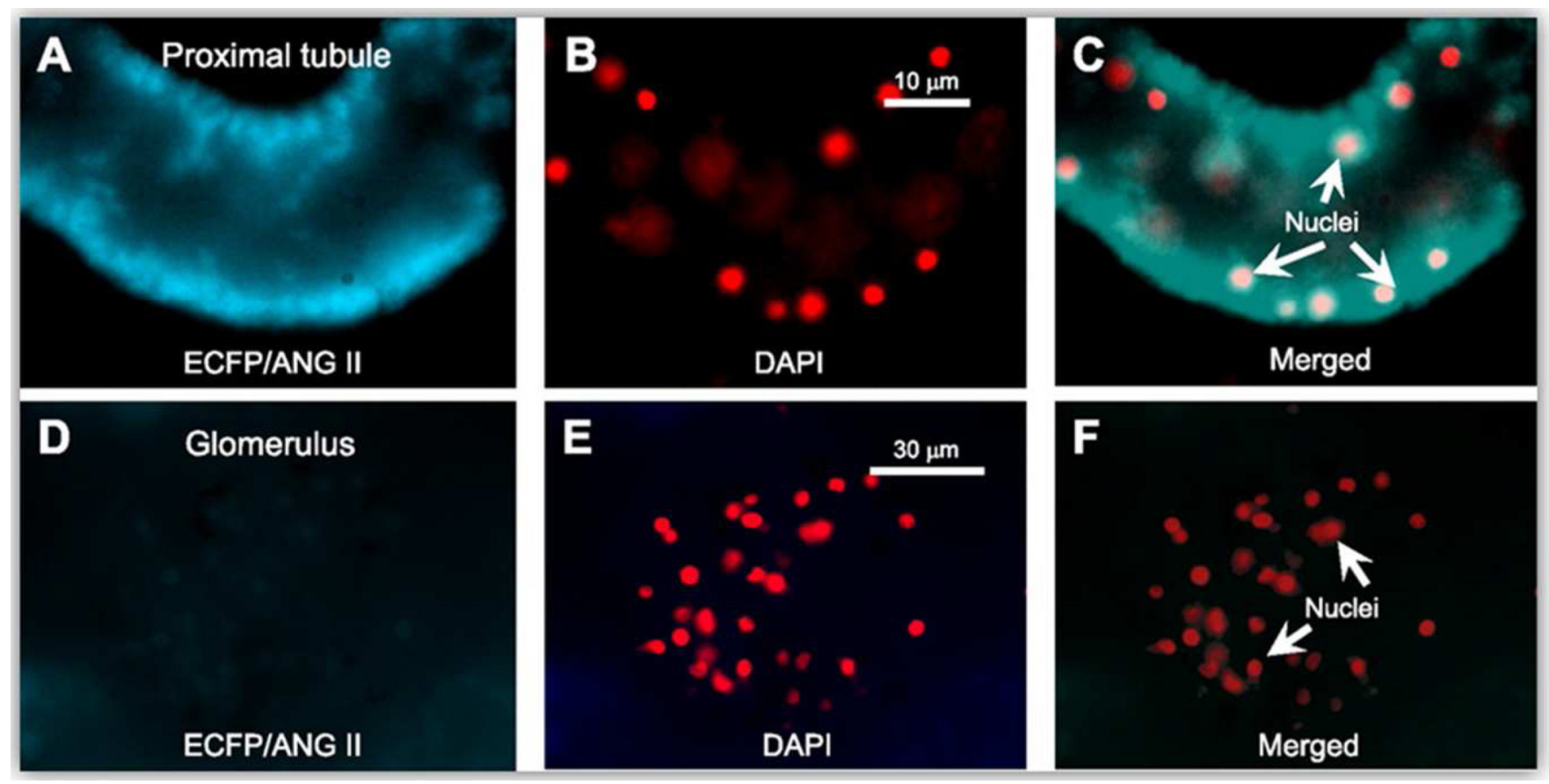

Figure 24.

Expression of an intracellular cyan fluorescent fusion of ANG II, ECFP/ANG II, selectively in freshly isolated proximal tubules of the rat kidney 2 weeks after intrarenal ECFP/ANG II transfer. The SGLT2 gene promoter was used to drive ECFP/ANG II expression selectively in proximal tubules of the kidney. Bars $=10 \mu \mathrm{m}$ for the proximal tubule or $30 \mu \mathrm{m}$ for the glomerulus. Reproduced from Li et al. with permission (310). 


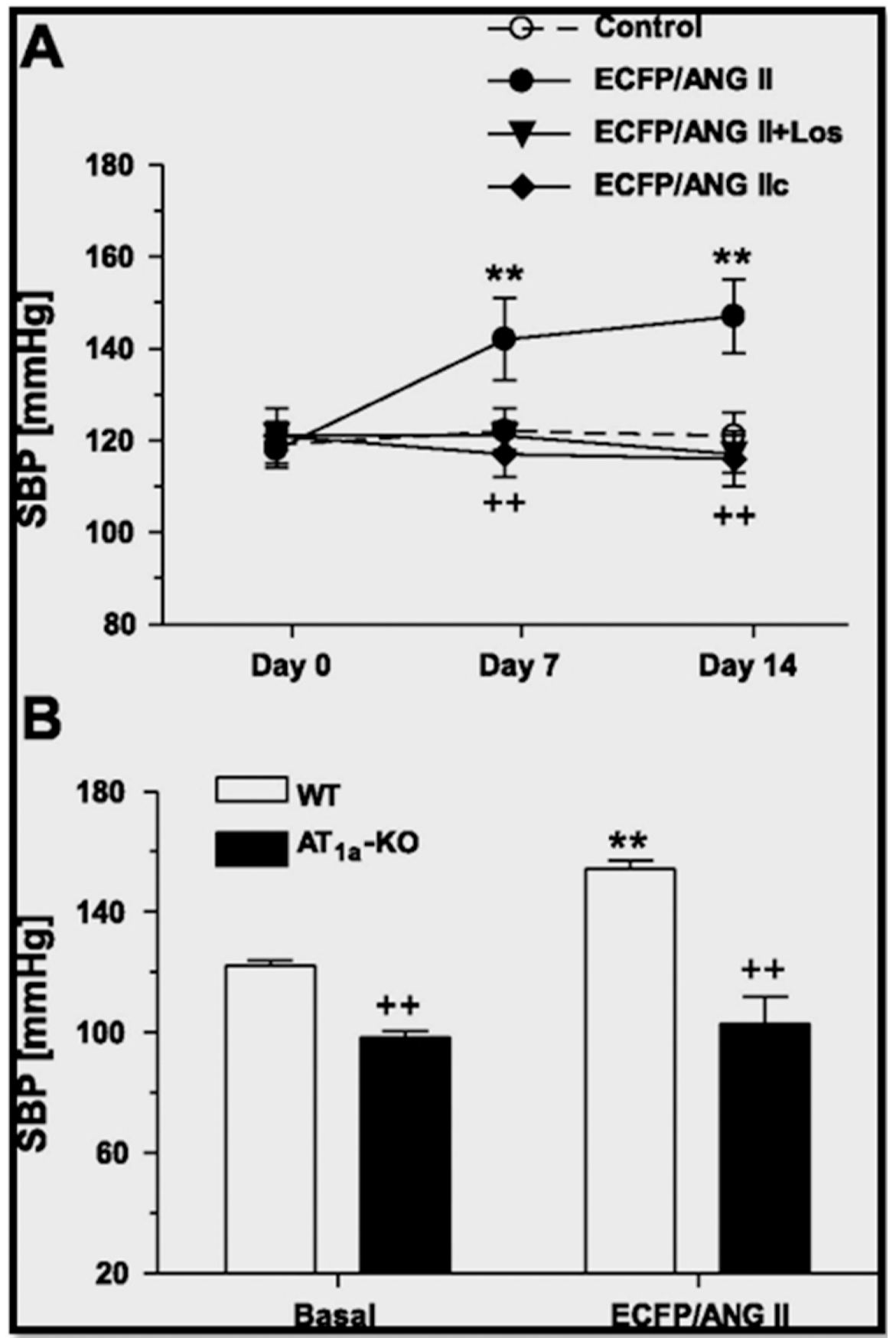

Figure 25.

Effects of proximal tubule-specific transfer of ECFP/ANG II or its scrambled control, ECFP/ANG IIc, with or without losartan treatment on systolic blood pressure in rats (SBP; $A$ ) or ECFP/ANG II transfer in wild-type or $\mathrm{AT}_{1 \mathrm{a}}-\mathrm{KO}$ mice $(B) .{ }^{*} p<0.05$ or $* * p<0.01$ vs. basal SBP. ${ }^{+} p<0.05$ or ${ }^{++} p<0.01$ vs. SBP in ECFP/ANG II-transferred rats. ${ }^{\#} p<0.05$ or ${ }^{++} p<0.01$ vs. SBP in wild-type mice at basal or 2 weeks after intrarenal ECFP/ANG II transfer. Reproduced from Li et al. with permission (310). 


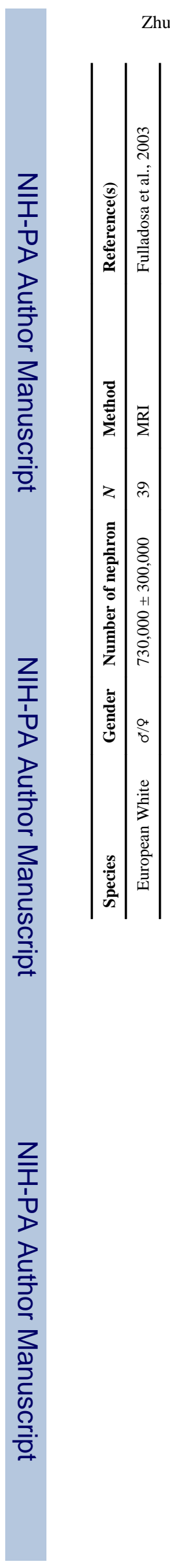


Table 2

Ultrastructural heterogeneity of proximal nephrons in mammalian kidneys including humans.

\begin{tabular}{|c|c|c|c|c|}
\hline Characteristics & S1 & S2 & S3 & References \\
\hline \multirow[t]{3}{*}{ Location } & Superficial/mid-cortex & Mid-cortex & Inner cortex \& OSOM & Maunsbach 1966 \\
\hline & & & & Madsen et al., 2007 \\
\hline & & & & Kriz \& Kaissling, 2008 \\
\hline \multicolumn{5}{|c|}{ Brush border membrane } \\
\hline Size & Taller \& wider & short & shorter & Maunsbach 1966 \\
\hline \multicolumn{5}{|c|}{ Endocytic compartment } \\
\hline & Most prominent & Less prominent & Least prominent & Maunsbach 1966 \\
\hline & & & & Madsen et al., 2007 \\
\hline Microvilli & Abundant & less abundant & Least abundant & Welling \& Welling, 1975 \\
\hline \multicolumn{5}{|c|}{ Vasuolar-lysosomal system } \\
\hline & Well-developed & Less developed & Least developed & Madsen \& Park, 1987 \\
\hline Golgi apparatus & Well-developed & Less developed & Least prominent & Madsen et al., 2007 \\
\hline \multirow[t]{2}{*}{ Megalin } & Most abundant & Abundant & less abundant & Kerjaschki et al., 1984 \\
\hline & & & & Christensen \& Birn, 2001 \\
\hline NHE3 & Abundant & Present & Least abundant & \\
\hline \multicolumn{5}{|c|}{ Alkaline phosphatase } \\
\hline & Present & Present & Present & Heidrich HG et al., 1972 \\
\hline Aminopeptidases & Abundant & Present & Less prominent & Madsen et al., 2007 \\
\hline \multicolumn{5}{|c|}{ Basolateral membrane } \\
\hline Invagination & Extensive & less extensive & Least entensive & Madsen et al., 2007 \\
\hline Lateral process & Extensive & Less prominent & Absent & Madsen et al., 2007 \\
\hline Mitochondria & Elongated & Small & Smaller & Madsen et al., 2007 \\
\hline \multirow[t]{2}{*}{$\mathrm{Na}^{+} / \mathrm{K}^{+}$-ATPase } & Abundant & Less abundant & Present but lower & Ernst 1975 \\
\hline & & & & Kashgarian et al., 1985 \\
\hline \multirow[t]{2}{*}{ Peroxisomes } & Present & Present & Present & Maunsbach 1966 \\
\hline & & & & Maunsbach 1966 \\
\hline
\end{tabular}

Abbreviations: NHE3, the sodium and hydrogen exchanger or antiporter 3. OSOM, the outer stripe of the outer medulla. 
Table 3

Functional heterogeneity of proximal nephrons in superficial and juxtamedullary cortex in mammalian kidneys.

\begin{tabular}{|c|c|c|c|}
\hline Characteristics & $\begin{array}{l}\text { Superficial nephron } \\
\text { pars convolute }\end{array}$ & $\begin{array}{l}\text { Juxtamedullary nephron } \\
\text { pars convoluta }\end{array}$ & References \\
\hline Absolute proximal reabsorption & Lower & Higher & Jacobson 1979 \\
\hline Fractional proximal reabsorption & Similar & Similar & Jacobson 1979 \\
\hline $\mathrm{Na}^{+} / \mathrm{HCO}_{3}{ }^{-}$reabsorption & Smaller & Greater & Jacobson 1979 \\
\hline $\mathrm{Na}^{+}$permselectivity & More permselective Early & Absent & $\begin{array}{l}\text { Maddox \& Gennari 1987; Jacobson \& } \\
\text { Kokko, } 1976\end{array}$ \\
\hline $\mathrm{Cl}^{-}$permselectivity & More permselective Late & Less permeable & Maddox /Gennari 1987 \\
\hline $\mathrm{HCO}_{3}^{-}-$to- $\mathrm{Cl}^{-}$permselectivity & Smaller & Greater & Schafer et al., 1978 \\
\hline Hydraulic pressure & Similar & Similar & Schafer et al., 1978 \\
\hline $\begin{array}{l}\text { Lumen-negative electrical Potential } \\
\text { difference }\end{array}$ & Absent & Persisted & Jacobson 1979 \\
\hline NHE3 expression & Abundant & Prominent & Biemesderfer et al., $1992 \& 1997$ \\
\hline $\mathrm{NaP}_{\mathrm{i}}$-cotransporter expression & Greater & Lower & Madjdpour et al., 2004 \\
\hline NBC expression & Lower & Higher & Abuladze N et al 1998 \\
\hline $\mathrm{Na}^{+} / \mathrm{HCO}^{-}$cotransport & Lower & Higher & Abuladze N et al 1998 \\
\hline PT reabsorptive response to RPP & Decreased & Decreased & Roman 1988 \\
\hline PT reabsorptive response to ANF & Unaltered & Increased & Haas \& Knox, 1989 \\
\hline
\end{tabular}

Abbreviations: $\mathrm{ANF}$, atrial natriuretic factor. $\mathrm{Na}^{+} / \mathrm{HCO}_{3}{ }^{-}$, sodium bicarbonate. $\mathrm{NBC}$, sodium and bicarbonate cotransporter. $\mathrm{NaP}$, sodium and phosphate cotransporter. PT, proximal tubule. RPP, renal perfusion pressure. 